\title{
Nitrogen isotopic fractionations during nitric oxide production in an agricultural soil
}

\author{
Zhongjie Yu ${ }^{1,2}$ and Emily M. Elliott ${ }^{1}$ \\ ${ }^{1}$ Department of Geology and Environmental Science, University of Pittsburgh, Pittsburgh, Pennsylvania 15260, USA \\ ${ }^{2}$ Department of Natural Resources and Environmental Sciences, University of Illinois Urbana-Champaign, \\ Urbana, Illinois 61801, USA
}

Correspondence: Zhongjie Yu (zjyu@illinois.edu)

Received: 26 September 2020 - Discussion started: 20 October 2020

Revised: 12 December 2020 - Accepted: 22 December 2020 - Published: 4 February 2021

\begin{abstract}
Nitric oxide (NO) emissions from agricultural soils play a critical role in atmospheric chemistry and represent an important pathway for loss of reactive nitrogen $(\mathrm{N})$ to the environment. With recent methodological advances, there is growing interest in the natural-abundance $\mathrm{N}$ isotopic composition $\left(\delta^{15} \mathrm{~N}\right)$ of soil-emitted $\mathrm{NO}$ and its utility in providing mechanistic information on soil NO dynamics. However, interpretation of soil $\delta^{15} \mathrm{~N}-\mathrm{NO}$ measurements has been impeded by the lack of constraints on the isotopic fractionations associated with NO production and consumption in relevant microbial and chemical reactions. In this study, anoxic $\left(0 \% \mathrm{O}_{2}\right)$, oxic $\left(20 \% \mathrm{O}_{2}\right)$, and hypoxic $\left(0.5 \% \mathrm{O}_{2}\right)$ incubations of an agricultural soil were conducted to quantify the net $\mathrm{N}$ isotope effects $\left({ }^{15} \eta\right)$ for NO production in denitrification, nitrification, and abiotic reactions of nitrite $\left(\mathrm{NO}_{2}^{-}\right)$using a newly developed $\delta^{15} \mathrm{~N}-\mathrm{NO}$ analysis method. A sodium nitrate $\left(\mathrm{NO}_{3}^{-}\right)$containing mass-independent oxygen-17 excess (quantified by a $\Delta^{17} \mathrm{O}$ notation) and three ammonium $\left(\mathrm{NH}_{4}^{+}\right)$fertilizers spanning a $\delta^{15} \mathrm{~N}$ gradient were used in soil incubations to help illuminate the reaction complexity underlying NO yields and $\delta^{15} \mathrm{~N}$ dynamics in a heterogeneous soil environment. We found strong evidence for the prominent role of $\mathrm{NO}_{2}^{-}$re-oxidation under anoxic conditions in controlling the apparent ${ }^{15} \eta$ for $\mathrm{NO}$ production from $\mathrm{NO}_{3}^{-}$ in denitrification (i.e., $49 \%$ to $60 \%$ ). These results highlight the importance of an under-recognized mechanism for the reversible enzyme $\mathrm{NO}_{2}^{-}$oxidoreductase to control the $\mathrm{N}$ isotope distribution between the denitrification products. Through a $\Delta^{17} \mathrm{O}$-based modeling of co-occurring denitrification and $\mathrm{NO}_{2}^{-}$re-oxidation, the ${ }^{15} \eta$ for $\mathrm{NO}_{2}^{-}$reduction to $\mathrm{NO}$ and $\mathrm{NO}$ reduction to nitrous oxide $\left(\mathrm{N}_{2} \mathrm{O}\right)$ were con-
\end{abstract}

strained to be $15 \%$ to $22 \%$ and $-8 \%$ o to $2 \%$, respectively. Production of NO in the oxic and hypoxic incubations was contributed by both $\mathrm{NH}_{4}^{+}$oxidation and $\mathrm{NO}_{3}^{-}$consumption, with both processes having a significantly higher $\mathrm{NO}$ yield under $\mathrm{O}_{2}$ stress. Under both oxic and hypoxic conditions, $\mathrm{NO}$ production from $\mathrm{NH}_{4}^{+}$oxidation proceeded with a large ${ }^{15} \eta$ (i.e., $55 \%$ o to $84 \%$ ) possibly due to expression of multiple enzyme-level isotopic fractionations during $\mathrm{NH}_{4}^{+}$oxidation to $\mathrm{NO}_{2}^{-}$that involves $\mathrm{NO}$ as either a metabolic byproduct or an obligatory intermediate for $\mathrm{NO}_{2}^{-}$production. Adding $\mathrm{NO}_{2}^{-}$to sterilized soil triggered substantial NO production, with a relatively small ${ }^{15} \eta(19 \%$ o). Applying the estimated ${ }^{15} \eta$ values to a previous $\delta^{15} \mathrm{~N}$ measurement of in situ soil $\mathrm{NO}_{x}$ emission $\left(\mathrm{NO}_{x}=\mathrm{NO}+\mathrm{NO}_{2}\right)$ provided promising evidence for the potential of $\delta^{15} \mathrm{~N}-\mathrm{NO}$ measurements in revealing NO production pathways. Based on the observational and modeling constraints obtained in this study, we suggest that simultaneous $\delta^{15} \mathrm{~N}-\mathrm{NO}$ and $\delta^{15} \mathrm{~N}-\mathrm{N}_{2} \mathrm{O}$ measurements can lead to unprecedented insights into the sources of and processes controlling $\mathrm{NO}$ and $\mathrm{N}_{2} \mathrm{O}$ emissions from agricultural soils.

\section{Introduction}

Agricultural production of food has required a tremendous increase in the application of nitrogen $(\mathrm{N})$ fertilizers since the 1960s (Davidson, 2009). In order to maximize crop yields, $N$ fertilizers are often applied in excess to agricultural soils, resulting in loss of reactive $\mathrm{N}$ to the environment (Galloway et al., 2003). Loss of $\mathrm{N}$ in the form of gaseous nitric oxide 
(NO) has long been recognized for its adverse impacts on air quality and human health (Veldkamp and Keller, 1997). Once emitted to the atmosphere, $\mathrm{NO}$ is rapidly oxidized to nitrogen dioxide $\left(\mathrm{NO}_{2}\right)$, and these compounds (collectively referred to as $\mathrm{NO}_{x}$ ) drive production and deposition of atmospheric nitrate $\left(\mathrm{NO}_{3}^{-}\right)$(Calvert et al., 1985) and play a critical role in the formation of tropospheric ozone $\left(\mathrm{O}_{3}\right)$ - a toxic air pollutant and potent greenhouse gas (Crutzen, 1979). Despite the observations that emission of $\mathrm{NO}$ from agricultural soils can sometimes exceed that of nitrous oxide $\left(\mathrm{N}_{2} \mathrm{O}\right)$ - a climatically important trace gas primarily produced from reduction of NO in soils (Liu et al., 2017), NO is frequently overlooked in soil $\mathrm{N}$ studies due to its high reactivity and transient presence relative to $\mathrm{N}_{2} \mathrm{O}$ (Medinets et al., 2015). Consequently, the contribution of soil $\mathrm{NO}$ emission to contemporary $\mathrm{NO}_{x}$ inventories at regional to global scales is highly uncertain (e.g., ranging from $3 \%$ to $>30 \%$ ) (Hudman et al., 2010; Vinken et al., 2014) and remains the subject of much current debate (Almaraz et al., 2018; Maaz et al., 2018).

As the central hub of the biogeochemical $\mathrm{N}$ cycle, $\mathrm{NO}$ can be produced and consumed in numerous microbial and chemical reactions in soils (Medinets et al., 2015). Among these processes, nitrification and denitrification are the primary sources responsible for $\mathrm{NO}$ emission from $\mathrm{N}$-enriched agricultural soils (Firestone and Davidson, 1989). Denitrification is the sequential reduction of $\mathrm{NO}_{3}^{-}$and nitrite $\left(\mathrm{NO}_{2}^{-}\right)$to $\mathrm{NO}, \mathrm{N}_{2} \mathrm{O}$, and dinitrogen $\left(\mathrm{N}_{2}\right)$ and can be mediated by a diversity of soil heterotrophic microorganisms (Zumft, 1997). The enzymatic system of denitrification comprises a series of dedicated reductases whereby $\mathrm{NO}_{2}^{-}$reductase (NIR) and NO reductase (NOR) are the key enzymes that catalyze production and reduction of NO, respectively (Ye et al., 1994). As such, NO is often viewed as a free intermediate of the denitrification process (Russow et al., 2009). In comparison, nitrification is a two-step aerobic process in which oxidation of ammonia $\left(\mathrm{NH}_{3}\right)$ to $\mathrm{NO}_{2}^{-}$is mediated by ammoniaoxidizing bacteria (AOB) or archaea (AOA), while the subsequent oxidation of $\mathrm{NO}_{2}^{-}$to $\mathrm{NO}_{3}^{-}$is performed by nitriteoxidizing bacteria (NOB) (Lehnert et al., 2018). Although production of $\mathrm{NO}$ during the nitrification process has been linked to $\mathrm{NH}_{3}$ oxidation (Hooper et al., 2004; Caranto and Lancaster, 2017) and $\mathrm{NO}_{2}^{-}$reduction by $\mathrm{AOB} / \mathrm{AOA}$-encoded NIR (Wrage-Mönning et al., 2018), the metabolic role of NO in AOB and AOA remains ambiguous, making it difficult to elucidate the enzymatic pathways driving NO release by nitrification (Beeckman et al., 2018; Stein, 2019). Additionally, $\mathrm{NO}$ can also be produced from abiotic reactions involving soil $\mathrm{NO}_{2}^{-}$or its protonated form - nitrous acid $\left(\mathrm{HNO}_{2}\right)$ (Venterea et al., 2005; Lim et al., 2018). However, despite empirical evidence for the dependence of soil NO emission on soil $\mathrm{N}$ availability and moisture content (Davidson and Verchot, 2000), the source contribution of soil NO emission across temporal and spatial scales is poorly understood (Hudman et al., 2012). This is largely due to the lack of a robust means for source partitioning soil-emitted NO under dynamic environmental conditions.

Natural-abundance stable $\mathrm{N}$ and oxygen $(\mathrm{O})$ isotopes in $\mathrm{N}$-containing molecules have long provided insights into the sources and relative rates of biogeochemical processes comprising the $\mathrm{N}$ cycle (Granger and Wankel, 2016). The unique power of stable isotope ratio measurements stems from the distinct partitioning of isotopes between chemical species or phases, known as isotopic fractionation. Thus, in order to extract the greatest information from the distributions of isotopic species, a rigorous understanding of the direction and magnitude of isotopic fractionations associated with each relevant transformation is required. Both kinetic and equilibrium isotope effects can lead to isotopic fractionations between N-bearing compounds in soils (Granger and Wankel, 2016; Denk et al., 2017). During kinetic processes, isotopic fractionation occurs as a result of differences in the reaction rates of isotopically substituted molecules (i.e., isotopologues), leading to either enrichment or, in a few rare cases, depletion of heavy isotopes in the reaction substrate (Fry, 2006; Casciotti, 2009). The degree of kinetic isotope fractionation can be quantified by a kinetic isotope fractionation factor $\left(\alpha_{\mathrm{k}}\right)$, which is often represented by the ratio of reaction rate constants of light isotopologues to that of heavy isotopologues. In this definition, $\alpha_{\mathrm{k}}$ is larger than 1 for normal kinetic isotope fractionation. For equilibrium reactions, equilibrium isotope fractionation arises from differences in the zero-point energies of two species undergoing isotopic exchange, leading to enrichment of heavy isotopes in the more strongly bonded form (Fry, 2006; Casciotti, 2009). In this case, the isotope ratios of two species at equilibrium are defined by an equilibrium isotope fractionation factor $\left(\alpha_{\mathrm{eq}}\right)$, which is also related to the kinetic isotope fractionation factors of forward and backward equilibrium reactions (Fry, 2006). By convention, isotopic fractionation can be expressed in units of per mill (\%o) as an isotope effect $(\epsilon): \epsilon=(\alpha-1) \times 1000$. Nevertheless, in a heterogeneous soil environment, expression of intrinsic kinetic and equilibrium isotope effects for biogeochemical $\mathrm{N}$ transformations is often limited due to transport limitation in soil substrates, the multi-step nature of transformation processes, and the presence of diverse soil microbial communities that transform $\mathrm{N}$ via parallel and/or competing reaction pathways (Maggi and Riley, 2010). As such, interpretation of $\mathrm{N}$ isotope distribution in soils has largely relied on measuring net isotope effects $(\eta)$, which are often characterized by incubating soil samples under environmentally relevant conditions, that favor expression of intrinsic isotope effects for specific $\mathrm{N}$ transformations (Lewicka-Szczebak et al., 2014). For example, it has been shown that the net $\mathrm{N}$ isotope effects for $\mathrm{N}_{2} \mathrm{O}$ production in soil nitrification, denitrification, and abiotic reactions are distinctively different under certain soil conditions (Denk et al., 2017), rendering natural-abundance $\mathrm{N}$ isotopes of $\mathrm{N}_{2} \mathrm{O}$ a useful index for inferring sources of $\mathrm{N}_{2} \mathrm{O}$ in agricultural soils (Toyoda et al., 2017). 
While the isotopic dynamics underlying soil $\mathrm{N}_{2} \mathrm{O}$ emissions has been extensively studied, there has been little investigation into the $\mathrm{N}$ isotopic composition (notated as $\delta^{15} \mathrm{~N}$ in units of $\left.\% \circ ; \delta=\left(\left(R_{\text {sample }} / R_{\text {standard }}\right)-1\right) \times 1000\right)$ of soilemitted NO due to measurement difficulties (Yu and Elliott, 2017). Using a tubular denuder that trapped NO released from urea and ammonium $\left(\mathrm{NH}_{4}^{+}\right)$-fertilized soils, $\mathrm{Li}$ and Wang (2008) revealed a gradual increase in $\delta^{15} \mathrm{~N}-\mathrm{NO}$ from $-49 \%$ o to $-19 \%$ and simultaneous ${ }^{15} \mathrm{~N}$ enrichment in soil $\mathrm{NH}_{4}^{+}$and $\mathrm{NO}_{3}^{-}$over a 2-week laboratory incubation. Similar $\delta^{15} \mathrm{~N}$ variations (i.e., $-44 \%$ o to $-14 \%$ ) were recently reported for in situ soil $\mathrm{NO}_{x}$ emission in a manure-fertilized cornfield (Miller et al., 2018). Moreover, the magnitude of $\delta^{15} \mathrm{~N}-\mathrm{NO}_{x}$ measured in this study depended on manure application methods, implying that $\mathrm{NO}_{x}$ was mainly sourced from nitrification of manure-derived $\mathrm{NH}_{4}^{+}$(Miller et al., 2018). Based on a newly developed soil NO collection system that quantitatively converts soil-emitted $\mathrm{NO}$ to $\mathrm{NO}_{2}$ for collection in triethanolamine (TEA) solutions, our previous work demonstrated substantial variations in $\delta^{15} \mathrm{~N}-\mathrm{NO}(-54 \%$ to $-37 \%$ ) in connection with changes in moisture content in a forest soil (Yu and Elliott, 2017). Furthermore, the measured in situ $\delta^{15} \mathrm{~N}-\mathrm{NO}$ values spanned a wide range $(-60 \%$ o to $-23 \%$ ) and were highly sensitive to added $\mathrm{N}$ substrates (i.e., $\mathrm{NH}_{4}^{+}, \mathrm{NO}_{3}^{-}$, and $\mathrm{NO}_{2}^{-}$), indicating that $\mathrm{NO}$ produced from different sources may bear distinguishable $\delta^{15} \mathrm{~N}$ imprints (Yu and Elliott, 2017). Nevertheless, despite the potential of $\delta^{15} \mathrm{~N}-\mathrm{NO}$ measurements in providing mechanistic information on soil NO dynamics, interpretation of $\delta^{15} \mathrm{~N}-\mathrm{NO}$ has been largely impeded by the knowledge gap as to how $\delta^{15} \mathrm{~N}-\mathrm{NO}$ is controlled by $\mathrm{N}$ isotopic fractionations during NO production and consumption in soils.

To this end, we conducted a series of controlled incubation experiments to quantify the net $\mathrm{N}$ isotope effects for $\mathrm{NO}$ production in an agricultural soil. Replicate soil incubations were conducted to measure the yield and $\delta^{15} \mathrm{~N}$ of soil-emitted NO under anoxic $\left(0 \% \mathrm{O}_{2}\right)$, oxic $\left(20 \% \mathrm{O}_{2}\right)$, and hypoxic $\left(0.5 \% \mathrm{O}_{2}\right)$ conditions, respectively. A sodium $\mathrm{NO}_{3}^{-}$fertilizer mined in the Atacama Desert, Chile (Yu and Elliott, 2018), was used to amend the soil in all three incubation experiments. This Chilean $\mathrm{NO}_{3}^{-}$originated from atmospheric deposition and thus contained an anomalous ${ }^{17} \mathrm{O}$ excess (quantified by the $\Delta^{17} \mathrm{O}$ notation) as a result of mass-independent isotopic fractionations during its photochemical formation in the atmosphere (Michalski et al., 2004). Because isotopic fractionations during biogeochemical $\mathrm{NO}_{3}^{-}$production and consumption are mass-dependent, $\Delta^{17} \mathrm{O}-\mathrm{NO}_{3}^{-}$is a conservative tracer of gross nitrification and $\mathrm{NO}_{3}^{-}$consumption and provides a quantitative benchmark for disentangling isotopic overprinting on $\delta^{15} \mathrm{~N}-\mathrm{NO}_{3}^{-}$and $\delta^{18} \mathrm{O}-\mathrm{NO}_{3}^{-}$during co-occurring nitrification and denitrification ( $\mathrm{Yu}$ and Elliott, 2018) (see Sect. S1 in the Supplement for more details). As additional tracers, three isotopically different $\mathrm{NH}_{4}^{+}$fertilizers were used in parallel treatments of the oxic and hypoxic incubations to quantify the nitrifier source contribu- tion of $\mathrm{NO}$ production with changing $\mathrm{O}_{2}$ availability. By integrating multi-species measurements of $\mathrm{N}$ and $\mathrm{O}$ isotopes in an isotopologue-specific modeling framework, we were able for the first time to unambiguously link the yield and $\delta^{15} \mathrm{~N}$ variations of soil-emitted NO to nitrification and denitrification carried out by whole soil microbial communities and to characterize the net isotope effects for $\mathrm{NO}$ production from soil $\mathrm{NO}_{3}^{-}, \mathrm{NH}_{4}^{+}$, and $\mathrm{NO}_{2}^{-}$under different redox conditions. The quantified isotope effects are discussed in the context of chemical and enzymatic pathways leading to net NO production in the soil environment and are applied to a previous field study (Miller et al., 2018) to provide implications for tracing the sources of NO emission from agricultural soils.

\section{Materials and methods}

\subsection{Soil characteristics and preparation}

Soil samples used in this study were collected in July 2017 from a conventional corn-soybean rotation field in central Pennsylvania, USA, managed by the USDA (Agricultural Research Service, University Park, PA, USA). The soil is a well-drained Hagerstown silt loam (fine, mixed, semiactive, mesic Typic Hapludalfs) with sand, silt, and clay content of $21 \%, 58 \%$, and $21 \%$, respectively. The sampled surface layer $(0-10 \mathrm{~cm})$ had a bulk density of $1.2 \mathrm{~g} \mathrm{~cm}^{-3}$ and a $\mathrm{pH}\left(1: 1\right.$ water) of 5.7. Total $\mathrm{N}$ content was $0.2 \%$ and $\delta^{15} \mathrm{~N}$ of total $\mathrm{N}$ was $5.3 \%$. Soil $\mathrm{C}: \mathrm{N}$ ratio was 11.4 and organic carbon content was $1.8 \%$. In the laboratory, soils were homogenized and sieved to $2 \mathrm{~mm}$ (but not air-dried) and then stored in resealable plastic bags at $4{ }^{\circ} \mathrm{C}$ until further analyses and incubations. Gravimetric water content of the sieved and homogenized soils was $0.14 \mathrm{~g} \mathrm{H}_{2} \mathrm{Og}^{-1}$. Indigenous $\mathrm{NH}_{4}^{+}$ and $\mathrm{NO}_{3}^{-}$concentrations were 0.7 and $19.8 \mu \mathrm{g} \mathrm{Ng}^{-1}$, respectively. Throughout this paper, soil $\mathrm{N}$ concentrations, NO fluxes, and $\mathrm{N}$ transformation rates are expressed on the basis of soil ovendry $\left(105^{\circ} \mathrm{C}\right)$ weight.

\subsection{Net NO production and collection of NO for $\delta^{15} \mathrm{~N}$ analysis}

The recently developed soil dynamic flux chamber (DFC) system was used to measure net NO production rates and to collect soil-emitted NO for $\delta^{15} \mathrm{~N}$ analysis ( $\mathrm{Yu}$ and $\mathrm{El}-$ liott, 2017). A schematic of the DFC system is shown in Fig. 1a. Detailed development and validation procedures for the NO collection method were presented in $\mathrm{Yu}$ and Elliott (2017). Briefly, custom-made flow-through incubators modified from 1 L Pyrex medium bottles (13951 L, Corning, USA) were used for all the incubation experiments (Fig. 1b). Each incubator was stoppered with two $42 \mathrm{~mm}$ Teflon septa secured by an open-topped screw cap and equipped with two vacuum valves for purging and closure of the incubator headspace. To measure net NO production from enclosed soil samples, a flow of $\mathrm{NO}$-free air with desired $\mathrm{O}_{2}$ 
content was directed through the incubator into a chemiluminescent $\mathrm{NO}-\mathrm{NO}_{x}-\mathrm{NH}_{3}$ analyzer (model 146i, Thermo Fisher Scientific) (Fig. 1a) (Yu and Elliott, 2017). Outflow NO concentration was monitored continuously until steady, and then the net NO production rate was determined from the flow rate and steady-state NO concentration. To collect $\mathrm{NO}$ for $\delta^{15} \mathrm{~N}$ analysis, a subsample of the incubator outflow was forced to pass through a NO collection train (Fig. 1a) where $\mathrm{NO}$ is converted to $\mathrm{NO}_{2}$ by excess $\mathrm{O}_{3}(\sim 3 \mathrm{ppm})$ in a Teflon reaction tube $(9.5 \mathrm{~mm}$ i.d., ca. $240 \mathrm{~cm}$ length) and subsequently collected in a $500 \mathrm{~mL}$ gas washing bottle containing a $20 \%(v / v, 70 \mathrm{~mL})$ TEA solution (Yu and Elliott, 2017). The collection products were about $90 \% \mathrm{NO}_{2}^{-}$and $10 \% \mathrm{NO}_{3}^{-}$(Yu and Elliott, 2017). Results from comprehensive method testing showed that the NO collection efficiency was $98.5 \% \pm 3.5 \%$ over a wide range of $\mathrm{NO}$ concentrations (12 to $749 \mathrm{ppb}$ ) and environmental conditions (e.g., temperature from 11 to $31^{\circ} \mathrm{C}$ and relative humidity of the incubator outflow from $27 \%$ to $92 \%$ ) (Yu and Elliott, 2017). Moreover, it was confirmed that high concentrations of ammonia $\left(\mathrm{NH}_{3}\right)$ (e.g., $500 \mathrm{ppb}$ ) and nitrous acid (HONO) (removed by an inline HONO scrubber, Fig. 1a) in the incubator outflow do not interfere with NO collection (Yu and Elliott, 2017).

\subsection{Anoxic incubation}

To prepare for the anoxic incubation, the soil samples were spread out on a covered tray for pre-conditioning under room temperature $\left(21^{\circ} \mathrm{C}\right)$ for $24 \mathrm{~h}$. Next, the soil was amended with the Chilean $\mathrm{NO}_{3}^{-}$fertilizer $\left(\delta^{15} \mathrm{~N}=0.3 \%\right.$ o $\pm 0.1 \%$, $\delta^{18} \mathrm{O}=55.8 \% \circ \pm 0.1 \% \circ, \Delta^{17} \mathrm{O}=18.6 \% \circ \pm 0.1 \%$ ) to achieve a fertilization rate of $35 \mu \mathrm{g} \mathrm{NO}_{3}^{-}-\mathrm{N} \mathrm{g}^{-1}$ and a target soil water content of $0.21 \mathrm{~g} \mathrm{H}_{2} \mathrm{Og}^{-1}$ (equivalent to $46 \%$ water-filled pore space, WFPS). The fertilized soil samples were thoroughly homogenized using a glass rod in the tray. A total of $100 \mathrm{~g}$ (dry-weight equivalent) of soil was then weighed into each of eight incubators, resulting in a soil depth of about $1.5 \mathrm{~cm}$. The incubators were connected in parallel using a Teflon purging manifold (Fig. 1c), vacuumed and filled with ultra-high-purity $\mathrm{N}_{2}$ for three cycles, and incubated in the dark with a continuous flow of $\mathrm{N}_{2}$ circulating through each of the eight incubators at 0.015 standard liters per minute (SLPM). The sample fertilization and preparation procedures were repeated three times to establish three batches of replicate samples, leading to 24 soil samples in total for the anoxic incubation.

The first NO measurement and collection event was conducted $24 \mathrm{~h}$ after the onset of the anoxic incubation, and daily sampling was conducted thereafter. At each sampling event, one incubator from each replicate sample batch was isolated by closing the vacuum valves, removed from the purging manifold, and then measured using the DFC system. To prevent $\mathrm{O}_{2}$ contamination by residual air in the DFC system, the DFC system was evacuated and flushed with $\mathrm{N}_{2}$ five times before the vacuum valves were re-opened. A flow of $\mathrm{N}_{2}$ was then supplied at 1 SLPM for continuous NO concentration measurement and collection. Samples from the replicate batches were measured successively.

Following the completion of measurement and collection of each sample, the incubator was opened from the top and the soil was combined with $500 \mathrm{~mL}$ deionized water for extraction of soil $\mathrm{NO}_{3}^{-}$and $\mathrm{NO}_{2}^{-}$(McKenney et al., 1982). Because $\mathrm{NO}_{2}^{-}$accumulation was found in pilot experiments, deionized water, rather than routinely used $\mathrm{KCl}$ solutions, was used for the extraction to ensure accurate $\mathrm{NO}_{2}^{-}$determination (Homyak et al., 2015). To extract soil $\mathrm{NO}_{3}^{-}$and $\mathrm{NO}_{2}^{-}$, the soil slurry was agitated vigorously on a stir plate for $10 \mathrm{~min}$ and then centrifuged for $10 \mathrm{~min}$ at $3400 \mathrm{~g}$. The resultant supernatant was filtered through a sterile $0.2 \mu \mathrm{m}$ filter (Homyak et al., 2015). In light of high $\mathrm{NO}_{2}^{-}$concentrations observed in the pilot experiments, the filtrate was divided into two $60 \mathrm{~mL}$ Nalgene bottles, with one of the bottles receiving sulfamic acid to remove $\mathrm{NO}_{2}^{-}$(Granger and Sigman, 2009). This $\mathrm{NO}_{2}^{-}$-removed sample was used for $\mathrm{NO}_{3}^{-}$isotope analysis, while the other sample without sulfamic acid treatment was used for determining $\mathrm{NO}_{2}^{-}$and $\mathrm{NO}_{3}^{-}$concentrations and combined $\delta^{15} \mathrm{~N}$ analysis of $\mathrm{NO}_{2}^{-}+\mathrm{NO}_{3}^{-}$. Two important control tests, based on $\mathrm{NO}_{2}^{-} / \mathrm{NO}_{3}^{-}$spiking and acetylene $\left(\mathrm{C}_{2} \mathrm{H}_{2}\right)$ addition, were conducted to evaluate the robustness of the adopted soil incubation and extraction methods. The results confirmed that the water extraction method was robust for determining concentrations and isotopic composition of soil $\mathrm{NO}_{3}^{-}$and $\mathrm{NO}_{2}^{-}$and that aerobic $\mathrm{NO}_{3}^{-}$production from $\mathrm{NH}_{4}^{+}$ oxidation was negligible during the soil incubation and extraction procedures (Tables S1 and S2 in the Supplement; see Sect. S2 for more details).

\subsection{Oxic and hypoxic incubations}

The same pre-conditioning and fertilization protocol described for the anoxic incubation was used for the oxic and hypoxic incubations. Three isotopically different $\mathrm{NH}_{4}^{+}$ fertilizers were used in parallel treatments of each incubation experiment: (1) $\delta^{15} \mathrm{~N}-\mathrm{NH}_{4}^{+}=1.9 \%$ (low ${ }^{15} \mathrm{~N}$ enrich-

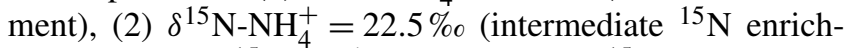
ment), and (3) $\delta^{15} \mathrm{~N}^{4} \mathrm{NH}_{4}^{+}=45.0 \%$ (high ${ }^{15} \mathrm{~N}$ enrichment). An off-the-shelf ammonium sulfate $\left(\left(\mathrm{NH}_{4}\right)_{2} \mathrm{SO}_{4}\right)$ reagent was used in the low- $\delta^{15} \mathrm{~N}-\mathrm{NH}_{4}^{+}$treatment, while the fertilizers with intermediate and high enrichment of ${ }^{15} \mathrm{~N}$ were prepared by gravimetrically mixing the $\left(\mathrm{NH}_{4}\right)_{2} \mathrm{SO}_{4}$ reagent with $\mathrm{NH}_{4}^{+}$reference materials IAEA-N2 $\left(\delta^{15} \mathrm{~N}-\mathrm{NH}_{4}^{+}=20.3 \%\right.$ o $)$ and USGS26 $\left(\delta^{15} \mathrm{~N}^{-\mathrm{NH}_{4}^{+}}=53.7 \%\right)$. In both oxic and hypoxic incubations, each of the three $\delta^{15} \mathrm{~N}^{-\mathrm{NH}_{4}^{+}}$treatments consisted of three replicate sample batches where each batch consisted of eight samples, resulting in 72 samples for each incubation experiment.

At the onset of each incubation experiment, soil samples ( $100 \mathrm{~g}$ dry-weight equivalent) were amended with the desired $\mathrm{NH}_{4}^{+}$fertilizer $\left(90 \mu \mathrm{g} \mathrm{Ng}^{-1}\right)$ and the Chilean $\mathrm{NO}_{3}^{-}$ fertilizer $\left(15 \mu \mathrm{g} \mathrm{Ng}^{-1}\right)$ to the target soil water content of 

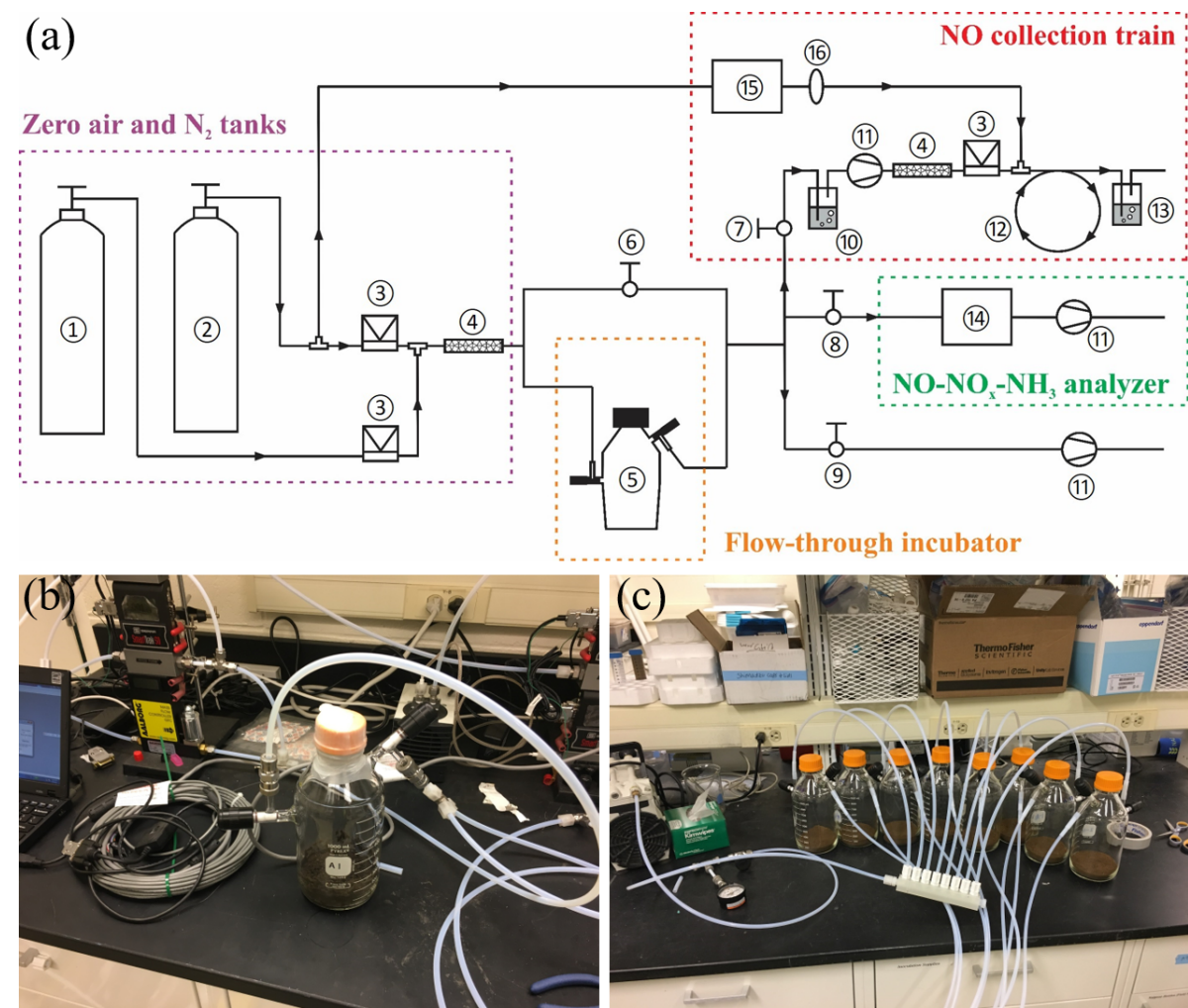

Figure 1. (a) Schematic of the DFC system (not to scale) consisting of the following: (1) zero air tank, (2) $\mathrm{N}_{2}$ tank, (3) mass flow controller, (4) Nafion moisture exchanger, (5) flow-through incubator, (6-9) needle valves for controlling vacuum and flushing of the DFC system, (10) HONO scrubber, (11) diaphragm pump, (12) Teflon reaction tube, (13) gas washing bottle containing TEA solution, (14) $\mathrm{NO}_{-} \mathrm{NO}_{x}-\mathrm{NH}_{3}$ analyzer, (15) $\mathrm{O}_{3}$ generator, and (16) in-line PTFE particulate filter assembly. (b) Photo of the flow-through incubator. (c) Photo of the Teflon purging manifold for connection of the incubators in parallel.

$0.21 \mathrm{~g} \mathrm{H}_{2} \mathrm{Og}^{-1}$ (46\% WFPS). Following the amendment, two soil samples from each replicate batch were immediately extracted - one with $500 \mathrm{~mL}$ of deionized water for soil $\mathrm{NO}_{2}^{-}$ and $\mathrm{NO}_{3}^{-}$using the extraction method described above and the other one with $500 \mathrm{~mL}$ of a $2 \mathrm{M} \mathrm{KCl}$ solution for determination of soil $\mathrm{NH}_{4}^{+}$. The remaining samples were incubated under desired $\mathrm{O}_{2}$ conditions until further measurements. In the oxic incubation, the incubators were connected in parallel using the purging manifold and continuously flushed by a flow of zero air $\left(20 \% \mathrm{O}_{2}+80 \% \mathrm{~N}_{2}\right)$. In the hypoxic incubation, a flow of synthetic air with $0.5 \% \mathrm{O}_{2}$ content (balanced by $99.5 \% \mathrm{~N}_{2}$ ) was used to incubate the soil samples. The synthetic air was generated by mixing the zero air with ultra-high-purity $\mathrm{N}_{2}$ using two mass flow controllers (model SmartTrak 50, Sierra Instruments).

Replicate NO measurement and collection events were conducted at 24,48 , and $72 \mathrm{~h}$ following the onset of the oxic and hypoxic incubations. Because net NO production rates were low under oxic and hypoxic conditions, all remaining soil samples in each replicate batch were connected in parallel for NO measurement and collection using the DFC system. This parallel connection ensured high outflow NO concentrations (i.e., $>30 \mathrm{ppb}$ ) required for quantitative NO collection (Yu and Elliott, 2017). The flow rate of purging air $\left(20 \% \mathrm{O}_{2}\right.$ for the oxic incubation and $0.5 \% \mathrm{O}_{2}$ for the hypoxic incubation) during the DFC measurement was 0.25 SLPM to each incubator. Following the NO measurement and collection, two soil samples from each replicate batch were extracted for determination of soil $\mathrm{NO}_{3}^{-} / \mathrm{NO}_{2}^{-}$ $\left(500 \mathrm{~mL}\right.$ deionized water) and $\mathrm{NH}_{4}^{+}(500 \mathrm{~mL} 2 \mathrm{M} \mathrm{KCl})$, respectively. Because NO concentrations were too low for reliable $\mathrm{NO}$ collection at $72 \mathrm{~h}$ after the onset of the incubations, only net NO production rates were measured using the remaining two soil samples in each replicate batch.

\subsection{Abiotic NO production}

The potential for NO production from abiotic reactions was assessed using sterilized soil samples. Soil samples (100 g dry-weight equivalent) were weighed into the incubators and then autoclaved at $121^{\circ} \mathrm{C}$ and $1.3 \mathrm{~atm}$ for $30 \mathrm{~min}$. The autoclaved samples were pre-incubated under oxic and anoxic conditions, respectively, for $24 \mathrm{~h}$ and then fertilized with the Chilean $\mathrm{NO}_{3}^{-}\left(35 \mu \mathrm{g} \mathrm{NO}_{3}^{-}-\mathrm{N} \mathrm{g}^{-1}\right)$ or the lab $\left(\mathrm{NH}_{4}\right)_{2} \mathrm{SO}_{4}$ $\left(90 \mu \mathrm{NH}_{4}^{+}-\mathrm{Ng}^{-1}\right)$. The fertilizer solutions were added to the soil surface through the Teflon septa using a sterile sy- 
ringe equipped with a 25 -gauge needle. These samples were then measured periodically for net NO production. Because $\mathrm{NO}_{2}^{-}$was found to accumulate during the anoxic incubation (see below), four soil samples were sterilized, pre-incubated under anoxic condition, and then fertilized with a $\mathrm{NaNO}_{2}$ solution $\left(\delta^{15} \mathrm{~N}^{-\mathrm{NO}_{2}^{-}}=1.4 \%\right.$ $\pm 0.2 \%$ $)\left(8 \mu \mathrm{g} \mathrm{Ng}{ }^{-1}\right)$ for immediate $\mathrm{NO}$ measurement and collection. These $\mathrm{NO}_{2}^{-}$-amended samples were thereafter incubated under anoxic conditions and measured periodically for net NO production until undetectable.

\subsection{Chemical and isotopic analyses}

Soil $\mathrm{NO}_{3}^{-}$concentrations were determined using a Dionex ion chromatograph ICS-2000 with a precision of $(1 \sigma)$ of $\pm 5.0 \mu \mathrm{g} \mathrm{NL}^{-1}$. Soil $\mathrm{NO}_{2}^{-}$concentrations were analyzed using the Griess-Ilosvay colorimetric reaction with a precision of $\pm 1.2 \mu \mathrm{g} \mathrm{NL}^{-1}$. Soil $\mathrm{NH}_{4}^{+}$concentrations were measured using a modified fluorometric $o$-phthaldialdehyde (OPA) method for soil $\mathrm{KCl}$ extracts (Kang et al., 2003) with a precision of $\pm 7.0 \mu \mathrm{g} \mathrm{NL}^{-1}$. $\mathrm{NO}_{2}^{-}+\mathrm{NO}_{3}^{-}$concentration in the TEA collection samples was measured using a modified spongy cadmium method with a precision of $\pm 1.6 \mu \mathrm{g} \mathrm{NL}^{-1}$ (Yu and Elliott, 2017).

The denitrifier method (Sigman et al., 2001; Casciotti et al., 2002) was used to measure $\delta^{15} \mathrm{~N}$ and $\delta^{18} \mathrm{O}$ of $\mathrm{NO}_{3}^{-}$in the $\mathrm{NO}_{2}^{-}$-removed soil extracts and the $\delta^{15} \mathrm{~N}$ of $\mathrm{NO}_{3}^{-}+\mathrm{NO}_{2}^{-}$ in the extracts without sulfamic acid treatment. In brief, a denitrifying bacterium (Pseudomonas aureofaciens) lacking the $\mathrm{N}_{2} \mathrm{O}$ reductase enzyme was used to convert $20 \mathrm{nmol}$ of $\mathrm{NO}_{3}^{-}$into gaseous $\mathrm{N}_{2} \mathrm{O}$. The $\mathrm{N}_{2} \mathrm{O}$ was then purified in a series of chemical traps, cryo-focused, and finally analyzed on a GV Instruments Isoprime continuous flow isotope ratio mass spectrometer (CF-IRMS) at $m / z 44,45$, and 46 at the University of Pittsburgh Regional Stable Isotope Laboratory for Earth and Environmental Science Research where all isotope analyses were conducted for this study. International $\mathrm{NO}_{3}^{-}$reference standards IAEA-N3, USGS34, and USGS35 were used to calibrate the $\delta^{15} \mathrm{~N}$ and $\delta^{18} \mathrm{O}$ analyses. The long-term precision is $\pm 0.3 \%$ and $\pm 0.5 \%$, respectively, for the $\delta^{15} \mathrm{~N}$ and $\delta^{18} \mathrm{O}$ analyses. Because the denitrifier method does not differentiate $\mathrm{NO}_{3}^{-}$and $\mathrm{NO}_{2}^{-}$for the $\delta^{15} \mathrm{~N}$ analysis, $\delta^{15} \mathrm{~N}$ of $\mathrm{NO}_{2}^{-}$was estimated using an isotopic mass balance when $\mathrm{NO}_{2}^{-}$accounted for a significant fraction of the total $\mathrm{NO}_{3}^{-}+\mathrm{NO}_{2}^{-}$pool.

$\Delta^{17} \mathrm{O}$ of $\mathrm{NO}_{3}^{-}$was measured using the coupled bacterial reduction and thermal decomposition method described by Kaiser et al. (2007). The denitrifying bacteria were used to convert $200 \mathrm{nmol}$ of $\mathrm{NO}_{3}^{-}$to $\mathrm{N}_{2} \mathrm{O}$, which was subsequently converted to $\mathrm{O}_{2}$ and $\mathrm{N}_{2}$ by reduction over a gold surface at $800^{\circ} \mathrm{C}$. The produced $\mathrm{O}_{2}$ and $\mathrm{N}_{2}$ were separated using a $5 \AA$ molecular sieve gas chromatograph, and the $\mathrm{O}_{2}$ was then analyzed for $\delta^{17} \mathrm{O}$ and $\delta^{18} \mathrm{O}$ using the CF-IRMS. $\Delta^{17} \mathrm{O}$ was calculated from the measured $\delta^{17} \mathrm{O}$ and $\delta^{18} \mathrm{O}$ using Eq. (1) (see Sect. S1) and calibrated by USGS34, USGS35, and a
$1: 1$ mixture of USGS34 and USGS35.

$\Delta^{17} \mathrm{O}=\left[\ln \left(\frac{\delta^{17} \mathrm{O}}{1000}+1\right)-0.52 \ln \left(\frac{\delta^{18} \mathrm{O}}{1000}+1\right)\right] \times 1000$

The precision of the $\Delta^{17} \mathrm{O}$ analysis of USGS35 and the USGS35:USGS34 mixture is $\pm 0.3 \%$ (Yu and Elliott, 2018). Following Kaiser et al. (2007), the measured $\Delta^{17} \mathrm{O}-\mathrm{NO}_{3}^{-}$was used in the reduction of molecular isotope ratios of $\mathrm{N}_{2} \mathrm{O}$ to correct for the isobaric interference (i.e., $m / z 45$ ) on the measured $\delta^{15} \mathrm{~N}-\mathrm{NO}_{3}^{-}$.

$\delta^{15} \mathrm{~N}$ of $\mathrm{NH}_{4}^{+}$in the $\mathrm{KCl}$ extracts was measured by coupling the $\mathrm{NH}_{3}$ diffusion method (Zhang et al., 2015) and the hypobromite $\left(\mathrm{BrO}^{-}\right)$oxidation method (Zhang et al., 2007) with the denitrifier method (Felix et al., 2013). Briefly, an aliquot of soil $\mathrm{KCl}$ extract with $60 \mathrm{nmol} \mathrm{NH}_{4}^{+}$was pipetted into a $20 \mathrm{~mL}$ serum vial containing an acidified glass fiber disk. The solution was made alkaline by adding magnesium oxide $(\mathrm{MgO})$ to volatilize $\mathrm{NH}_{3}$, which was subsequently captured on the acidic disk as $\mathrm{NH}_{4}^{+}$. After incubation under $37^{\circ} \mathrm{C}$ for $10 \mathrm{~d}, \mathrm{NH}_{4}^{+}$was eluted from the disk using deionized water, diluted to $10 \mu \mathrm{M}$, oxidized by $\mathrm{BrO}^{-}$to $\mathrm{NO}_{2}^{-}$, and finally measured for $\delta^{15} \mathrm{~N}^{2} \mathrm{NO}_{2}^{-}$at $20 \mathrm{nmol}$ using the denitrifier method. International $\mathrm{NH}_{4}^{+}$reference standards IAEAN1, USGS25, and USGS26 underwent the same preparation procedure as the soil $\mathrm{KCl}$ extracts and were used along with the $\mathrm{NO}_{3}^{-}$reference standards to correct for blanks and instrument drift. The precision of the $\delta^{15} \mathrm{~N}^{-\mathrm{NH}_{4}^{+}}$analysis is $\pm 0.5 \%$ (Yu and Elliott, 2018).

$\delta^{15} \mathrm{~N}$ of NO collected in the TEA solution was measured following the method described in Yu and Elliott (2017). Briefly, the TEA collection samples were first neutralized with $12 \mathrm{~N} \mathrm{HCl}$ to $\mathrm{pH} \sim 7$, and then 10 to $20 \mathrm{nmol}$ of the collected product $\mathrm{NO}_{2}^{-}+\mathrm{NO}_{3}^{-}$was converted to $\mathrm{N}_{2} \mathrm{O}$ using the denitrifier method. In light of the low $\delta^{15} \mathrm{~N}$ values of soil-emitted $\mathrm{NO}$ and the presence of $\mathrm{NO}_{2}^{-}$as the dominant collection product, a low- $\delta^{15} \mathrm{~N}^{-\mathrm{NO}_{2}^{-}}$isotopic standard $\left(\mathrm{KNO}_{2}\right.$, RSIL20, USGS Reston; $\delta^{15} \mathrm{~N}=-79.6 \%$ ) was used together with the international $\mathrm{NO}_{3}^{-}$reference standards to calibrate the $\delta^{15} \mathrm{~N}-\mathrm{NO}$ analysis. Following the identical treatment principle, we prepared the isotopic standards in the same matrix (i.e., 20\% TEA) as the collection samples and matched both the molar $\mathrm{N}$ amount and injection volume $( \pm 5 \%)$ between the collection samples and the standards to minimize the blank interferences associated with the bacterial medium and the TEA solution. The precision and accuracy of the $\delta^{15} \mathrm{~N}-\mathrm{NO}$ analysis, determined by repeated sampling of an analytical NO tank $\left(\delta^{15} \mathrm{~N}-\mathrm{NO}=-71.4 \%\right.$ o under diverse collection conditions, is $\pm 1.1 \%$ (Yu and Elliott, 2017). 


\section{Results}

Sixty-three NO collection samples were obtained from the incubation experiments. The NO collection efficiency calculated based on the measured $\mathrm{NO}_{2}^{-}+\mathrm{NO}_{3}^{-}$concentration in the TEA solution and the theoretical concentration based on the measured net NO production rate (Yu and Elliott, 2017) was on average $99.1 \% \pm 3.7 \%$. Out of the 63 collection samples, four samples had a NO collection efficiency lower than $95 \%$. These samples were excluded from further data analysis and interpretation. The measured $\mathrm{N}$ concentrations, net NO production rates, and isotope data from all the incubation experiments are available in Tables S5 to S11.

\subsection{Anoxic incubation}

During the anoxic incubation, soil $\mathrm{NO}_{3}^{-}$concentration decreased linearly from $49.3 \pm 0.1$ to $23.1 \pm 0.2 \mu \mathrm{g} \mathrm{Ng}^{-1}$ (Fig. 2a), while $\mathrm{NO}_{2}^{-}$concentration increased linearly from $0.4 \pm 0.1$ to $6.9 \pm 0.1 \mu \mathrm{g} \mathrm{Ng}^{-1}$ (Fig. 2b). The net NO production rate $\left(f_{\mathrm{NO}-\text {-anoxic }}\right)$ increased progressively from the first sampling day $\left(72 \pm 8 \mathrm{ng} \mathrm{Ng}^{-1} \mathrm{~h}^{-1}\right)$ to sampling day 5 and then stabilized at about $82 \mathrm{ng} \mathrm{Ng}^{-1} \mathrm{~h}^{-1}$ (Fig. 2c).

$\delta^{15} \mathrm{~N}-\mathrm{NO}_{3}^{-}$and $\delta^{15} \mathrm{~N}-\mathrm{NO}$ values increased from $4.7 \% \circ \pm$ $0.3 \%$ o to $38.7 \%_{\circ} \pm 1.5 \%$ and $-44.7 \% \circ \pm 0.3 \%$ o to $-22.8 \%$ ot $2.2 \%$, respectively, over the anoxic incubation (Fig. $2 \mathrm{~d}$ and f). The difference between $\delta^{15} \mathrm{~N}-\mathrm{NO}_{3}^{-}$and $\delta^{15} \mathrm{~N}-\mathrm{NO}$ values increased significantly from $49.4 \%$ to $59.5 \%$ o toward the end of the incubation (Fig. 2d and f). Based on the closedsystem Rayleigh model, the apparent $\mathrm{N}$ isotopic fractionation during $\mathrm{NO}_{3}^{-}$consumption was estimated to be $43.3 \%$ 。 $0.9 \%$ (Fig. S3 in the Supplement). $\delta^{15} \mathrm{~N}^{-\mathrm{NO}_{2}^{-}}$was estimated for samples collected in the last 3 sampling days where $\mathrm{NO}_{2}^{-}$ accounted for $>15 \%$ of the $\mathrm{NO}_{3}^{-}+\mathrm{NO}_{2}^{-}$pool. The estimated $\delta^{15} \mathrm{~N}^{-\mathrm{NO}_{2}^{-}}$values were $-6.9 \% \pm \pm 3.7 \%$ o, $-6.0 \%$ $\pm 2.5 \%$, and $-0.9 \% \circ \pm 1.3 \%$, respectively (Fig. 2e). Although limited to the last 3 sampling days, $\delta^{15} \mathrm{~N}-\mathrm{NO}_{2}^{-}$was lower than $\delta^{15} \mathrm{~N}-\mathrm{NO}_{3}^{-}$by $33.6 \%$ to $37.9 \%$ (Fig. $2 \mathrm{~d}$ and e) but was higher than the concurrently measured $\delta^{15} \mathrm{~N}-\mathrm{NO}$ values by a relatively constant offset of $21.5 \% \circ \pm 0.7 \% \circ$ (Fig. 2e and f). Surprisingly, both $\delta^{18} \mathrm{O}-\mathrm{NO}_{3}^{-}$values $(33.4 \%$ o $\pm 0.2 \%$ to $23.1 \% \circ \pm 0.3 \%$ o $)$ and $\Delta^{17} \mathrm{O}-\mathrm{NO}_{3}^{-}$values $(10.0 \%$ o $\pm 0.2 \%$ o to $0.7 \% \circ \pm 0.2 \%$ o decreased progressively over the course of the anoxic incubation and were entirely decoupled from $\delta^{15} \mathrm{~N}$ $\mathrm{NO}_{3}^{-}$(Fig. $2 \mathrm{~g}$ and $\mathrm{h}$ ).

\subsection{Oxic and hypoxic incubations}

Over the oxic incubation, soil $\mathrm{NH}_{4}^{+}$concentration decreased linearly with increasing $\mathrm{NO}_{3}^{-}$concentration under all three $\delta^{15} \mathrm{~N}^{-\mathrm{NH}_{4}^{+}}$treatments (Fig. $3 \mathrm{a}$ and b). In the hypoxic incubation, changes in $\mathrm{NH}_{4}^{+}$and $\mathrm{NO}_{3}^{-}$concentrations were more limited, although the linear trends were still evident (Fig. 3a and b). Under both oxic and hypoxic conditions, the total concentration of soil $\mathrm{NH}_{4}^{+}$and $\mathrm{NO}_{3}^{-}$remained nearly constant over the entire incubations (i.e., variations $<4 \%$ ), and soil $\mathrm{NO}_{2}^{-}$concentration was below the detection limit in both incubations. In the oxic incubation, $\delta^{15} \mathrm{~N}^{-\mathrm{NH}_{4}^{+}}$values uniformly increased by $8.6 \%$ to $13.1 \%$ under all three $\delta^{15} \mathrm{~N}-\mathrm{NH}_{4}^{+}$treatments (Fig. 3e), while $\delta^{15} \mathrm{~N}^{-\mathrm{NO}_{3}^{-}}$values varied distinctly, depending on the initial $\delta^{15} \mathrm{~N}^{-\mathrm{NH}_{4}^{+}}$values (Fig. 3d). Specifically, $\delta^{15} \mathrm{~N}^{-\mathrm{NO}_{3}^{-}}$values increased by $7.8 \%$ o and decreased by $10.9 \%$ under the high and low $\delta^{15} \mathrm{~N}^{-\mathrm{NH}_{4}^{+}}$ treatments, respectively, and remained relatively constant under the intermediate $\delta^{15} \mathrm{~N}^{-N_{4}^{+}}$treatment (Fig. 3d). Limited increases in $\delta^{15} \mathrm{~N}^{-\mathrm{NH}_{4}^{+}}$values $(<2 \%$ ) were observed under all three $\delta^{15} \mathrm{~N}-\mathrm{NH}_{4}^{+}$treatments in the hypoxic incubation (Fig. 3e). Correspondingly, variations in $\delta^{15} \mathrm{~N}^{-\mathrm{NO}_{3}^{-}}$values were much smaller in the hypoxic incubation compared to those revealed in the oxic incubation (Fig. 3d). In both oxic and hypoxic incubations, $\delta^{18} \mathrm{O}-\mathrm{NO}_{3}^{-}$(Fig. $3 \mathrm{~g}$ ) and $\Delta^{17} \mathrm{O}$ $\mathrm{NO}_{3}^{-}$(Fig. 3h) values decreased progressively under all three $\delta^{15} \mathrm{~N}-\mathrm{NH}_{4}^{+}$treatments, although the rates of decrease were significantly higher in the oxic incubation (Fig. $3 g$ and $h$ ).

The net NO production was significantly higher in the hypoxic incubation $\left(f_{\text {NO-hypoxic }} ; 9.0\right.$ to $10.4 \mathrm{ng} \mathrm{N} \mathrm{g}^{-1} \mathrm{~h}^{-1}$ ) than in the oxic incubation $\left(f_{\text {NO-oxic }} ; 7.1\right.$ to $\left.8.5 \mathrm{ng} \mathrm{N} \mathrm{g}^{-1} \mathrm{~h}^{-1}\right)$ (Fig. 3c). The measured $\delta^{15} \mathrm{~N}-\mathrm{NO}$ values ranged from $-16.8 \% \circ \pm 0.3 \%$ to $-54.9 \% \circ \pm 0.8 \%$ in the oxic incubation and from $-21.3 \% \circ \pm 0.0 \%$ o to $-51.4 \% \circ \pm 0.4 \%$ in the hypoxic incubation (Fig. 3f). Pooling all the $\delta^{15} \mathrm{~N}-\mathrm{NO}$ measurements, we found that $\delta^{15} \mathrm{~N}$ values between $\mathrm{NH}_{4}^{+}$and $\mathrm{NO}$ differed from $58.9 \%$ o to $70.7 \%$ across the three $\delta^{15} \mathrm{~N}_{-} \mathrm{NH}_{4}^{+}$ treatments in the oxic incubation and from $50.4 \%$ to $69.6 \%$ in the hypoxic incubation (Fig. 4). In both incubations, the largest difference was observed under the high- $\delta{ }^{15} \mathrm{~N}_{-} \mathrm{NH}_{4}^{+}$ treatment, while the smallest difference was observed under the low $\delta^{15} \mathrm{~N}_{-} \mathrm{NH}_{4}^{+}$treatment. Under both oxic and hypoxic conditions, there was a significant linear relationship between the measured $\delta^{15} \mathrm{~N}-\mathrm{NO}$ and $\delta^{15} \mathrm{~N}_{-} \mathrm{NH}_{4}^{+}$values from all three $\delta^{15} \mathrm{~N}^{-\mathrm{NH}_{4}^{+}}$treatments (Fig. 4). The slope of the linear relationship is $0.78 \pm 0.03( \pm 1 \mathrm{SE})$ and $0.61 \pm 0.05$ for the oxic and hypoxic incubations, respectively (Fig. 4).

\subsection{Abiotic NO production}

Addition of $\mathrm{NO}_{3}^{-}$or $\mathrm{NH}_{4}^{+}$to the sterilized soil did not result in detectable NO production under either oxic or anoxic condition. Immediate NO release was, however, triggered by $\mathrm{NO}_{2}^{-}$addition under anoxic conditions (Fig. 5a). The abiotic NO production rate $\left(f_{\mathrm{NO}-\text {-abiotic }}\right)$ reached a steady level of $83 \pm 5 \mathrm{ng} \mathrm{Ng}^{-1} \mathrm{~h}^{-1}$ several minutes after the $\mathrm{NO}_{2}^{-}$addition and then decreased exponentially to $<3 \mathrm{ng} \mathrm{N} \mathrm{g}^{-1} \mathrm{~h}^{-1}$ over the following $8 \mathrm{~d}$ (Fig. 5a). The natural logarithm of $f_{\text {NO-abiotic }}$ showed a linear relationship with time (Fig. $5 b$ ). The NO produced following the $\mathrm{NO}_{2}^{-}$addition had a $\delta^{15} \mathrm{~N}$ value of $-17.8 \% \circ \pm 0.4 \%$, giving rise to a $\delta^{15} \mathrm{~N}$ offset between $\mathrm{NO}_{2}^{-}$and $\mathrm{NO}$ of $19.2 \%$ o $\pm 0.5 \%$. 

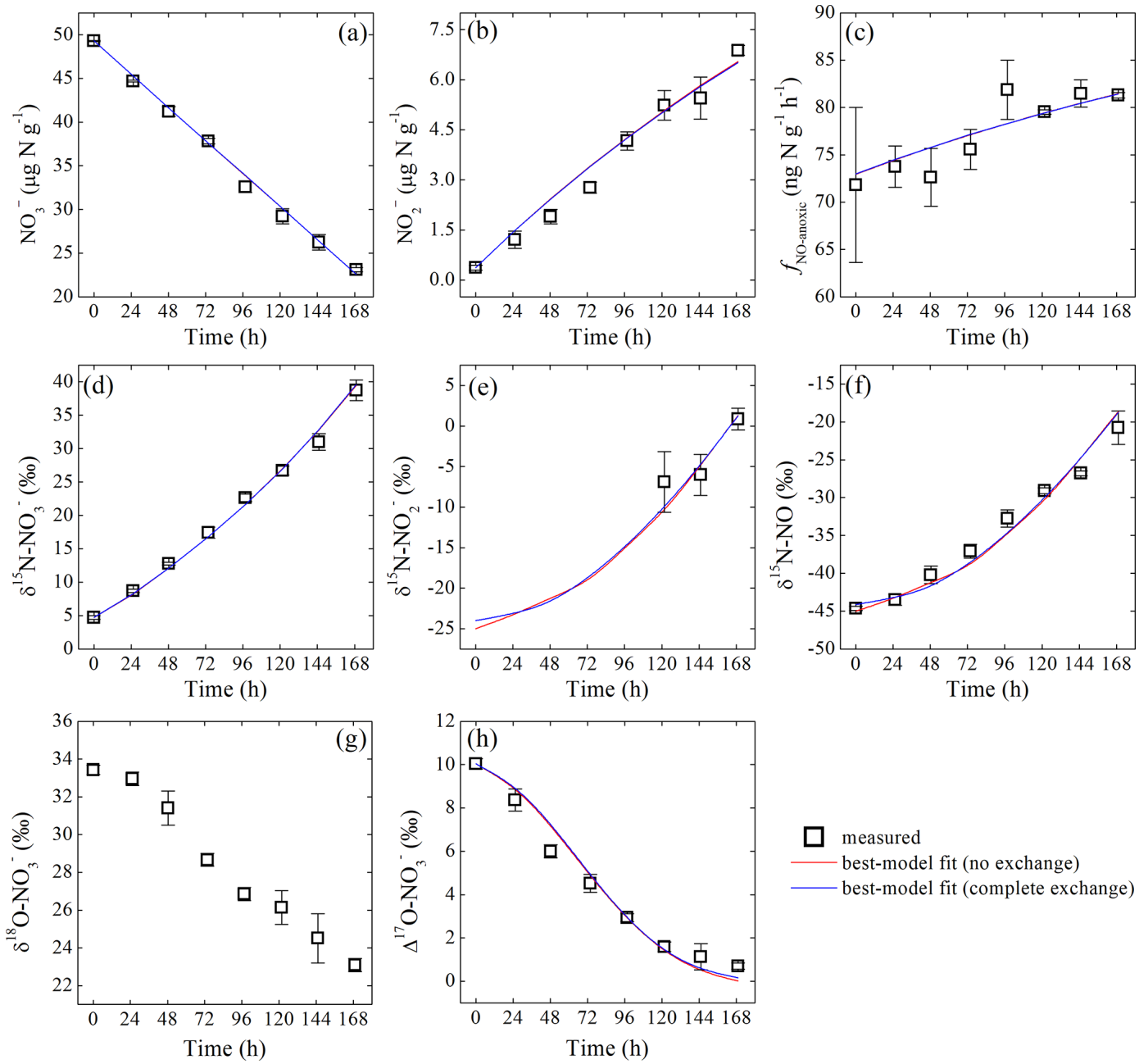

$\square$ measured

best-model fit (no exchange)

best-model fit (complete exchange)

Figure 2. Measured and modeled concentrations of $\mathrm{NO}_{3}^{-}$(a) and $\mathrm{NO}_{2}^{-}$(b); net $\mathrm{NO}$ production rate (c); $\delta^{15} \mathrm{~N}$ values of $\mathrm{NO}_{3}^{-}(\mathbf{d}), \mathrm{NO}_{2}^{-}(\mathbf{e})$, and $\mathrm{NO}(\mathbf{f})$; and $\delta^{18} \mathrm{O}(\mathbf{g})$ and $\Delta^{17} \mathrm{O}(\mathbf{h})$ of $\mathrm{NO}_{3}^{-}$during the anoxic incubation.

\section{Discussion}

Because interpretations of the results from the incubation experiments build upon each other, here we discuss the results from incubation of the sterilized soils (hereafter, abiotic incubation), anoxic incubation, and oxic/hypoxic incubations successively.

\subsection{Reaction characteristics and $\mathrm{N}$ isotopic fractionation during abiotic NO production}

The immediate release of $\mathrm{NO}$ upon the addition of $\mathrm{NO}_{2}^{-}$ highlights the chemically unstable nature of $\mathrm{NO}_{2}^{-}$and the critical role of chemical $\mathrm{NO}_{2}^{-}$reactions in driving soil $\mathrm{NO}$ emissions (Venterea et al., 2005; Lim et al., 2018). The strong linearity between $\ln \left(f_{\text {NO-abiotic }}\right)$ and time (Fig. $\left.5 b\right)$ suggests apparent first-order kinetics for the abiotic NO production from $\mathrm{NO}_{2}^{-}$(Eqs. 2 and 3) (McKenney et al., 1990). $f_{\text {NO-abiotic }}=s_{\text {abiotic }} \times k_{\text {abiotic }} \times\left[\mathrm{NO}_{2}^{-}\right]_{t}$

$\left[\mathrm{NO}_{2}^{-}\right]_{t}=\left[\mathrm{NO}_{2}^{-}\right]_{0} e^{-k_{\text {abiotic }} \times t}$

In Eqs. (2) and (3), $t$ is time; $k_{\text {abiotic }}$ is the pseudo-first-order rate constant for $\mathrm{NO}_{2}^{-}$loss; $s_{\text {abiotic }}$ is the apparent stoichiometric coefficient for NO production from $\mathrm{NO}_{2}^{-}$; and $\left[\mathrm{NO}_{2}^{-}\right]_{t}$ and $\left[\mathrm{NO}_{2}^{-}\right]_{0}$ are $\mathrm{NO}_{2}^{-}$concentration at time $t$ and $t=0$ in the sterilized soil, respectively. Combining Eqs. (2) and (3) and then log-transforming both sides yield

$$
\begin{aligned}
\ln \left(f_{\text {NO-abiotic }}\right)= & -k_{\text {abiotic }} \times t \\
& +\ln \left(s_{\text {abiotic }} \times k_{\text {abiotic }} \times\left[\mathrm{NO}_{2}^{-}\right]_{0}\right) .
\end{aligned}
$$

According to Eq. (4), $k_{\text {abiotic }}$ and $s_{\text {abiotic }}$ are estimated using the slope and intercept of the linear regression of $\ln \left(f_{\text {NO-abiotic }}\right)$ vs. time (Fig. 5b). Given $\left[\mathrm{NO}_{2}^{-}\right]_{0}=$ $8 \mu \mathrm{g} \mathrm{N} \mathrm{g}^{-1}, s_{\text {abiotic }}$ and $k_{\text {abiotic }}$ are estimated to be $0.52 \pm 0.05$ 

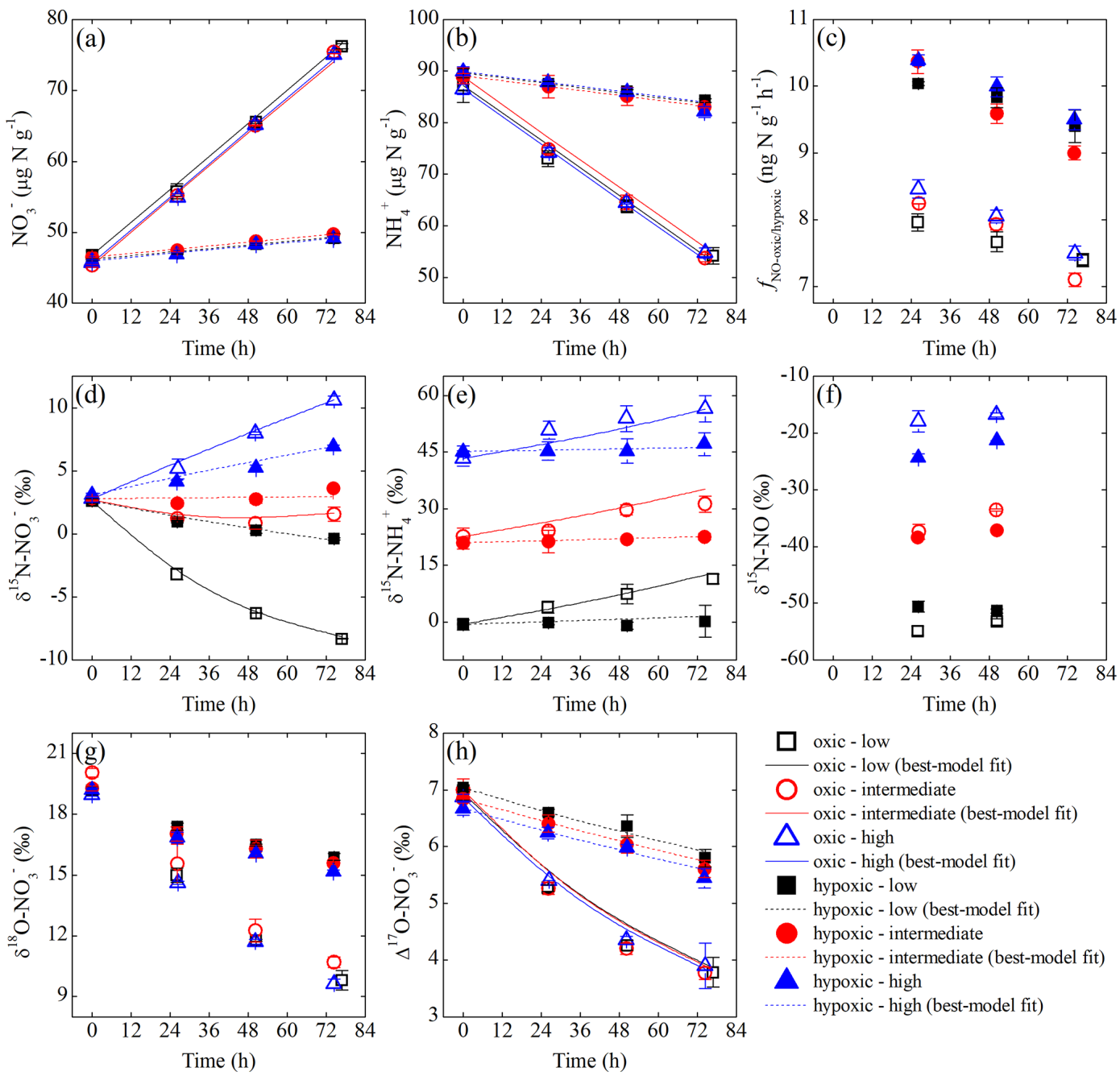

oxic - low

oxic - low (best-model fit)

oxic - intermediate

- oxic - intermediate (best-model fit)

$\triangle$ oxic-high

oxic - high (best-model fit)

hypoxic - low

hypoxic - low (best-model fit)

hypoxic - intermediate

hypoxic - intermediate (best-model fit)

Aypoxic-high

hypoxic - high (best-model fit)

Figure 3. Measured and modeled concentrations of $\mathrm{NO}_{3}^{-}$(a) and $\mathrm{NH}_{4}^{+}$(b); net $\mathrm{NO}$ production rate (c); $\delta^{15} \mathrm{~N}$ values of $\mathrm{NO}_{3}^{-}$(d), $\mathrm{NH}_{4}^{+}$(e), and $\mathrm{NO}(\mathbf{f})$; and $\delta^{18} \mathrm{O}(\mathrm{g})$ and $\Delta^{17} \mathrm{O}(\mathbf{h})$ of $\mathrm{NO}_{3}^{-}$under the three $\delta^{15} \mathrm{~N}-\mathrm{NH}_{4}^{+}$treatments (differed by color) of the oxic (open symbols) and hypoxic (solid symbols) incubations.

$( \pm \mathrm{SE})$ and $0.019 \pm 0.002 \mathrm{~h}^{-1}$, respectively, suggesting that $\mathrm{NO}$ accounted for $52 \% \pm 5 \%$ of the reacted $\mathrm{NO}_{2}^{-}$during the abiotic incubation. The estimated $k_{\text {abiotic }}$ is within the range (i.e., 0.00055 to $0.73 \mathrm{~h}^{-1}$ ) derived by a recent study based on soil samples spanning a wide range of $\mathrm{pH}$ values (3.4 to 7.2) (Lim et al., 2018). Based on the estimated $k_{\text {abiotic }}, 97 \%$ of the added $\mathrm{NO}_{2}^{-}$was lost by the end of the abiotic incubation.

Several reaction pathways with distinct stoichiometry have been proposed for abiotic $\mathrm{NO}$ production from $\mathrm{NO}_{2}^{-}$in soils. Under acidic soil conditions, self-decomposition of $\mathrm{HNO}_{2}$ produces $\mathrm{NO}$ and nitric acid $\left(\mathrm{HNO}_{3}\right)$ with a stoichiometric $\mathrm{HNO}_{2}$-to-NO ratio ranging from 0.5 to 0.66 (i.e., 1 mole of $\mathrm{HNO}_{2}$ produces 0.5 to 0.66 moles of NO) (Van Cleemput and Samater, 1995). Although at $\mathrm{pH} 5.7 \mathrm{HNO}_{2}$ constituted $<1 \%$ of the $\mathrm{NO}_{2}^{-}+\mathrm{HNO}_{2}$ pool in this soil, $\mathrm{HNO}_{2}$ decomposition can occur on acidic clay mineral surfaces, even though bulk soil pH is circumneutral (Venterea et al.,
2005). However, given the complete $\mathrm{NO}_{2}^{-}$consumption in the abiotic incubation, $\mathrm{HNO}_{2}$ decomposition confined to acidic microsites could not account for all observed NO production. Under anoxic conditions, $\mathrm{NO}_{2}^{-} / \mathrm{HNO}_{2}$ can also be stoichiometrically reduced to $\mathrm{NO}$ by transition metals (e.g., $\mathrm{Fe}(\mathrm{II})$ ) and diverse organic molecules (e.g., humic and fulvic acids, lignins, and phenols) in a process termed chemodenitrification (Zhu-Barker et al., 2015). The produced NO from chemo-denitrification can undergo further reduction to form $\mathrm{N}_{2} \mathrm{O}$ and $\mathrm{N}_{2}$ (Zhu-Barker et al., 2015). In addition, both $\mathrm{NO}_{2}^{-}$and $\mathrm{NO}$ in soil solution can be consumed as nitroso donors in abiotic nitrosation reactions, resulting in $\mathrm{N}$ incorporation into soil organic matter (Heil et al., 2016; Lim et al., 2018). Therefore, our observation that about half of the reacted $\mathrm{NO}_{2}^{-}$was recovered as $\mathrm{NO}$ may result from multiple competing $\mathrm{NO}_{2}^{-}$sinks, parallel NO-producing pathways, and possibly abiotic NO consumption in the sterilized soil. The 


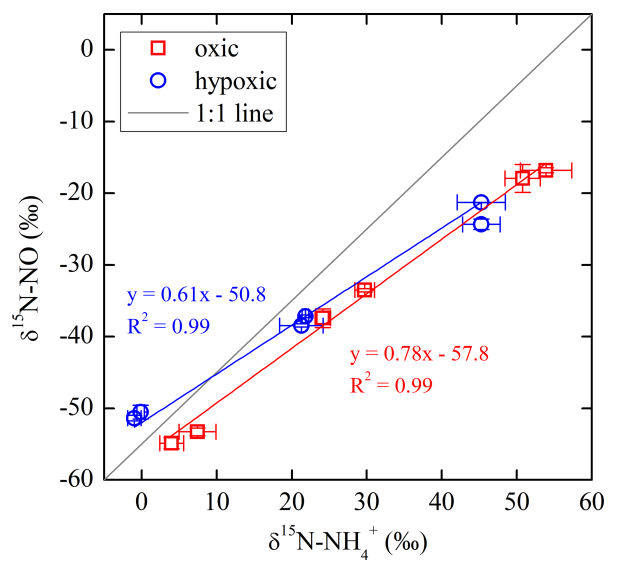

Figure 4. $\delta^{15} \mathrm{~N}-\mathrm{NO}$ as a function of $\delta^{15} \mathrm{~N}-\mathrm{NH}_{4}^{+}$in the oxic and hypoxic incubations.

other half of the reacted $\mathrm{NO}_{2}^{-}$that could not be accounted for by the measured $\mathrm{NO}$ was likely present in the forms of $\mathrm{N}_{2} \mathrm{O}, \mathrm{N}_{2}$, and/or nitrosated organic compounds in the soil.

The observed $\delta^{15} \mathrm{~N}$ difference between $\mathrm{NO}_{2}^{-}$and $\mathrm{NO}$ (i.e., ${ }^{15} \eta_{\mathrm{NO}_{2} / \mathrm{NO} \text { (abiotic) }}=19.2 \%$ o $\pm 0.5 \%$ o) likely reflects a combined $\mathrm{N}$ isotope effect for all of the competing NO production pathways during the abiotic incubation. While very little isotope data exist for abiotic $\mathrm{NO}_{2}^{-}$reactions in the literature, the measured ${ }^{15} \eta_{\mathrm{NO}_{2} / \mathrm{NO} \text { (abiotic) }}$ in this study is consistent with reported $\mathrm{N}$ isotope effects (i.e., $15 \%$ to $25 \%$ ) for abiotic $\mathrm{NO}_{2}^{-}$reduction by $\mathrm{Fe}(\mathrm{II})$ at similar $\mathrm{NO}_{2}^{-}$consumption rates to this study (0.02 to $0.05 \mathrm{~h}^{-1}$ ) (Buchwald et al., 2016). On the other hand, the measured ${ }^{15} \eta_{\mathrm{NO}_{2} / \mathrm{NO} \text { (abiotic) is }}$ lower than the reported $\delta^{15} \mathrm{~N}$ offsets between $\mathrm{NO}_{2}^{-}$and $\mathrm{N}_{2} \mathrm{O}$

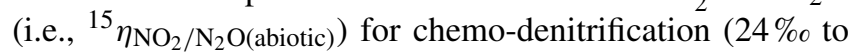
29\%o) (Jones et al., 2015; Wei et al., 2019). This seems to suggest that the observed abiotic NO production was mainly driven by chemo-denitrification and that accumulation of NO as an chemo-denitrification intermediate may explain why

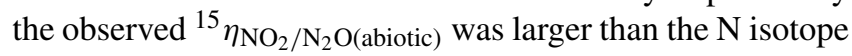
effect for $\mathrm{Fe}(\mathrm{II})$-catalyzed $\mathrm{NO}_{2}^{-}$reduction in previous batch experiments (Jones et al., 2015; Buchwald et al., 2016). Future studies adopting simultaneous $\delta^{15} \mathrm{~N}-\mathrm{NO}$ and $\delta^{15} \mathrm{~N}-\mathrm{N}_{2} \mathrm{O}$ measurements will be required to elucidate the role of $\mathrm{NO}$ as the $\mathrm{N}_{2} \mathrm{O}$ precursor during chemo-denitrification.

It is important to note that the autoclaving is a harsh sterilization method and can substantially alter soil physical and chemical properties. For example, Buessecker et al. (2019) recently showed that autoclaved peat soil had 10-fold-higher total fluorescence compared to non-sterilized controls, indicating dramatic increases in solubility and lability of organic molecules by autoclaving. Furthermore, autoclaving has also been shown to substantially increase abiotic $\mathrm{N}_{2} \mathrm{O}$ production from $\mathrm{NO}_{2}^{-}$-amended soils (Wei et al., 2019). Conversely, milder sterilization methods (e.g., gamma-irradiation) that presumably cause less alteration of soil properties may not completely inactivate biological NO production due to the high diversity of biological NO production pathways in soils (e.g., non-specific reactions catalyzed by extracellular enzymes) (Medinets et al., 2015). Further research is warranted to compare different sterilization methods for their effects on abiotic NO production and ${ }^{15} \eta_{\mathrm{NO}_{2} / \mathrm{NO} \text { (abiotic). }}$.

\subsection{Reaction reversibility between $\mathrm{NO}_{3}^{-}$and $\mathrm{NO}_{2}^{-}$and $\mathrm{N}$ isotope distribution between $\mathrm{NO}_{3}^{-}, \mathrm{NO}_{2}^{-}$, and $\mathrm{NO}$ during the anoxic incubation}

The measured $f_{\text {NO-anoxic }}$ ( 72 to $82 \mathrm{ng} \mathrm{Ng}^{-1} \mathrm{~h}^{-1}$ ) (Fig. 2c) is well within the range reported for anoxic soil incubations (e.g., 5 to $500 \mathrm{ng} \mathrm{g}^{-1} \mathrm{~h}^{-1}$ ) (Medinets et al., 2015) and is about two-thirds of the net consumption rate of $\mathrm{NO}_{3}^{-}+\mathrm{NO}_{2}^{-}$ during the anoxic incubation. That the majority of consumed $\mathrm{NO}_{3}^{-}+\mathrm{NO}_{2}^{-}$was recovered as $\mathrm{NO}$ supports the emerging notion that $\mathrm{NO}$ can be the end product of denitrification once limitations on gas diffusion are lifted in soils (Russow et al., 2009; Loick et al., 2016). Applying the derived $k_{\text {abiotic }}$ and $s_{\text {abiotic }}$ in the abiotic incubation to the measured $\mathrm{NO}_{2}^{-}$ concentrations under anoxic condition produced a range of $f_{\text {NO-abiotic }}$ from $<4$ to $68 \mathrm{ng} \mathrm{N}^{-1} \mathrm{~h}^{-1}$ (Fig. S4). While this modeled $f_{\text {NO-abiotic }}$ appears to contribute up to $80 \%$ of the measured $f_{\text {NO-anoxic }}$ (Fig. S4), $f_{\text {NO-anoxic }}$ was high and remained stable even without any significant accumulation of $\mathrm{NO}_{2}^{-}$in the soil (Fig. $2 \mathrm{~b}$ and c), suggesting that $k_{\text {abiotic }}$ was likely overestimated in the abiotic incubation (see above). Assuming that net biological NO production was maintained at the level of $f_{\mathrm{NO} \text {-anoxic }}$ measured during the first sampling event and that $s_{\text {abiotic }}$ was constant and equal to 0.52 , a back-of-the-envelope calculation based on the difference in $f_{\mathrm{NO}-\text { anoxic }}$ between the first and last sampling events and the $\mathrm{NO}_{2}^{-}$concentration measured at the end of the anoxic incubation indicates that $k_{\text {abiotic }}$ was likely on the order of $0.0027 \mathrm{~h}^{-1}$, or about 7 times lower than the $k_{\text {abiotic }}$ derived in the abiotic incubation. Although qualitative, this calculation suggests a minor contribution of abiotic NO production to the measured $f_{\text {NO-anoxic }}(<12 \%$; Fig. S4).

The large increases in $\delta^{15} \mathrm{~N}-\mathrm{NO}_{3}^{-}$and $\delta^{15} \mathrm{~N}-\mathrm{NO}$ values over the anoxic incubation (Fig. 2d and f) are congruent with strong $\mathrm{N}$ isotopic fractionations during microbial denitrification (Mariotti et al., 1981; Granger et al., 2008). However, the observed net isotope effect for $\mathrm{NO}$ production from $\mathrm{NO}_{3}^{-}$ (i.e., ${ }^{15} \eta_{\mathrm{NO}_{3} / \mathrm{NO}} ; 49.4 \%$ to $59.5 \%$ ) is larger than the apparent $\mathrm{N}$ isotope effect for $\mathrm{NO}_{3}^{-}$consumption $(43.3 \%$ o $\pm 0.9 \%$ o) (Fig. S3). The large magnitude and increasing pattern of ${ }^{15} \eta_{\mathrm{NO}_{3} / \mathrm{NO}}$, together with the accumulation of $\mathrm{NO}_{2}^{-}$in the soil, point to complexity beyond single-step isotopic fractionations and highlight the need to carefully examine fractionation mechanisms for all intermediate steps leading to net $\mathrm{NO}$ production (i.e., $\mathrm{NO}_{3}^{-}$to $\mathrm{NO}_{2}^{-}, \mathrm{NO}_{2}^{-}$to $\mathrm{NO}$, and $\mathrm{NO}$ to $\mathrm{N}_{2} \mathrm{O}$ ). Moreover, it is surprising that both $\delta^{18} \mathrm{O}-\mathrm{NO}_{3}^{-}$ and $\Delta^{17} \mathrm{O}-\mathrm{NO}_{3}^{-}$values decreased over the anoxic incubation (Fig. $2 \mathrm{~g}$ and h). Interestingly, similar decreasing trends in $\delta^{18} \mathrm{O}-\mathrm{NO}_{3}^{-}$values (e.g., up to $4 \%$ over $25 \mathrm{~h}$ ) have been 

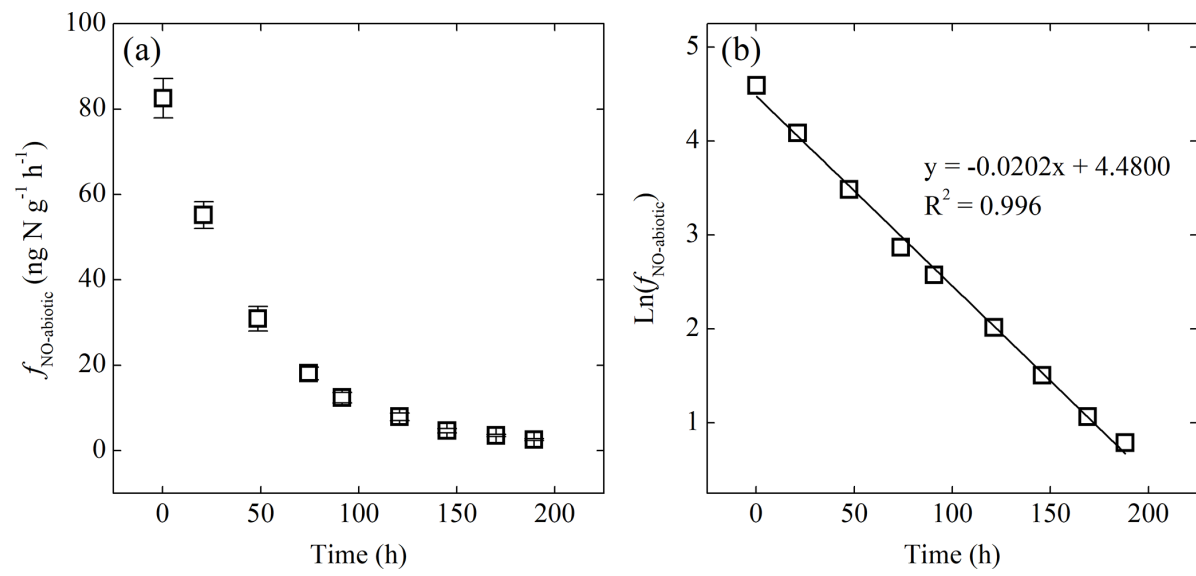

Figure 5. (a) Net NO production rate $\left(f_{\mathrm{NO}}\right.$-abiotic $)$ of the $\mathrm{NO}_{2}^{-}$-amended sterilized soil as a function of time. (b) Plot of the natural logarithm of $f_{\mathrm{NO} \text {-abiotic }}$ vs. time showing first-order decay of $f_{\mathrm{NO} \text {-abiotic }}$.

reported by Lewicka-Szczebak et al. (2014) for two anoxically incubated agricultural soils amended with a high- $\delta^{18} \mathrm{O}$ Chilean $\mathrm{NO}_{3}^{-}$fertilizer similar to ours (i.e., $\delta^{18} \mathrm{O}^{-\mathrm{NO}_{3}^{-}}=$ $56 \%$ ), although $\Delta^{17} \mathrm{O}-\mathrm{NO}_{3}^{-}$was not reported in this previous study. The decreasing $\delta^{18} \mathrm{O}-\mathrm{NO}_{3}^{-}$values, observed here and by Lewicka-Szczebak et al. (2014), appear to contradict the well-established paradigm that variations in $\delta^{15} \mathrm{~N}^{-\mathrm{NO}_{3}^{-}}$ and $\delta^{18} \mathrm{O}^{-\mathrm{NO}_{3}^{-}}$values follow a linear trajectory with a slope of 0.5 to 1 during dissimilatory $\mathrm{NO}_{3}^{-}$reduction (Granger et al., 2008). Furthermore, as $\Delta^{17} \mathrm{O}-\mathrm{NO}_{3}^{-}$is in theory not altered by microbial denitrification - a mass-dependent fractionation process (Michalski et al., 2004; Yu and Elliott, 2018), the decreasing $\Delta^{17} \mathrm{O}-\mathrm{NO}_{3}^{-}$values observed in this study indicate that processes capable of diluting or erasing the $\Delta^{17} \mathrm{O}$ signal may occur concurrently with denitrification during the anoxic incubation. Importantly, if this dilution or removal of the $\Delta^{17} \mathrm{O}$ signal was accompanied by $\mathrm{N}$ isotopic fractionations, there may be cascading effects on the distribution of $\mathrm{N}$ isotopes between $\mathrm{NO}_{3}^{-}, \mathrm{NO}_{2}^{-}$, and $\mathrm{NO}$.

The decreasing $\delta^{18} \mathrm{O}-\mathrm{NO}_{3}^{-}$and $\Delta^{17} \mathrm{O}-\mathrm{NO}_{3}^{-}$values could be potentially explained by an $\mathrm{O}$ isotope equilibration between $\mathrm{NO}_{3}^{-}$and soil $\mathrm{H}_{2} \mathrm{O}$, catalyzed either chemically or biologically via a reversible reaction between $\mathrm{NO}_{3}^{-}$and $\mathrm{NO}_{2}^{-}$ (Granger and Wankel, 2016). However, it has been shown in controlled laboratory experiments that dissimilatory $\mathrm{NO}_{3}^{-}$ reduction catalyzed by bacterial nitrate reductase (NAR) is irreversible at the enzyme level (Treibergs and Granger, 2017) and that abiotic $\mathrm{O}$ isotope exchange between $\mathrm{NO}_{3}^{-}$and $\mathrm{H}_{2} \mathrm{O}$ is extremely slow (half-life $>10^{9}$ years at $25^{\circ} \mathrm{C}$ and $\mathrm{pH} 7$ ) and therefore irrelevant under natural soil conditions (Kaneko and Poulson, 2013). Although fungi use a distinct enzyme system for denitrification (Shoun et al., 2012), there is no evidence for enzymatic reversibility of fungal NAR in the literature. Furthermore, by converting $\mathrm{NH}_{4}^{+}$and $\mathrm{NO}_{2}^{-}$ simultaneously to $\mathrm{N}_{2}$ and $\mathrm{NO}_{3}^{-}$, anaerobic $\mathrm{NH}_{4}^{+}$oxidation (anammox) could dilute the $\Delta^{17} \mathrm{O}$ signal by producing $\mathrm{NO}_{3}^{-}$ with $\Delta^{17} \mathrm{O}=0$ (Brunner et al., 2013). However, due to the low indigenous $\mathrm{NH}_{4}^{+}$concentration, anammox is considered not pertinent during the anoxic incubation. Given the complete recovery of $\mathrm{NO}_{3}^{-}$concentrations and isotopes in the control experiments (Tables $\mathrm{S} 1$ and S2), as well as the significantly increased $\delta^{15} \mathrm{~N}_{-} \mathrm{NO}_{3}^{-}$values during the anoxic incubation, we excluded $\mathrm{NO}_{3}^{-}$production from aerobic $\mathrm{NH}_{4}^{+}$ oxidation as a possible explanation for the observed declines in $\delta^{18} \mathrm{O}-\mathrm{NO}_{3}^{-}$and $\Delta^{17} \mathrm{O}-\mathrm{NO}_{3}^{-}$values.

Therefore, having ruled out the above possibilities led us to postulate that the decreasing $\delta^{18} \mathrm{O}-\mathrm{NO}_{3}^{-}$and $\Delta^{17} \mathrm{O}-\mathrm{NO}_{3}^{-}$ values may result from anaerobic $\mathrm{NO}_{2}^{-}$oxidation mediated by $\mathrm{NOB}$ in the soil. The enzyme catalyzing $\mathrm{NO}_{2}^{-}$oxidation to $\mathrm{NO}_{3}^{-}$in $\mathrm{NOB}-\mathrm{NO}_{2}^{-}$oxidoreductase (NXR) - is metabolically versatile and has been shown to catalyze $\mathrm{NO}_{3}^{-}$reduction under anoxic conditions by operating in reverse (Friedman et al., 1986; Freitag et al., 1987; Bock et al., 1988; Koch et al., 2015). Moreover, during NXR-catalyzed $\mathrm{NO}_{2}^{-}$oxidation, the required $\mathrm{O}$ atom originates from $\mathrm{H}_{2} \mathrm{O}$ molecules (Reaction R1), so that $\mathrm{NO}_{2}^{-}$can in theory be oxidized to $\mathrm{NO}_{3}^{-}$ without the presence of $\mathrm{O}_{2}$ by donating electrons to redoxactive intracellular components (Wunderlich et al., 2013) or alternative electron acceptors in niche environments (Babbin et al., 2017).

$\mathrm{NO}_{3}^{-}+2 \mathrm{H}^{+}+2 \mathrm{e}^{-} \Leftrightarrow \mathrm{H}_{2} \mathrm{O}+\mathrm{NO}_{2}^{-}$

In a denitrifying environment, anaerobic oxidation of denitrification-produced $\mathrm{NO}_{2}^{-}$back to $\mathrm{NO}_{3}^{-}$(i.e., $\mathrm{NO}_{2}^{-}$reoxidation) can dilute $\delta^{18} \mathrm{O}-\mathrm{NO}_{3}^{-}$and $\Delta^{17} \mathrm{O}-\mathrm{NO}_{3}^{-}$values by incorporating a "new" $\mathrm{O}$ atom from $\mathrm{H}_{2} \mathrm{O}$ into the reacting $\mathrm{NO}_{3}^{-}$pool (Reaction R1) (Granger and Wankel, 2016). Under acidic and circumneutral $\mathrm{pH}$ conditions, this dilution effect can be further enhanced by chemically and perhaps biologically catalyzed $\mathrm{O}$ isotope equilibration between $\mathrm{NO}_{2}^{-}$and $\mathrm{H}_{2} \mathrm{O}$ (Casciotti et al., 2007; Buchwald and Casciotti, 2010), which effectively erases the isotopic imprints of denitrification on $\mathrm{NO}_{2}^{-}$prior to its re-oxidation. The reversibility of 
$\mathrm{NXR}$ and its direct control on $\mathrm{O}$ isotopes in $\mathrm{NO}_{3}^{-}$have been convincingly demonstrated by Wunderlich et al. (2013) using a pure culture of Nitrobacter vulgaris. By incubating N. vulgaris in a $\mathrm{NO}_{3}^{-}$solution under anoxic conditions, Wunderlich et al. (2013) showed that $\mathrm{NO}_{2}^{-}$was produced in the solution by $N$. vulgaris and that $N$. vulgaris promoted incorporation of amended ${ }^{18} \mathrm{O}-\mathrm{H}_{2} \mathrm{O}$ labels into $\mathrm{NO}_{3}^{-}$through a re-oxidation of the accumulated $\mathrm{NO}_{2}^{-}$(Wunderlich et al., 2013).

Importantly, there is mounting evidence from the marine $\mathrm{N}$ cycle community that $\mathrm{NO}_{2}^{-}$re-oxidation plays a critical role in the $\mathrm{N}$ isotope partitioning between $\mathrm{NO}_{3}^{-}$and $\mathrm{NO}_{2}^{-}$. At the process scale, $\mathrm{NO}_{2}^{-}$re-oxidation co-occurring with dissimilatory $\mathrm{NO}_{3}^{-}$reduction can lead to a large $\delta^{15} \mathrm{~N}$ difference between $\mathrm{NO}_{3}^{-}$and $\mathrm{NO}_{2}^{-}$beyond what would be expected to result from $\mathrm{NO}_{3}^{-}$reduction alone (Gaye et al., 2013; Dale et al., 2014; Dähnke and Thamdrup, 2016; Peters et al., 2016; Martin and Casciotti, 2017; Buchwald et al., 2018). This large $\delta^{15} \mathrm{~N}$ difference is thought to arise from a rare, but intrinsic, inverse kinetic isotope effect associated with $\mathrm{NO}_{2}^{-}$re-oxidation (e.g., -13\%o) (Casciotti, 2009). As such, in a net denitrifying environment, $\mathrm{NO}_{2}^{-}$re-oxidation functions as an apparent branching pathway along the sequential reduction of $\mathrm{NO}_{3}^{-}$, preferentially re-oxidizing ${ }^{15} \mathrm{NO}_{2}^{-}$back to $\mathrm{NO}_{3}^{-}$. At the enzyme scale, the bidirectional NXR enzyme has been proposed to catalyze intracellular coupled $\mathrm{NO}_{3}^{-}$reduction and $\mathrm{NO}_{2}^{-}$oxidation (i.e., bidirectional interconversion of $\mathrm{NO}_{3}^{-}$and $\mathrm{NO}_{2}^{-}$), facilitating expression of an equilibrium $\mathrm{N}$ isotope effect between $\mathrm{NO}_{3}^{-}$and $\mathrm{NO}_{2}^{-}$(Reaction $\mathrm{R} 2$ ) (Wunderlich et al., 2013; Kemeny et al., 2016).

$$
{ }^{14} \mathrm{NO}_{2}^{-}+{ }^{15} \mathrm{NO}_{3}^{-} \Leftrightarrow{ }^{15} \mathrm{NO}_{2}^{-}+{ }^{14} \mathrm{NO}_{3}^{-}
$$

Evidence from pure culture studies of anammox bacteria carrying the NXR enzyme (Brunner et al., 2013) and theoretical quantum calculations (Casciotti, 2009) suggest that this $\mathrm{N}$ isotope equilibration favors partitioning of ${ }^{14} \mathrm{~N}$ into $\mathrm{NO}_{2}^{-}$with an equilibrium isotope effect ranging from $-50 \%$ o to $-60 \%$ o (negative sign is used to denote that this $\mathrm{N}$ isotope equilibration partitions ${ }^{14} \mathrm{~N}$ to the left side of Reaction R2). This NXR-catalyzed $\mathrm{NO}_{3}^{-} / \mathrm{NO}_{2}^{-}$interconversion was invoked to explain the extremely low $\delta^{15} \mathrm{~N}_{-} \mathrm{NO}_{2}^{-}$values relative to $\delta^{15} \mathrm{~N}^{-\mathrm{NO}_{3}^{-}}$(up to $90 \%$ ) in the surface Antarctic Ocean, where aerobic $\mathrm{NO}_{2}^{-}$oxidation is inhibited by low nutrient availability (Kemeny et al., 2016). Hypothetically, if expressed at either the process or the enzyme level, the $\mathrm{N}$ isotope effect for $\mathrm{NO}_{2}^{-}$re-oxidation could propagate into denitrification-produced NO, giving rise to an increased $\delta^{15} \mathrm{~N}$ difference between $\mathrm{NO}_{3}^{-}$and $\mathrm{NO}\left({ }^{15} \eta_{\mathrm{NO}_{3} / \mathrm{NO}}\right)$.

To test whether $\mathrm{NO}_{2}^{-}$re-oxidation can explain the observed declines in $\delta^{18} \mathrm{O}-\mathrm{NO}_{3}^{-}$and $\Delta^{17} \mathrm{O}-\mathrm{NO}_{3}^{-}$values and $\delta^{15} \mathrm{~N}$ distribution between $\mathrm{NO}_{3}^{-}, \mathrm{NO}_{2}^{-}$, and $\mathrm{NO}$, we modified an isotopologue-specific (i.e., ${ }^{14} \mathrm{~N},{ }^{15} \mathrm{~N},{ }^{16} \mathrm{O},{ }^{17} \mathrm{O}$, and ${ }^{18} \mathrm{O}$ ) numerical model previously described by $\mathrm{Yu}$ and $\mathrm{El}-$ liott (2018) to simulate co-occurring denitrification and $\mathrm{NO}_{2}^{-}$ re-oxidation in two steps. Without a clear identification of the alternative electron acceptors that coupled with anaerobic $\mathrm{NO}_{2}^{-}$oxidation in the studied soil, we followed the reaction scheme proposed by Wunderlich et al. (2013) and Kemeny et al. (2016) (Reaction R1) to parameterize the NXRcatalyzed $\mathrm{NO}_{2}^{-}$re-oxidation as the backward reaction of a dynamic equilibrium between $\mathrm{NO}_{3}^{-}$and $\mathrm{NO}_{2}^{-}$(Fig. 6) - that is, the NXR-catalyzed $\mathrm{NO}_{2}^{-}$re-oxidation (backward reaction) is balanced by an NXR-catalyzed $\mathrm{NO}_{3}^{-}$reduction (forward reaction), leading to no net $\mathrm{NO}_{2}^{-}$oxidation or $\mathrm{NO}_{3}^{-}$reduction in the soil. Importantly, this representation is consistent with the observation that both $\mathrm{NO}_{3}^{-}$consumption and $\mathrm{NO}_{2}^{-}$accumulation followed a pseudo-zero-order kinetics over the anoxic incubation (Fig. 2a and b), which implies no net contribution from the $\mathrm{NO}_{3}^{-} / \mathrm{NO}_{2}^{-}$interconversion. Given previous findings that the NXR-catalyzed $\mathrm{O}$ exchange between $\mathrm{NO}_{3}^{-}$and $\mathrm{NO}_{2}^{-}$depends on $\mathrm{NO}_{2}^{-}$availability (Wunderlich et al., 2013), the backward $\mathrm{NO}_{2}^{-}$re-oxidation was assumed to be first order (with respect to $\mathrm{NO}_{2}^{-}$), defined by a first-order rate constant, $k_{\mathrm{NXR}(\mathrm{b})}$. With respect to the $\mathrm{O}$ isotope equilibration between $\mathrm{H}_{2} \mathrm{O}$ and the reacting $\mathrm{NO}_{2}^{-}$pool, we considered two extreme-case scenarios: (1) no exchange and (2) complete exchange. In the no-exchange scenario, the imprints of denitrification on $\delta^{18} \mathrm{O}-\mathrm{NO}_{2}^{-}$and $\Delta^{17} \mathrm{O}-\mathrm{NO}_{2}^{-}$ values are preserved, such that only one $\mathrm{H}_{2} \mathrm{O}$-derived $\mathrm{O}$ atom is incorporated into $\mathrm{NO}_{3}^{-}$with each $\mathrm{NO}_{2}^{-}$molecule being reoxidized (Reaction R1). In the complete-exchange scenario, $\delta^{18} \mathrm{O}$ and $\Delta^{17} \mathrm{O}$ values of $\mathrm{NO}_{2}^{-}$always reflect those of soil $\mathrm{H}_{2} \mathrm{O}\left(\delta^{18} \mathrm{O}-\mathrm{H}_{2} \mathrm{O} \approx-10 \%\right.$, $\Delta^{17} \mathrm{O}-\mathrm{H}_{2} \mathrm{O}=0 \%$ (Fig. 6), and therefore all three $\mathrm{O}$ atoms in $\mathrm{NO}_{3}^{-}$produced from $\mathrm{NO}_{2}^{-}$reoxidation originate from $\mathrm{H}_{2} \mathrm{O}$. Furthermore, we considered both abiotic NO production and denitrification as the source of NO during the anoxic incubation (Fig. 6). To account for the potential overestimation in $k_{\text {abiotic }}$ (see above), we used a reduced $k_{\text {abiotic }}\left(0.0027 \mathrm{~h}^{-1}\right)$ to model net abiotic NO pro-

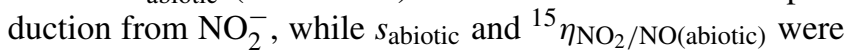
fixed at $0.52 \% o$ and $19.2 \%$, respectively. With respect to $\delta^{15} \mathrm{~N}$ of denitrification-produced NO, we assumed that NIRcatalyzed $\mathrm{NO}_{2}^{-}$reduction to $\mathrm{NO}$ and NOR-catalyzed NO reduction to $\mathrm{N}_{2} \mathrm{O}$ were each associated with a kinetic $\mathrm{N}$ isotope effect $\left({ }^{15} \eta_{\text {NIR }}\right.$ and $\left.{ }^{15} \eta_{\text {NOR }}\right)$. The closed-system Rayleigh equation was then used to simulate the coupled NO production and reduction in denitrification at each model time interval (Lewicka-Szczebak et al., 2014). Detailed model derivation and formulation are provided in the Supplement (Sect. S3.1).

With this model of co-occurring denitrification and $\mathrm{NO}_{2}^{-}$ re-oxidation, we first solved for the rates of denitrifiercatalyzed $\mathrm{NO}_{3}^{-}\left(R_{\mathrm{NAR}}\right), \mathrm{NO}_{2}^{-}\left(R_{\mathrm{NIR}}\right)$, and $\mathrm{NO}\left(R_{\mathrm{NOR}}\right)$ reductions and $k_{\mathrm{NXR}(\mathrm{b})}$ (four unknowns) using the measured $\mathrm{NO}_{3}^{-}$ and $\mathrm{NO}_{2}^{-}$concentrations, $f_{\text {NO-anoxic }}$, and $\Delta^{17} \mathrm{O}-\mathrm{NO}_{3}^{-}$values (four measured variables). This first modeling step was robustly constrained by the measured $\Delta^{17} \mathrm{O}-\mathrm{NO}_{3}^{-}$, which essentially functions as a ${ }^{15} \mathrm{NO}_{3}^{-}$tracer (Yu and Elliott, 2018) and is therefore particularly sensitive to $\mathrm{NO}_{2}^{-}$re-oxidation. In the second modeling step, the measured $\delta^{15} \mathrm{~N}^{-\mathrm{NO}_{3}^{-}}, \delta^{15} \mathrm{~N}-$ 


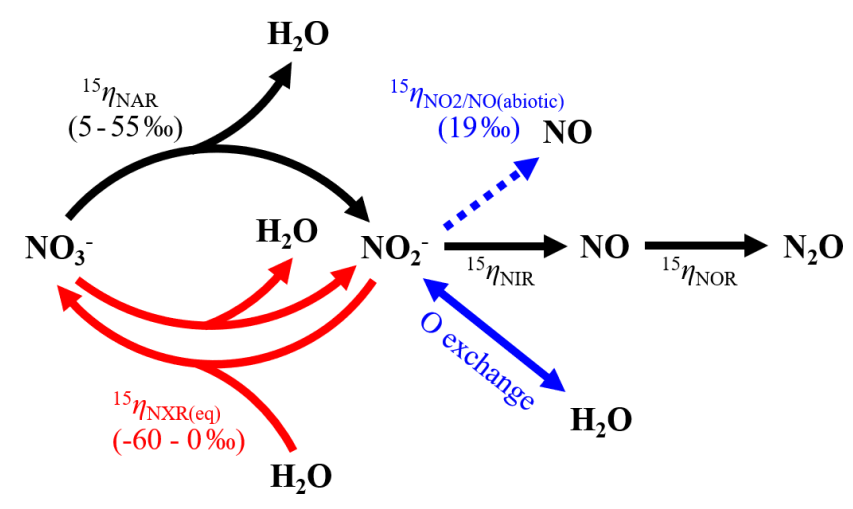

Figure 6. Model structure of co-occurring denitrification and $\mathrm{NO}_{2}^{-}$ re-oxidation and associated $\mathrm{N}$ isotope effects. Nitrogen transformations driven by denitrifiers and nitrifiers are shown by solid black and red arrows, respectively, and abiotic $\mathrm{O}$ exchange between $\mathrm{NO}_{2}^{-}$ and $\mathrm{H}_{2} \mathrm{O}$ by the solid blue arrow. The dashed blue arrow denotes net $\mathrm{NO}$ yield from abiotic $\mathrm{NO}_{2}^{-}$reactions.

$\mathrm{NO}_{2}^{-}$, and $\delta^{15} \mathrm{~N}-\mathrm{NO}$ values (three measured variables) were used to optimize the kinetic $\mathrm{N}$ isotope effects for NARcatalyzed $\mathrm{NO}_{3}^{-}$reduction $\left({ }^{15} \eta_{\mathrm{NAR}}\right),{ }^{15} \eta_{\mathrm{NIR}},{ }^{15} \eta_{\mathrm{NOR}}$, and the equilibrium $\mathrm{N}$ isotope effect for NXR-catalyzed $\mathrm{NO}_{3}^{-} / \mathrm{NO}_{2}^{-}$ interconversion ( ${ }^{15} \eta_{\mathrm{NXR} \text { (eq) }}$ ) (Reaction R2; Fig. 6) (four unknowns). This modeling system is under-determined (number of measured variables is less than the number of unknowns) and thus cannot be solved uniquely. Thus, instead of definitively solving for the four unknown isotope effects, we explored their best combination to fit the measured $\delta^{15} \mathrm{~N}$ values of $\mathrm{NO}_{3}^{-}, \mathrm{NO}_{2}^{-}$, and $\mathrm{NO}$. Specifically, to reduce the number of unknowns for model optimization, ${ }^{15} \eta_{\text {NAR }}$ and ${ }^{15} \eta_{\text {NXR(eq) }}$ were treated as known values, and ${ }^{15} \eta_{\text {NIR }}$ and ${ }^{15} \eta_{\text {NOR }}$ were solved by mapping through the entire space of ${ }^{15} \eta_{\text {NAR }}$ and ${ }^{15} \eta_{\text {NXR(eq) }}$ (at a resolution of $1 \%$ ), defined by their respective widest range of possible values. We used a range of $5 \%$ o to $55 \%$ or for ${ }^{15} \eta_{\mathrm{NAR}}$, consistent with a recent compilation based on soil incubations and denitrifier pure cultures (Denk et al., 2017). Given the existing observational and theoretical constraints (Casciotti, 2009; Brunner et al., 2013), a range of $-60 \%$ to $0 \%$ was assigned to

${ }^{15} \eta_{\mathrm{NXR}(\mathrm{eq})}$, which is equivalent to the argument that the impact of $\mathrm{NO}_{3}^{-} / \mathrm{NO}_{2}^{-}$interconversion on the $\mathrm{N}$ isotope distribution between $\mathrm{NO}_{3}^{-}$and $\mathrm{NO}_{2}^{-}$can vary from null to a strong partitioning of ${ }^{14} \mathrm{~N}$ to $\mathrm{NO}_{2}^{-}$. We further defined the lower percentile 2.5 of the error-weighted residual sum of squares (RSS) between simulated and measured $\delta^{15} \mathrm{~N}$ values of $\mathrm{NO}_{3}^{-}$, $\mathrm{NO}_{2}^{-}$, and $\mathrm{NO}$ as the threshold for selection of the best-fit models. Detailed information regarding model optimization can be found in the Supplement (Sect. S3.2).

Results from the first modeling step are summarized in Table 1, and the best-fit models were plotted in Fig. 2 to compare with the measured data. Because the NXRcatalyzed $\mathrm{NO}_{3}^{-} / \mathrm{NO}_{2}^{-}$interconversion was assumed to result in no change in $\mathrm{NO}_{3}^{-}$and $\mathrm{NO}_{2}^{-}$concentrations, $R_{\mathrm{NAR}}$ $\left(0.158 \mu \mathrm{g} \mathrm{Ng}^{-1} \mathrm{~h}^{-1}\right), R_{\mathrm{NIR}}\left(0.112 \mu \mathrm{g} \mathrm{Ng}^{-1} \mathrm{~h}^{-1}\right)$, and $R_{\mathrm{NOR}}$ $\left(0.039 \mu \mathrm{g} \mathrm{N} \mathrm{g}^{-1} \mathrm{~h}^{-1}\right)$ can be well described by zero-order kinetics and are not sensitive to model scenarios for $\mathrm{O}$ exchange between $\mathrm{NO}_{2}^{-}$and $\mathrm{H}_{2} \mathrm{O}$ (Table 1). Moreover, the observed $\mathrm{NO}_{2}^{-}$accumulation and $f_{\mathrm{NO} \text {-anoxic }}$ dynamics can be well reproduced using the modeled denitrification rates and the downward adjustment of $k_{\text {abiotic }}$ (Fig. 2b and c). $k_{\mathrm{NXR}(\mathrm{b})}$ was estimated to be 0.64 and $0.25 \mathrm{~h}^{-1}$ under the no-exchange and complete-exchange scenarios, respectively (Table 1). Under both scenarios, the simulated $\Delta^{17} \mathrm{O}-\mathrm{NO}_{3}^{-}$ values exhibit a characteristic decreasing trend and are in excellent agreement with measured $\Delta^{17} \mathrm{O}-\mathrm{NO}_{3}^{-}$values (Fig. $2 \mathrm{~h}$ ). The larger $k_{\mathrm{NXR}(\mathrm{b})}$ under the no-exchange scenario is expected and can be explained by the faster back reaction (i.e., $\mathrm{NO}_{2}^{-}$re-oxidation) required to reproduce the observed dilution of $\Delta^{17} \mathrm{O}-\mathrm{NO}_{3}^{-}$, because only one new $\mathrm{O}$ atom is incorporated into $\mathrm{NO}_{3}^{-}$with each $\mathrm{NO}_{2}^{-}$molecule being re-oxidized. Although the measured $\delta^{18} \mathrm{O}_{-} \mathrm{NO}_{3}^{-}$values did not provide quantitative constraints for the model optimization, the isotopologue-specific model with the optimized denitrification rates and $k_{\mathrm{NXR}(\mathrm{b})}$ was run forward to test whether the decreasing $\delta^{18} \mathrm{O}-\mathrm{NO}_{3}^{-}$values can also be possibly explained by co-occurring denitrification and $\mathrm{NO}_{2}^{-}$ re-oxidation (details are provided in Sect. S4). The results showed that $\mathrm{NO}_{3}^{-}$reduction (acting to increase $\delta^{18} \mathrm{O}-\mathrm{NO}_{3}^{-}$ values) and $\mathrm{NO}_{2}^{-}$re-oxidation (acting to decrease $\delta^{18} \mathrm{O}-\mathrm{NO}_{3}^{-}$ values) have counteracting effects on the forward-modeled $\delta^{18} \mathrm{O}^{-} \mathrm{NO}_{3}^{-}$(Fig. S2) and that the decreasing trend in $\delta^{18} \mathrm{O}$ $\mathrm{NO}_{3}^{-}$values can be well reproduced under both no-exchange and complete-exchange scenarios with a reasonable assumption on the net $\mathrm{O}$ isotope effects for denitrification and $\mathrm{NO}_{2}^{-}$ re-oxidation (Fig. S2; see Sect. S4) (Granger and Wankel, 2016). Therefore, although $k_{\mathrm{NXR}(\mathrm{b})}$ cannot be definitively quantified in this study due to the unknown degree of $\mathrm{O}$ exchange between $\mathrm{NO}_{2}^{-}$and $\mathrm{H}_{2} \mathrm{O}$, these simulation results provide confidence in our hypothesis that the observed decreases in $\delta^{18} \mathrm{O}-\mathrm{NO}_{3}^{-}$and $\Delta^{17} \mathrm{O}-\mathrm{NO}_{3}^{-}$values were driven by the reversible action of the NXR enzyme. It is important to note that the estimated $k_{\mathrm{NXR}(\mathrm{b})}$ is fairly large even under the complete-exchange scenario. Based on the $\mathrm{NO}_{2}^{-}$ concentration measured at the end of the anoxic incubation $\left(6.9 \mu \mathrm{g} \mathrm{N}^{-1}\right)$, a $k_{\mathrm{NXR}(\mathrm{b})}$ of $0.25 \mathrm{~h}^{-1}$ would require a $\mathrm{NO}_{2}^{-}$ re-oxidation rate $\left(1.7 \mu \mathrm{g} \mathrm{N} \mathrm{g}^{-1} \mathrm{~h}^{-1}\right)$ that is 1 order of magnitude higher than the estimated $R_{\mathrm{NAR}}$ and $R_{\mathrm{NIR}}$. However, the inferred maximum $\mathrm{NO}_{2}^{-}$re-oxidation rate under either model scenario ( 1.7 to $4.4 \mu \mathrm{g} \mathrm{g} \mathrm{g}^{-1} \mathrm{~h}^{-1}$ ) is still within the reported range for aerobic $\mathrm{NO}_{2}^{-}$oxidation in agricultural soils (e.g., up to 6-7 $\mu \mathrm{g} \mathrm{N} \mathrm{g}^{-1} \mathrm{~h}^{-1}$ ) (Taylor et al., 2019), which is indicative of high NOB activity even under anoxic conditions (Koch et al., 2015). It is also noteworthy that $\Delta^{17} \mathrm{O}$ analysis of $\mathrm{NO}_{2}^{-}$can in theory provide quantitative constraint on the degree of $\mathrm{O}$ isotope exchange between $\mathrm{NO}_{2}^{-}$ and $\mathrm{H}_{2} \mathrm{O}$ during the anoxic incubation, as has been previously demonstrated by $\Delta^{17} \mathrm{O}$ analysis of $\mathrm{N}_{2} \mathrm{O}$ to determine $\mathrm{O}$ exchange between $\mathrm{N}_{2} \mathrm{O}$ and $\mathrm{H}_{2} \mathrm{O}$ during denitrification 
(Lewicka-Szczebak et al., 2016). However, in this study, robust $\Delta^{17} \mathrm{O}-\mathrm{NO}_{2}^{-}$analysis was confounded by the low $\mathrm{NO}_{2}^{-}$ concentrations as well as the fact that $\mathrm{NO}_{2}^{-}$can undergo $\mathrm{O}$ exchange with $\mathrm{H}_{2} \mathrm{O}$ during sample processing and storage (Casciotti et al., 2007). Future development in soil $\Delta^{17} \mathrm{O}$ $\mathrm{NO}_{2}^{-}$analysis and calibration will benefit the use of $\Delta^{17} \mathrm{O}$ to disentangle $\mathrm{NO}_{2}^{-}$reaction complexity in soil environments.

Based on the modeled denitrification rates and $k_{\mathrm{NXR}(\mathrm{b})}$, the best-fit ${ }^{15} \eta_{\mathrm{NXR}(\mathrm{b})}$ was confined to a narrow range from $-40 \%$ o to $-35 \%$ o (Fig. 7a and b) and was not sensitive to model scenarios for $\mathrm{O}$ equilibration between $\mathrm{NO}_{2}^{-}$and $\mathrm{H}_{2} \mathrm{O}$ (Fig. 8b). While the best-fit ${ }^{15} \eta_{\text {NAR }}$ and ${ }^{15} \eta_{\text {NXR(b) }}$ were positively correlated, especially under the complete-exchange scenario (Fig. $7 \mathrm{a}$ and b), the best-fit ${ }^{15} \eta_{\text {NAR }}$ spanned a wide range $(5 \%$ to $45 \%$ ) and was significantly lower under the no-exchange scenario (RSS-weighted mean: 19\%o) relative to the complete-exchange scenario (RSS-weighted mean: $30 \%$ o) (Fig. 8a). On the other hand, the best-fit ${ }^{15} \eta_{\text {NIR }}(15 \%$ o to $22 \%$ ) and ${ }^{15} \eta_{\mathrm{NOR}}(-8 \%$ to $2 \%$ ) did not vary substantially and were similar between the two model scenarios (Figs. 7c-d and 8c-d). Under both model scenarios, the measured $\delta^{15} \mathrm{~N}^{-\mathrm{NO}_{3}^{-}}, \delta^{15} \mathrm{~N}-\mathrm{NO}_{2}^{-}$, and $\delta^{15} \mathrm{~N}-\mathrm{NO}$ values can be well simulated using the RSS-weighted mean ${ }^{15} \eta$ values from the best-fit models (Fig. $2 \mathrm{~d}$ to f). Specifically, the modeled difference between $\delta^{15} \mathrm{~N}-\mathrm{NO}_{3}^{-}$and $\delta^{15} \mathrm{~N}-\mathrm{NO}_{2}^{-}$values increased from about $29 \%$ at the beginning of the incubation to about $38 \% \circ$ at the end of the incubation (Fig. $2 \mathrm{~d}$ and e), whereas a constant $\delta^{15} \mathrm{~N}$ offset of about $20 \%$ was revealed between the modeled $\delta^{15} \mathrm{~N}^{-\mathrm{NO}_{2}^{-}}$and $\delta^{15} \mathrm{~N}-\mathrm{NO}$ values (Fig. 2e and f). Therefore, the modeled ${ }^{15} \eta$ values and $\delta^{15} \mathrm{~N}-\mathrm{NO}_{2}^{-}$dynamics reveal important new information for understanding the increasing ${ }^{15} \eta_{\mathrm{NO}_{3} \text { /NO }}$ over the anoxic incubation. During the early phase of the incubation, the $\mathrm{N}$ isotope partitioning between $\mathrm{NO}_{3}^{-}, \mathrm{NO}_{2}^{-}$, and $\mathrm{NO}$ was mainly controlled by denitrification and its associated isotope effects (i.e., ${ }^{15} \eta_{\text {NAR }},{ }^{15} \eta_{\text {NIR }}$, and ${ }^{15} \eta_{\text {NOR }}$ ). With the increasing accumulation of $\mathrm{NO}_{2}^{-}$in the soil, the dominant control on the $\delta^{15} \mathrm{~N}$ distribution shifted to the $\mathrm{N}$ isotope exchange between $\mathrm{NO}_{3}^{-}$and $\mathrm{NO}_{2}^{-}$, so that the difference between the $\delta^{15} \mathrm{~N}^{-\mathrm{NO}_{3}^{-}}$and $\delta^{15} \mathrm{~N}-\mathrm{NO}_{2}^{-}$values was primarily determined by ${ }^{15} \eta_{\text {NXR(eq) }}(-40 \%$ o to $-35 \%$ o). The revealed positive correlation between the best-fit ${ }^{15} \eta_{\text {NAR }}$ and ${ }^{15} \eta_{\text {NXR(b) }}$ (Fig. 7a and $b$ ) and the significantly lower ${ }^{15} \eta_{\text {NAR }}$ under the noexchange scenario (Fig. 8a) essentially reflect a trade-off between ${ }^{15} \eta_{\text {NAR }}$ and ${ }^{15} \eta_{\text {NXR(b) }}$ in controlling the $\delta^{15} \mathrm{~N}$ difference between $\mathrm{NO}_{3}^{-}$and $\mathrm{NO}_{2}^{-}$- that is, when the interconversion between $\mathrm{NO}_{3}^{-}$and $\mathrm{NO}_{2}^{-}$is fast and the magnitude of ${ }^{15} \eta_{\text {NXR(eq) }}$ is large (i.e., very negative), only a small ${ }^{15} \eta_{\text {NAR }}$ is required to sustain the large $\delta^{15} \mathrm{~N}$ difference between $\mathrm{NO}_{3}^{-}$ and $\mathrm{NO}_{2}^{-}$over the course of the anoxic incubation.

The estimated ${ }^{15} \eta_{\mathrm{NXR}(\mathrm{eq})}$ from the best-fit models is higher (i.e., closer to zero) than that derived from theoretical calculations and pure culture studies $(-50 \%$ o to $-60 \%$ ) (Casciotti, 2009; Brunner et al., 2013). Given the heterogeneous distribution of substrates in soils, the lower absolute mag- nitude of the best-fit ${ }^{15} \eta_{\mathrm{NXR} \text { (eq) }}$ may be due to the partial rate limitation by transport of $\mathrm{NO}_{2}^{-} / \mathrm{NO}_{3}^{-}$to the active site of NXR. As such, the best-fit ${ }^{15} \eta_{\text {NXR(eq) }}$ should provide a conservative estimate of the intrinsic equilibrium isotope effect. Thus, the results from the anoxic incubation underscore the important, yet previously unrecognized, role of the reversible $\mathrm{NO}_{3}^{-} / \mathrm{NO}_{2}^{-}$interconversion in controlling the $\delta^{15} \mathrm{~N}$ dynamics of soil $\mathrm{NO}_{3}^{-}$and its denitrification products. Substantial re-oxidation of $\mathrm{NO}_{2}^{-}$under anoxic conditions seems paradoxical but is underpinned by the increasingly recognized high degree of metabolic versatility of NOB, including simultaneous oxidation of an organic substrate and $\mathrm{NO}_{2}^{-}$, as well as parallel use of $\mathrm{NO}_{3}^{-}$and $\mathrm{O}_{2}$ as electron acceptors (Koch et al., 2015). In the absence of $\mathrm{O}_{2}$, few electron acceptors exist at common environmental $\mathrm{pH}$ that have a higher redox potential than the $\mathrm{NO}_{3}^{-} / \mathrm{NO}_{2}^{-}$pair (Wunderlich et al., 2013; Babbin et al., 2017). It is therefore likely that NOB would gain energy by performing the intracellular coupled oxidation of $\mathrm{NO}_{2}^{-}$and reduction of $\mathrm{NO}_{3}^{-}$to survive periods of $\mathrm{O}_{2}$ deprivation. Although anaerobic $\mathrm{NO}_{2}^{-}$oxidation until now has been conclusively shown only in anoxic ocean water columns (Sun et al., 2017; Babbin et al., 2017) and aquatic sediments (Wunderlich et al., 2013), soils host a huge diversity of coexisting NOB (Le Roux et al., 2016) and the physiological flexibility of NOB beyond aerobic $\mathrm{NO}_{2}^{-}$oxidation may contribute to the unexpected higher abundances and activities of NOB relative to $\mathrm{AOB}$ and $\mathrm{AOA}$ in agricultural soils (Høberg et al., 1996; Ke et al., 2013). Using the modified isotopologue-specific model, we demonstrate the possibility that large ${ }^{15} \eta_{\text {NAR }}$ can be an artifact of an isotopic equilibrium between $\mathrm{NO}_{3}^{-}$and $\mathrm{NO}_{2}^{-}$, occurring in connection with the bifunctional NXR enzyme. Therefore, effective expressions of ${ }^{15} \eta_{\text {NXR(eq) }}$ in concurrence with ${ }^{15} \eta_{\text {NAR }}$ may explain why ${ }^{15} \eta_{\text {NAR }}$ values estimated by some anoxic soil incubations (e.g., $25 \%$ o to $65 \%$ ) are far larger than those reported by studies of denitrifying and $\mathrm{NO}_{3}^{-}$-reducing bacterial cultures (e.g., 5\%o to 30\%o) (Denk et al., 2017) and why the slope of $\delta^{18} \mathrm{O}-\mathrm{NO}_{3}^{-}$vs. $\delta^{15} \mathrm{~N}-\mathrm{NO}_{3}^{-}$values during denitrification in many field studies was not constant and rarely close to unity as observed in pure denitrifying cultures (Granger and Wankely, 2016). Indeed, evidence for a reversible enzymatic pathway linking $\mathrm{NO}_{3}^{-}$and $\mathrm{NO}_{2}^{-}$under anoxic conditions has already been documented in previous soil studies (e.g., Kool et al., 2011; Lewicka-Szcebak et al., 2014), implying its wide occurrence in soils. More studies using soils from a broad range of environments are needed to pinpoint the exact mechanisms by which $\mathrm{NO}_{2}^{-}$can be anaerobically oxidized in soils. To that end, $\Delta^{17} \mathrm{O}_{-} \mathrm{NO}_{3}^{-}$can be used as a powerful benchmark for disentangling co-occurring $\mathrm{NO}_{3}^{-}$reduction and $\mathrm{NO}_{2}^{-}$re-oxidation.

The best-fit ${ }^{15} \eta_{\text {NIR }}(15 \%$ o to $22 \%$ ) falls within the range derived in anoxic soil incubations (11\%o to 33\%o) (Mariotti et al., 1982) and is consistent with results based on denitrifying bacteria carrying copper-containing NIR (22\%o) (Martin and Casciotti, 2016). Under both model scenarios, the best-fit 
Table 1. Means and $95 \%$ confidence intervals of modeled denitrification rates and $\mathrm{NO}_{2}^{-}$re-oxidation rate constants under the no-exchange and complete-exchange scenarios.

\begin{tabular}{llrr|rr}
\hline Parameter & Description & \multicolumn{2}{c|}{ No exchange } & \multicolumn{2}{c}{ Complete exchange } \\
\cline { 3 - 6 } & & Mean & $95 \% \mathrm{CI}$ & Mean & $95 \% \mathrm{CI}$ \\
\hline$R_{\text {NAR }}$ & Zero-order rate for $\mathrm{NO}_{3}^{-}$reduction $\left(\mu \mathrm{g} \mathrm{N} \mathrm{g}^{-1} \mathrm{~h}^{-1}\right)$ & 0.158 & 0.157 to 0.160 & 0.158 & 0.157 to 0.160 \\
$R_{\text {NIR }}$ & Zero-order rate for $\mathrm{NO}_{2}^{-}$reduction $\left(\mu \mathrm{g} \mathrm{Ng}^{-1} \mathrm{~h}^{-1}\right)$ & 0.112 & 0.111 to 0.113 & 0.112 & 0.111 to 0.113 \\
$R_{\text {NOR }}$ & Zero-order rate for $\mathrm{NO}$ reduction $\left(\mu \mathrm{g} \mathrm{g}^{-1} \mathrm{~h}^{-1}\right)$ & 0.039 & 0.038 to 0.040 & 0.039 & 0.038 to 0.040 \\
$k_{\mathrm{NXR}(\mathrm{b})}$ & First-order rate constant of $\mathrm{NO}_{2}^{-}$re-oxidation $\left(\mathrm{h}^{-1}\right)$ & 0.64 & 0.61 to 0.66 & 0.25 & 0.24 to 0.26 \\
\hline
\end{tabular}
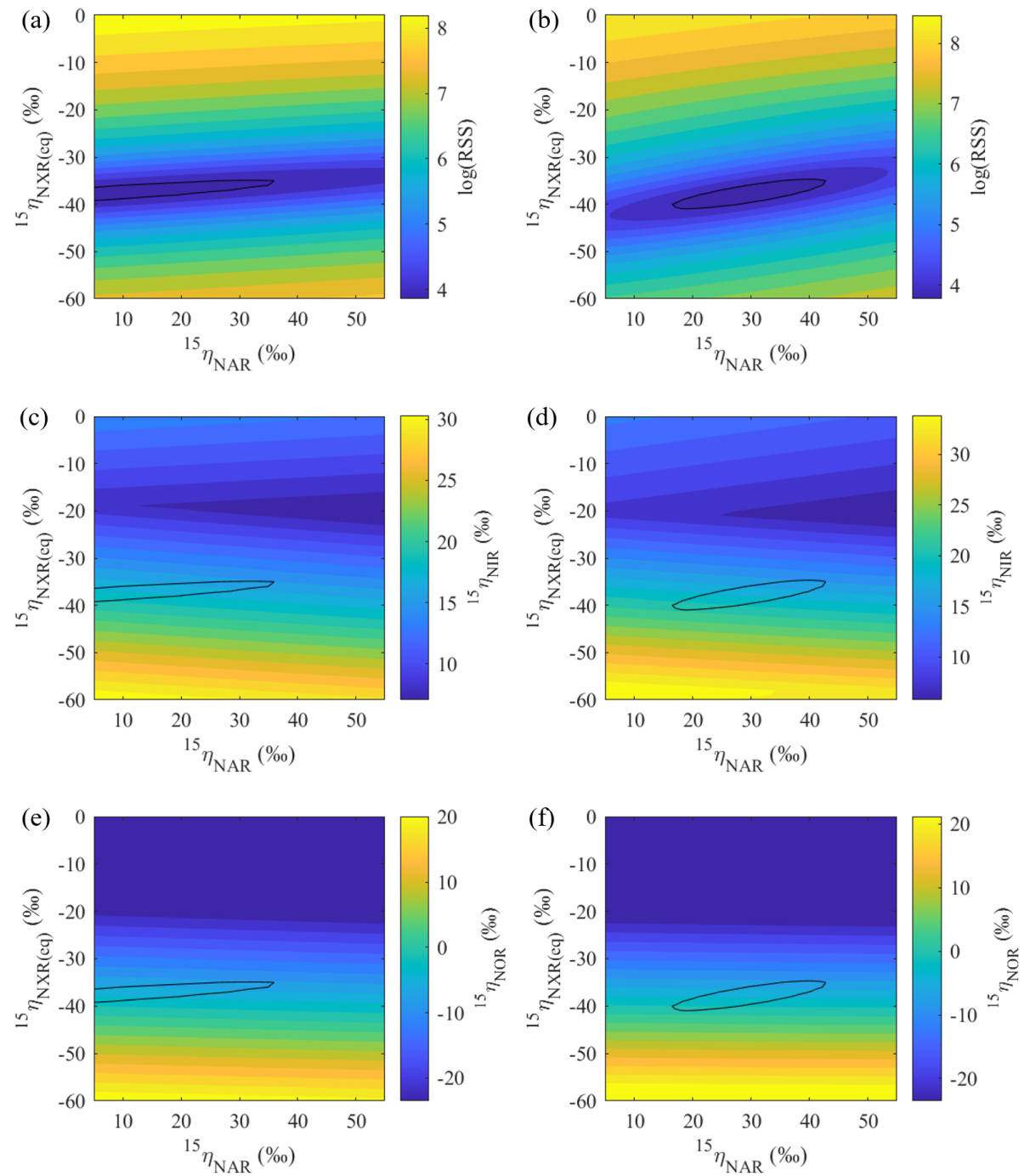

Figure 7. Contour maps showing variations in error-weighted residual sum of squares (RSS) between simulated and measured $\delta^{15} \mathrm{~N}$ values, modeled ${ }^{15} \eta_{\text {NIR }}$, and modeled ${ }^{15} \eta_{\text {NOR }}$ as a function of prescribed ${ }^{15} \eta_{\text {NAR }}$ and ${ }^{15} \eta_{\text {NXR }}$ under the no-exchange (a, c, e) and completeexchange (b, d, f) model scenarios. Bold contour lines encompass the best-fit models defined by the lower percentile 2.5 of the error-weighted RSS. 

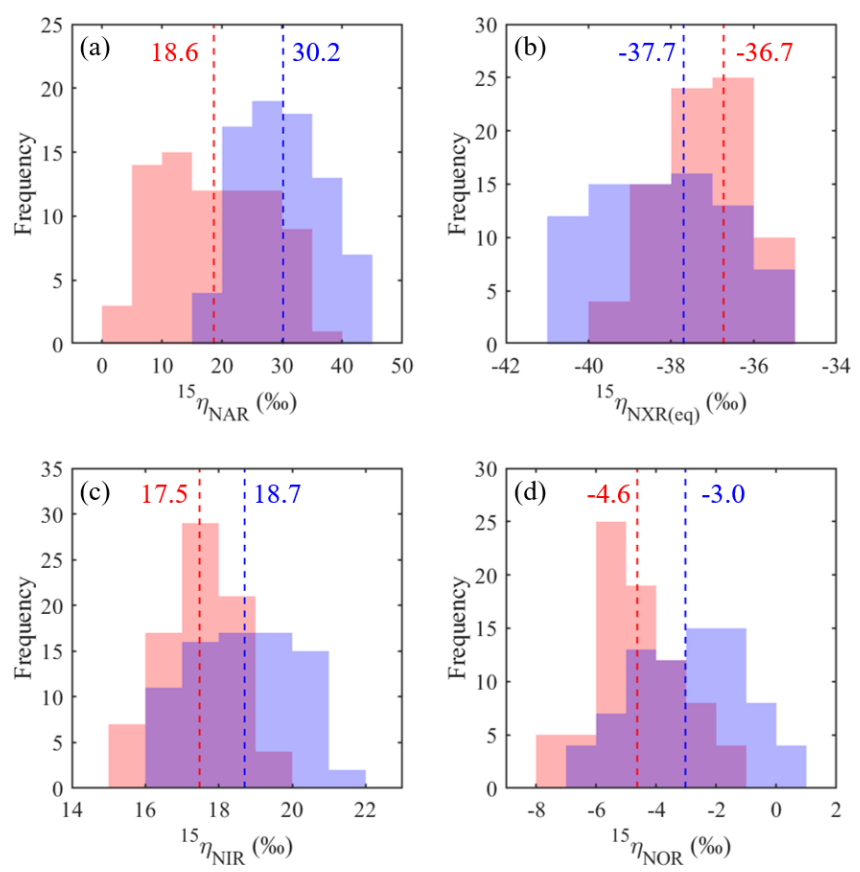

Figure 8. Frequency distributions of the best-fit ${ }^{15} \eta_{\text {NAR }}$ (a), ${ }^{15} \eta_{\text {NXR(eq) }}$ (b), ${ }^{15} \eta_{\text {NIR }}(\mathbf{c})$, and ${ }^{15} \eta_{\text {NOR }}(\mathbf{d})$ under the no-exchange (red) and complete-exchange (blue) model scenarios. Dashed vertical lines denote the RSS-weighted mean ${ }^{15} \eta$ values from the best-fit models under the two model scenarios.

${ }^{15} \eta_{\mathrm{NOR}}(-8 \%$ o to $2 \%$ ) is relatively small and more normal (i.e., ${ }^{15} \eta$ value closer to zero) than the bulk $\mathrm{N}$ isotope effect for $\mathrm{NO}$ reduction to $\mathrm{N}_{2} \mathrm{O}$ catalyzed by purified fungal NOR (P450nor) (-14\%o) (Yang et al., 2014). During P450norcatalyzed NO reduction, two NO molecules are sequentially bonded to the Fe active site of P450nor, and the observed inverse isotope effect was proposed to arise from a reversible bonding of the first NO molecule (Yang et al., 2014). To date, the $\mathrm{N}$ isotope effect for $\mathrm{NO}$ reduction catalyzed by bacterial NORs has not yet been quantified. Unlike P450nor, which contains only a single heme $\mathrm{Fe}$ at the active site, the active site of bacterial NORs has two Fe atoms (i.e., binuclear center). Therefore, three classes of mechanisms have been proposed for the two-electron reduction of $\mathrm{NO}$ by bacterial NORs, including sequential bonding of two NO molecules to either Fe catalytic center and simultaneous bonding of two NO molecules to both Fe centers (Kuypers et al., 2018; Lehnert et al., 2018). Although the precise catalytic mechanism remains uncertain, site-specific measurements of $\mathrm{N}$ isotopes in $\mathrm{N}_{2} \mathrm{O}$ (i.e., $\mathrm{N}_{2} \mathrm{O}$ isotopomers) produced from denitrifying bacteria indicate a similar magnitude for isotopic fractionations during the reduction of two NO molecules, in support of the simultaneous binding theory (Sutka et al., 2006; Yamazaki et al., 2014). Thus, if the bulk $\mathrm{N}$ isotope effect for bacterial NO reduction is higher than that for fungal NO reduction, the best-fit ${ }^{15} \eta_{\mathrm{NOR}}$ may reflect a mixed contribution of bacteria and fungi to NO consumption during the anoxic incubation. Alternatively, the model-inferred ${ }^{15} \eta_{\text {NOR }}$ might reflect a balance between enzymatic and diffusion isotope effects, as has been previously demonstrated for $\mathrm{N}_{2} \mathrm{O}$ reduction in soil denitrification (Lewicka-Szczebak et al., 2014). Because diffusion would be expected to have a small and normal kinetic isotope effect, if $\mathrm{NO}_{2}^{-}$reduction was limited by $\mathrm{NO}$ diffusion out of soil denitrifying sites, the estimated ${ }^{15} \eta_{\text {NOR }}$ would be shifted toward the isotope effect for NO diffusion. Diffusion might be particularly important in this study due to the flow-through condition during the anoxic incubation and the low solubility of NO, both of which favor gas diffusion while preventing re-entry of escaped NO to denitrifying cells. Thus, the small ${ }^{15} \eta_{\mathrm{NOR}}$ inferred from the best-fit models is likely a combination of diverse NO reduction pathways in this agricultural soil, as well as limited expression of enzymatic isotope effects imposed by NO diffusion. Regardless, the empirical finding of this study suggests that due to the small ${ }^{15} \eta_{\mathrm{NOR}}$, the bulk $\delta^{15} \mathrm{~N}$ values of denitrification-produced $\mathrm{N}_{2} \mathrm{O}$ should not be significantly altered by accumulation and diffusion of NO during denitrification.

\subsection{NO source contribution and $N$ isotope effects for NO production from $\mathrm{NH}_{4}^{+}$oxidation under oxic and hypoxic conditions}

The coupled decrease in $\mathrm{NH}_{4}^{+}$concentrations and increase in $\mathrm{NO}_{3}^{-}$concentrations (Fig. 3a and b) indicate active nitrification in both oxic and hypoxic incubations. Moreover, the two oxidation steps of nitrification were tightly coupled, resulting in no accumulation of $\mathrm{NO}_{2}^{-}$in the soil. Because $\mathrm{NO}_{3}^{-}$ produced from nitrification has a zero $\Delta^{17} \mathrm{O}$ value, the active nitrification was also reflected in the progressive dilution of $\Delta^{17} \mathrm{O}-\mathrm{NO}_{3}^{-}$under both oxic and hypoxic conditions ( $\mathrm{Yu}$ and Elliott, 2018). Based on the measured concentrations and isotopic composition of $\mathrm{NH}_{4}^{+}$and $\mathrm{NO}_{3}^{-}$, the isotopologuespecific model previously developed by Yu and Elliott (2018) was used to estimate the rates and net $\mathrm{N}$ isotope effects of net mineralization $\left(R_{\mathrm{OrgN} / \mathrm{NH}_{4}}\right.$ and $\left.{ }^{15} \eta_{\mathrm{OrgN} / \mathrm{NH}_{4}}\right)$, gross $\mathrm{NH}_{4}^{+}$ox-

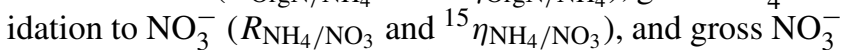

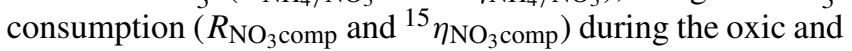
hypoxic incubations. As has been discussed above, this numerical model relies on the conservative nature of $\Delta^{17} \mathrm{O}$ $\mathrm{NO}_{3}^{-}$and its powerful application in tracing co-occurring nitrification and $\mathrm{NO}_{3}^{-}$consumption (consisting of $\mathrm{NO}_{3}^{-}$immobilization and denitrification in this case) (Yu and Elliott, 2018). Detailed model derivation, formulation, and optimization have been documented in Yu and Elliott (2018) and are also briefly summarized in Sect. S5. The modeling results based on the low- $\delta{ }^{15} \mathrm{~N}-\mathrm{NH}_{4}^{+}$treatment in the oxic incubation were reported by $\mathrm{Yu}$ and Elliott (2018). Here, we used data from all three $\delta^{15} \mathrm{~N}-\mathrm{NH}_{4}^{+}$treatments to more robustly constrain the $\mathrm{N}$ transformation rates and net $\mathrm{N}$ isotope effects for each incubation experiment (i.e., oxic and hypoxic). 
Table 2. Means and $95 \%$ confidence intervals of modeled gross $\mathrm{N}$ transformation rates, NO yields, and net N isotope effects in the oxic and hypoxic incubations.

\begin{tabular}{|c|c|c|c|c|c|}
\hline \multirow[t]{2}{*}{ Parameter } & \multirow[t]{2}{*}{ Description } & \multicolumn{2}{|r|}{ Oxic } & \multicolumn{2}{|r|}{ Hypoxic } \\
\hline & & Mean & $95 \% \mathrm{CI}$ & Mean & $95 \% \mathrm{CI}$ \\
\hline$R_{\mathrm{OrgN} / \mathrm{NH}_{4}}$ & Zero-order rate for net mineralization $\left(\mu \mathrm{g} \mathrm{Ng}^{-1} \mathrm{~h}^{-1}\right)$ & 0.014 & 0.013 to 0.016 & 0.012 & -0.011 to 0.038 \\
\hline$R_{\mathrm{NH}_{4} / \mathrm{NO}_{3}}$ & Zero-order rate for gross nitrification $\left(\mu \mathrm{g} \mathrm{Ng} \mathrm{g}^{-1} \mathrm{~h}^{-1}\right)$ & 0.458 & 0.455 to 0.460 & 0.111 & 0.110 to 0.113 \\
\hline$R_{\mathrm{NO}_{3} \text { comp }}$ & Zero-order rate for gross $\mathrm{NO}_{3}^{-}$consumption $\left(\mu \mathrm{g} \mathrm{Ng}^{-1} \mathrm{~h}^{-1}\right)$ & 0.071 & 0.070 to 0.072 & 0.070 & 0.049 to 0.091 \\
\hline${ }^{15} \eta_{\mathrm{OrgN} / \mathrm{NH}_{4}}$ & Net $\mathrm{N}$ isotope effect for net mineralization & $2 \%$ & $-27 \%$ o to $31 \%$ o & $0 \%$ & $-18 \%$ to $17 \%$ o \\
\hline${ }^{15} \eta_{\mathrm{NH}_{4} / \mathrm{NO}_{3}}$ & Net $\mathrm{N}$ isotope effect for gross nitrification & $28 \%$ & $27 \%$ to $30 \%$ & $23 \%$ & $12 \%$ to $33 \%$ \\
\hline${ }^{15} \eta_{\mathrm{NO}_{3} \mathrm{comp}}$ & Net $\mathrm{N}$ isotope effect for gross $\mathrm{NO}_{3}^{-}$consumption & $5 \%$ & $-16 \%$ o to $20 \%$ o & $7 \%$ & $-9 \%$ to $23 \%$ \\
\hline$f_{\mathrm{NH}_{4}}$ & Fraction of net NO production from nitrification & 0.72 & 0.65 to 0.78 & 0.58 & 0.55 to 0.61 \\
\hline$Y_{\mathrm{NH}_{4} / \mathrm{NO}}$ & NO yield in nitrification & $1.3 \%$ & $1.2 \%$ to $1.4 \%$ & $5.2 \%$ & $4.8 \%$ to $5.5 \%$ \\
\hline$Y_{\mathrm{NO}_{3} / \mathrm{NO}}$ & NO yield in $\mathrm{NO}_{3}^{-}$consumption & $3.2 \%$ & $2.5 \%$ to $4.0 \%$ & $6.1 \%$ & $4.3 \%$ to $9.3 \%$ \\
\hline \multirow[t]{2}{*}{${ }^{15} \eta_{\text {comb }}$} & $\begin{array}{l}\text { Combined net isotope effect for } \mathrm{NO} \text { production from } \mathrm{NH}_{4}^{+} \\
\text {and } \mathrm{NO}_{3}^{-}\end{array}$ & $56 \%$ & $54 \%$ to $58 \%$ & $51 \%$ & $50 \%$ to $52 \%$ \\
\hline & & \multicolumn{2}{|r|}{ Mean } & \multicolumn{2}{|r|}{$95 \% \mathrm{CI}$} \\
\hline${ }^{15} \eta_{\mathrm{NH}_{4} / \mathrm{NO}}$ & Net isotope effect for $\mathrm{NO}$ production from $\mathrm{NH}_{4}^{+}$oxidation & \multirow{2}{*}{\multicolumn{2}{|c|}{$\begin{array}{l}66 \% \circ \\
30 \% \text { o }\end{array}$}} & \multirow{2}{*}{\multicolumn{2}{|c|}{$\begin{array}{l}59 \% \text { to } 85 \% \\
1 \% \text { to } 42 \% \text { o }\end{array}$}} \\
\hline${ }^{15} \eta_{\mathrm{NO}_{3} / \mathrm{NO}}$ & Net isotope effect for $\mathrm{NO}$ production from $\mathrm{NO}_{3}^{-}$consumption & & & & \\
\hline
\end{tabular}

The modeling results are summarized in Table 2. Excellent agreement was obtained between the observed and simulated concentrations and isotopic composition of $\mathrm{NH}_{4}^{+}$and $\mathrm{NO}_{3}^{-}$ for both oxic and hypoxic incubations (Fig. 3). $R_{\mathrm{NH}_{4} / \mathrm{NO}_{3}}$ can be well described by zero-order kinetics and was estimated to be 0.46 and $0.11 \mu \mathrm{g} \mathrm{Ng}^{-1} \mathrm{~h}^{-1}$ for the oxic and hypoxic incubations, respectively (Table 2). The lower $R_{\mathrm{NH}_{4} / \mathrm{NO}_{3}}$ in the hypoxic incubation indicates that nitrification was limited by low $\mathrm{O}_{2}$ availability. Under both oxic and hypoxic conditions, oxidation of $\mathrm{NH}_{4}^{+}$to $\mathrm{NO}_{3}^{-}$was associated with a large ${ }^{15} \eta_{\mathrm{NH}_{4} / \mathrm{NO}_{3}}(23 \%$ o to $28 \%$; ; Table 2), consistent with the $\mathrm{N}$ isotope effects for $\mathrm{NH}_{3}$ oxidation in pure cultures of AOB and AOA (e.g., 13\%o to 41\%o) (Mariotti et al., 1981; Casciotti et al., 2003; Santoro and Casciotti, 2011). On the other hand, the estimated $R_{\mathrm{OrgN} / \mathrm{NH}_{4}}$ and $R_{\mathrm{NO}_{3} \text { comp were low }}$ and not significantly different between the two incubation experiments (Table 2). Nevertheless, while $R_{\mathrm{NO}_{3} \text { comp was }}$ only $16 \%$ of $R_{\mathrm{NH}_{4} / \mathrm{NO}_{3}}$ in the oxic incubation, $R_{\mathrm{NO}_{3} \text { comp ac- }}$ counted for a much larger fraction $(63 \%)$ of $R_{\mathrm{NH}_{4} / \mathrm{NO}_{3}}$ in the hypoxic incubation, mainly due to the reduced $R_{\mathrm{NH}_{4} / \mathrm{NO}_{3}}$ under the low- $\mathrm{O}_{2}$ condition. Due to the low magnitude of $R_{\mathrm{OrgN} / \mathrm{NH}_{4}}$ and $R_{\mathrm{NO}_{3} \text { comp }}$, the estimated ${ }^{15} \eta_{\mathrm{OrgN} / \mathrm{NH}_{4}}$ and ${ }^{15} \eta_{\mathrm{NO}_{3} \text { comp }}$ are associated with large errors and not significantly different from zero (Table 2).

By using three isotopically different $\mathrm{NH}_{4}^{+}$fertilizers in parallel treatments, we are able to quantify the fractional contribution of $\mathrm{NH}_{4}^{+}$oxidation to the measured net $\mathrm{NO}$ production $\left(f_{\mathrm{NH}_{4}}\right)$. Specifically, if $\mathrm{NO}$ was exclusively produced from soil $\mathrm{NH}_{4}^{+}$, we would expect to see a constant $\delta^{15} \mathrm{~N}$ difference between $\mathrm{NH}_{4}^{+}$and $\mathrm{NO}$ across the three $\delta^{15} \mathrm{~N}^{-\mathrm{NH}_{4}^{+}}$ treatments. In fact, the observed $\delta^{15} \mathrm{~N}$ differences were not constant, and the slope of $\delta^{15} \mathrm{~N}^{-\mathrm{NH}_{4}^{+}}$vs. $\delta^{15} \mathrm{~N}-\mathrm{NO}$ was sig- nificantly lower than unity under both oxic and hypoxic conditions (Fig. 4). This suggests that sources other than $\mathrm{NH}_{4}^{+}$ oxidation contributed to the observed net $\mathrm{NO}$ production. $\mathrm{Al}-$ though $\mathrm{NO}$ can be produced by numerous microbial and abiotic processes (Medinets et al., 2015), we argue that the other major NO source is mostly likely related to $\mathrm{NO}_{3}^{-}$consumption. This is based on the observation of high $\mathrm{NO}_{3}^{-}$concentrations in both oxic and hypoxic incubations, as well as the estimated low $R_{\mathrm{OrgN} / \mathrm{NH}_{4}}$ (Table 2), which indicates a low availability of labile organic $\mathrm{N}$ - another potential substrate for NO production (Stange et al., 2013) - in this agricultural soil. Therefore, based on the assumption that $\mathrm{NH}_{4}^{+}$oxidation and $\mathrm{NO}_{3}^{-}$consumption were the two primary $\mathrm{NO}$ sources during the oxic and hypoxic incubations, a two-source isotope mixing model was used to relate the measured $\delta^{15} \mathrm{~N}-\mathrm{NO}$ values to the concurrently measured $\delta^{15} \mathrm{~N}^{-N^{+}} H_{4}^{+}$and $\delta^{15} \mathrm{~N}$ $\mathrm{NO}_{3}^{-}$values:

$$
\begin{aligned}
\delta^{15} \mathrm{~N}-\mathrm{NO} & =f_{\mathrm{NH}_{4}} \times\left(\delta^{15} \mathrm{~N}_{-} \mathrm{NH}_{4}^{+}-{ }^{15} \eta_{\mathrm{NH}_{4} / \mathrm{NO}}\right) \\
& +\left(1-f_{\mathrm{NH}_{4}}\right) \times\left(\delta^{15} \mathrm{~N}^{-\mathrm{NO}_{3}^{-}}-{ }^{15} \eta_{\mathrm{NO}_{3} / \mathrm{NO}}\right),
\end{aligned}
$$

where ${ }^{15} \eta_{\mathrm{NH}_{4} / \mathrm{NO}}$ and ${ }^{15} \eta_{\mathrm{NO}_{3} / \mathrm{NO}}$ are the net isotope effects for $\mathrm{NO}$ production from $\mathrm{NH}_{4}^{+}$oxidation and $\mathrm{NO}_{3}^{-}$consumption, respectively. Rearranging Eq. (5) yields Eq. (6):

$$
\begin{aligned}
\delta^{15} \mathrm{~N}-\mathrm{NO} & =f_{\mathrm{NH}_{4}} \times \delta^{15} \mathrm{~N}-\mathrm{NH}_{4}^{+}+\left(1-f_{\mathrm{NH}_{4}}\right) \times \delta^{15} \mathrm{~N}^{-\mathrm{NO}_{3}} \\
& -\left[f_{\mathrm{NH}_{4}} \times{ }^{15} \eta_{\mathrm{NH}_{4} / \mathrm{NO}}+\left(1-f_{\mathrm{NH}_{4}}\right)\right. \\
& \left.\times{ }^{15} \eta_{\mathrm{NO}_{3} / \mathrm{NO}}\right] \\
{ }^{15} \eta_{\mathrm{comb}} & =f_{\mathrm{NH}_{4}} \times{ }^{15} \eta_{\mathrm{NH}_{4} / \mathrm{NO}} \\
& +\left(1-f_{\mathrm{NH}_{4}}\right) \times{ }^{15} \eta_{\mathrm{NO}_{3} / \mathrm{NO}}
\end{aligned}
$$



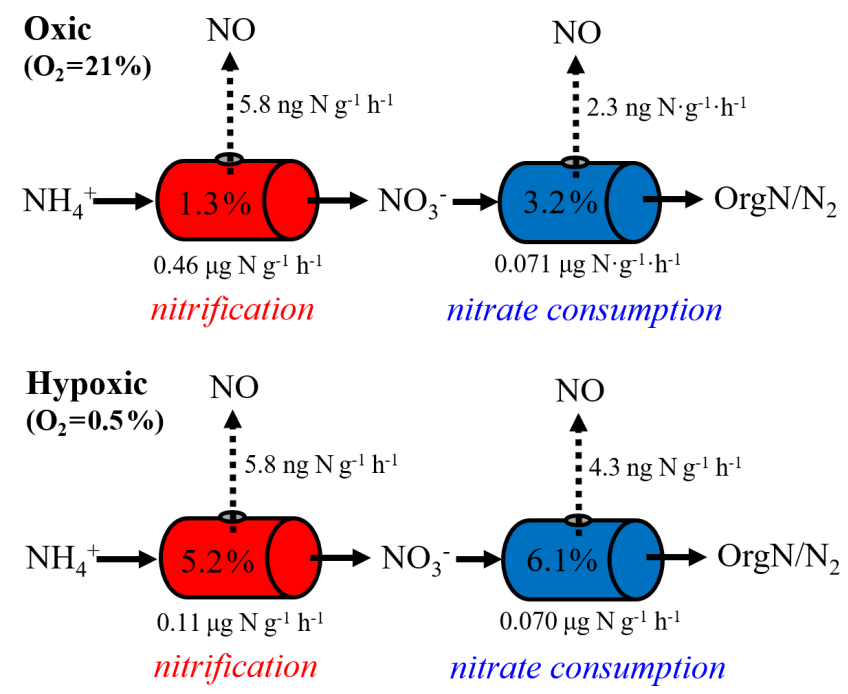

Figure 9. Hole-in-the-pipe illustration of NO production from gross nitrification and $\mathrm{NO}_{3}^{-}$consumption under oxic and hypoxic conditions. "OrgN" denotes organic nitrogen.

$$
\begin{aligned}
\delta^{15} \mathrm{~N}-\mathrm{NO} & =f_{\mathrm{NH}_{4}} \times \delta^{15} \mathrm{~N}-\mathrm{NH}_{4}^{+}+\left(1-f_{\mathrm{NH}_{4}}\right) \times \delta^{15} \mathrm{~N}^{-} \mathrm{NO}_{3}^{-} \\
& -{ }^{15} \eta_{\text {comb }} .
\end{aligned}
$$

Equation (6) essentially dictates that the $\delta^{15} \mathrm{~N}-\mathrm{NO}$ values can be modeled from the $\delta^{15} \mathrm{~N}-\mathrm{NH}_{4}^{+}$and $\delta^{15} \mathrm{~N}-\mathrm{NO}_{3}^{-}$values using a hypothetical isotope effect for $\mathrm{NO}$ production from the combined soil $\mathrm{NH}_{4}^{+}$and $\mathrm{NO}_{3}^{-}$pool $\left({ }^{15} \eta_{\text {comb }}\right.$; the last term in Eq. 6) that is a mixing of ${ }^{15} \eta_{\mathrm{NH}_{4} / \mathrm{NO}}$ and ${ }^{15} \eta_{\mathrm{NO}_{3} / \mathrm{NO}}$ controlled by $f_{\mathrm{NH}_{4}}$ (Eq. 7). Thus, assuming $f_{\mathrm{NH}_{4}}$ and ${ }^{15} \eta_{\text {comb }}$ were constant in each incubation experiment, $f_{\mathrm{NH}_{4}}$ and ${ }^{15} \eta_{\text {comb }}$ can be solved using the measured $\delta^{15} \mathrm{~N}-\mathrm{NO}, \delta^{15} \mathrm{~N}$ $\mathrm{NH}_{4}^{+}$, and $\delta^{15} \mathrm{~N}_{-} \mathrm{NO}_{3}^{-}$values from all three $\delta^{15} \mathrm{~N}-\mathrm{NH}_{4}^{+}$treatments (Eq. 8). $f_{\mathrm{NH}_{4}}$ was estimated to be 0.72 under the oxic incubation (Table 2), indicating that $72 \%$ of the measured net $\mathrm{NO}$ production was sourced from $\mathrm{NH}_{4}^{+}$oxidation, with the remainder being ascribed to $\mathrm{NO}_{3}^{-}$consumption. Under the hypoxic condition, the share of $\mathrm{NH}_{4}^{+}$oxidation decreased to $58 \%$ (Table 2). ${ }^{15} \eta_{\text {comb }}$ was estimated to be $56 \%$ o under the oxic condition and $51 \%$ under the hypoxic condition (Table 2). Combining the $\delta^{15} \mathrm{~N}$-based NO source partitioning

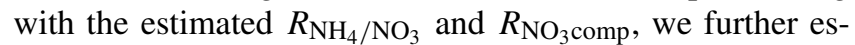
timated NO yield in $\mathrm{NH}_{4}^{+}$oxidation and $\mathrm{NO}_{3}^{-}$consumption, respectively, and where the results are illustrated according to the classic "hole-in-the-pipe" (HIP) concept (Fig. 9) (Davidson and Verchot, 2000). NO yield was $1.3 \%$ in $\mathrm{NH}_{4}^{+}$oxidation and $3.2 \%$ in $\mathrm{NO}_{3}^{-}$consumption in the oxic incubation (Fig. 9; Table 2). Under the hypoxic condition, NO yield was increased to $5.2 \%$ in $\mathrm{NH}_{4}^{+}$oxidation and $6.1 \%$ in $\mathrm{NO}_{3}^{-}$consumption (Fig. 9; Table 2).

Most previous laboratory and field studies suggest that soil NO emissions are predominately driven by nitrifica- tion, whereas NO produced from denitrification is further reduced to $\mathrm{N}_{2} \mathrm{O}$ before it escapes to the soil surface (Kester et al., 1997; Skiba et al., 1997). The minor role of denitrification is largely deduced from the supposition that denitrification is activated only under wet soil conditions (Davidson and Verchot, 2000). However, based on our $\delta^{15} \mathrm{~N}$-based NO source partitioning, about $30 \%$ of the net NO production was contributed by $\mathrm{NO}_{3}^{-}$consumption under oxic condition, highlighting the potential importance of denitrification in driving soil NO emissions under conditions not typically conducive to its occurrence. There is growing evidence that extensive anoxic microsites can develop in otherwise well-aerated soils due to micro-scale variability of $\mathrm{O}_{2}$ demand and soil texture-dependent gas diffusion limitations (Keiluweit et al., 2018). Although we would not predict high rates of heterotrophic respiration in this agricultural soil with low organic carbon, it is possible that rapid $\mathrm{O}_{2}$ consumption by nitrification may outpace $\mathrm{O}_{2}$ supply through diffusion in soil microsites, fostering development of anoxic niches in close association with nitrification hot spots (Kremen et al., 2005). Based on ${ }^{15} \mathrm{~N}$ labeling and direct ${ }^{15} \mathrm{NO}$ measurements using a gas chromatograph-quadrupole mass spectrometer, Russow et al. (2009) demonstrated that nitrification contributed about $70 \%$ of net NO production in a well-aerated, $\mathrm{NH}_{4}^{+}$-fertilized silt loam, in strong agreement with our results based on natural-abundance $\delta^{15} \mathrm{~N}$ measurements. An even lower contribution to NO production, e.g., $26 \%$ to $44 \%$, has been reported for nitrification in organic, $\mathrm{N}$-rich forest soils incubated under oxic conditions (Stange et al., 2013). The persistence of denitrifying microsites in the studied soil is further corroborated by the nearly doubled net $\mathrm{NO}$ production from $\mathrm{NO}_{3}^{-}$consumption in the hypoxic incubation (Fig. 9). Importantly, the actual NO yield in denitrification might be much higher than those estimated for gross $\mathrm{NO}_{3}^{-}$consumption during the oxic and hypoxic incubations (i.e., $3.2 \%$ and $6.1 \%$ ), as denitrification occurring in anoxic niches might only comprise a small fraction of the estimated $R_{\mathrm{NO}_{3} \text { comp. }}$.

Interestingly, while $R_{\mathrm{NH}_{4} / \mathrm{NO}_{3}}$ was significantly lower in the hypoxic incubation, the net $\mathrm{NO}$ production from $\mathrm{NH}_{4}^{+}$ oxidation was similar between the two incubation experiments, indicating a higher $\mathrm{NO}$ yield in nitrification when $\mathrm{O}_{2}$ availability became limited (Fig. 9). However, mechanisms underlying the differential NO yield in nitrification are difficult to elucidate owing to the high complexity of biochemical pathways of NO production by AOB and AOA. In AOB, the prevailing view of $\mathrm{NH}_{3}$ oxidation is that it occurs via a twostep enzymatic process, involving hydroxylamine $\left(\mathrm{NH}_{2} \mathrm{OH}\right)$ as an obligatory intermediate (Fig. 10). The first step is catalyzed by $\mathrm{NH}_{3}$ monooxygenase (AMO), which uses copper and $\mathrm{O}_{2}$ to hydroxylate $\mathrm{NH}_{3}$ to $\mathrm{NH}_{2} \mathrm{OH}$. Next, a multiheme enzyme, $\mathrm{NH}_{2} \mathrm{OH}$ oxidoreductase $(\mathrm{HAO})$, catalyzes the fourelectron oxidation of $\mathrm{NH}_{2} \mathrm{OH}$ to $\mathrm{NO}_{2}^{-}$via enzyme-bound nitroxyl ([HNO-Fe]) and nitrosyl ([NO-Fe]) intermediates (Lehnert et al., 2018) (Fig. 10). Under this $\mathrm{NH}_{2} \mathrm{OH}$ obli- 


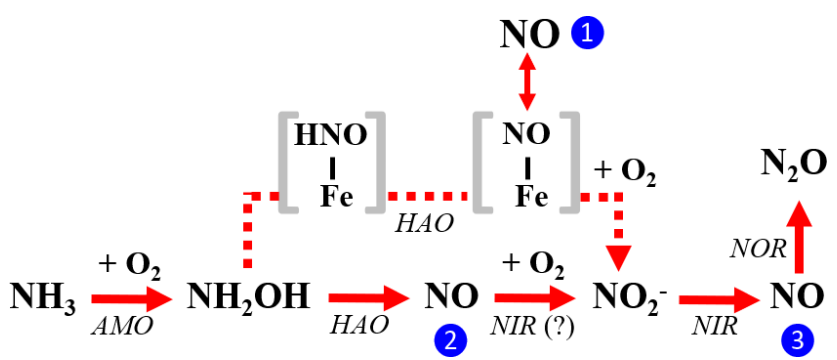

Figure 10. The three enzymatic pathways for NO production during $\mathrm{NH}_{3}$ oxidation to $\mathrm{NO}_{2}^{-}$by AOB: the $\mathrm{NH}_{2} \mathrm{OH}$ obligatory intermediate pathway is indicated by blue circle 1 , the $\mathrm{NH}_{2} \mathrm{OH} / \mathrm{NO}$ obligatory intermediate pathway is indicated by blue circle 2 , and the nitrifier-denitrification pathway is indicated by blue circle 3 . Square brackets enclose proposed enzyme-bound intermediates [HNO-Fe] and $[\mathrm{NO}-\mathrm{Fe}]$ of the $\mathrm{NH}_{2} \mathrm{OH}$ obligatory intermediate pathway. The role of AOB-encoded nitrite reductase (NIR) in catalyzing NO oxidation to $\mathrm{NO}_{2}^{-}$in the $\mathrm{NH}_{2} \mathrm{OH} / \mathrm{NO}$ obligatory intermediate pathway is hypothetical.

gate intermediate model, NO emission was proposed to result from dissociation of $\mathrm{NO}$ from the enzyme-bound nitrosyl complex under high- $\mathrm{NH}_{3}$ and/or low- $\mathrm{O}_{2}$ conditions (Fig. 10) (Hooper et al., 2004; Beeckman et al., 2018). However, there is recent strong evidence that $\mathrm{HAO}$ generally catalyzes the three-electron oxidation of $\mathrm{NH}_{2} \mathrm{OH}$ to $\mathrm{NO}$ under both aerobic and anaerobic conditions; the HAO-produced $\mathrm{NO}$ is further oxidized to $\mathrm{NO}_{2}^{-}$by an unknown enzyme (Caranto and Lancaster, 2017). In this way, NO would not be a byproduct of incomplete $\mathrm{NH}_{2} \mathrm{OH}$ oxidation but rather required as an obligatory intermediate for $\mathrm{NO}_{2}^{-}$production (Fig. 10). It was further proposed that $\mathrm{AOB}$-encoded copper-containing NIR may catalyze the final one-electron oxidation of $\mathrm{NO}$ to $\mathrm{NO}_{2}^{-}$ by operating in reverse (Lancaster et al., 2018). Under this $\mathrm{NH}_{2} \mathrm{OH} / \mathrm{NO}$ obligate intermediate model, high intracellular $\mathrm{NO}$ concentrations arise when the rate of NO production outpaces the rate of its oxidation to $\mathrm{NO}_{2}^{-}$, leading to $\mathrm{NO}$ leakage from cells. Consequently, under $\mathrm{O}_{2}$ stress, decreases in the rate of $\mathrm{NO}$ oxidation to $\mathrm{NO}_{2}^{-}$might be expected, and this may explain the observed increase in nitrification NO yield in the hypoxic incubation. Additionally, some AOB strains can produce $\mathrm{NO}$ in a process termed nitrifier denitrification, in which $\mathrm{NO}$ is produced through NIR-catalyzed $\mathrm{NO}_{2}^{-}$reduction and can be further reduced to $\mathrm{N}_{2} \mathrm{O}$ by AOB-encoded NOR (Wrage-Mönning et al., 2018) (Fig. 10). Compared to AOB, the $\mathrm{NH}_{3}$ oxidation pathway in AOA remains unclear (Beeckman et al., 2018). The current model is that $\mathrm{NH}_{3}$ is first oxidized by an archaeal AMO to $\mathrm{NH}_{2} \mathrm{OH}$ and subsequently converted to $\mathrm{NO}_{2}^{-}$by an unknown $\mathrm{HAO}$ counterpart (Kozlowski et al., 2016). NO seems to be mandatory for archaeal $\mathrm{NH}_{2} \mathrm{OH}$ oxidation and has been proposed to act as a co-substrate for the $\mathrm{NO}_{2}^{-}$production (Kozlowski et al., 2016). Consequently, NO is usually produced and immedi-

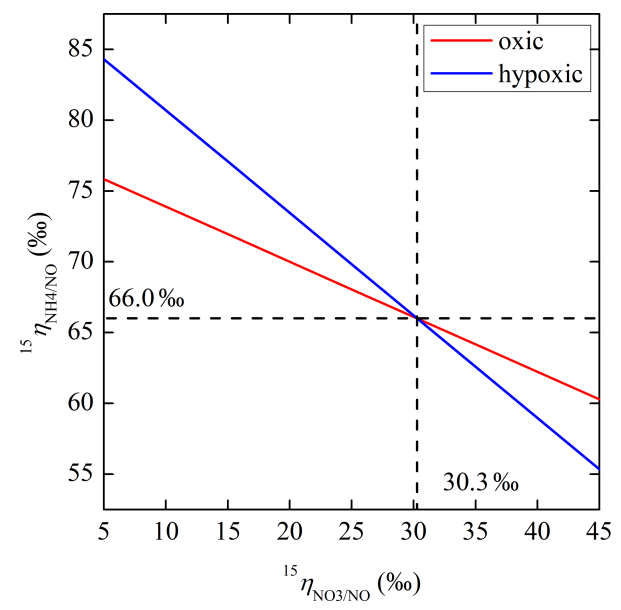

Figure 11. Relative magnitude of net $\mathrm{N}$ isotope effects for NO production from $\mathrm{NH}_{4}^{+}$oxidation $\left({ }^{15} \eta_{\mathrm{NH}_{4} / \mathrm{NO}}\right)$ and $\mathrm{NO}_{3}^{-}$consumption $\left({ }^{15} \eta_{\mathrm{NO}_{3} / \mathrm{NO}}\right)$ in the oxic and hypoxic incubations.

ately consumed with tighter control in AOA than in AOB (Kozlowski et al., 2016).

To shed further light on the inner workings of net $\mathrm{NO}$ production from $\mathrm{NH}_{4}^{+}$, we turn to constraining ${ }^{15} \eta_{\mathrm{NH}_{4} / \mathrm{NO}}$. Specifically, the inherent linkage between ${ }^{15} \eta_{\text {comb }},{ }^{15} \eta_{\mathrm{NH}_{4} / \mathrm{NO}}$, and ${ }^{15} \eta_{\mathrm{NO}_{3} / \mathrm{NO}}$ (Eq. 7) allows one to probe the relative magnitude of ${ }^{15} \eta_{\mathrm{NH}_{4} / \mathrm{NO}}$ and ${ }^{15} \eta_{\mathrm{NO}_{3} / \mathrm{NO}}$ using the determined ${ }^{15} \eta_{\text {comb }}$ and $f_{\mathrm{NH}_{4}}$. Given that $\mathrm{NO}_{2}^{-}$was absent in the soil and that NO reduction in denitrification was likely associated with a small isotope effect (i.e., ${ }^{15} \eta_{\mathrm{NOR}}$; see above), ${ }^{15} \eta_{\mathrm{NO}_{3} / \mathrm{NO}}$ in the oxic and hypoxic incubations should mainly reflect ${ }^{15} \eta_{\mathrm{NAR}}$. Thus, by assigning the entire possible range of the best-fit ${ }^{15} \eta_{\mathrm{NAR}}$ derived in the anoxic incubation (5\% to $45 \%$; Fig. 7a) to ${ }^{15} \eta_{\mathrm{NO}_{3} / \mathrm{NO}},{ }^{15} \eta_{\mathrm{NH}_{4} / \mathrm{NO}}$ was estimated to range from $60 \%$ to $76 \%$ in the oxic incubation and from $55 \%$ to $84 \%$ in the hypoxic incubation (Fig. 11). If we take one step further by assuming that both ${ }^{15} \eta_{\mathrm{NO}_{3} / \mathrm{NO}}$ and ${ }^{15} \eta_{\mathrm{NH}_{4} / \mathrm{NO}}$ were identical between the oxic and hypoxic incubations, then ${ }^{15} \eta_{\mathrm{NO}_{3} / \mathrm{NO}}$ and ${ }^{15} \eta_{\mathrm{NH}_{4} / \mathrm{NO}}$ could be uniquely determined to be $30 \%$ and $66 \%$, respectively (Fig. 11; Table 2). Thus, the relative magnitude of ${ }^{15} \eta_{\mathrm{NO}_{3} / \mathrm{NO}}$ and ${ }^{15} \eta_{\mathrm{NH}_{4} / \mathrm{NO}}$ provides insights into the differential relationship between $\delta^{15} \mathrm{~N}-\mathrm{NH}_{4}^{+}$and $\delta^{15} \mathrm{~N}-\mathrm{NO}$ across the three $\delta^{15} \mathrm{~N}^{-\mathrm{NH}_{4}^{+}}$treatments in the oxic and hypoxic incubations (Fig. 4). In the oxic incubation, if we assume that ${ }^{15} \eta_{\mathrm{NH}_{4} / \mathrm{NO}}=66 \%$ and ${ }^{15} \eta_{\mathrm{NO}_{3} / \mathrm{NO}}=30 \%$, the $\delta^{15} \mathrm{~N}$ of $\mathrm{NO}$ produced from $\mathrm{NH}_{4}^{+}$oxidation under the low $\delta^{15} \mathrm{~N}^{-\mathrm{NH}_{4}^{+}}$ treatment (about $-60 \%$ ) would be much lower than the $\delta^{15} \mathrm{~N}$ of $\mathrm{NO}$ from $\mathrm{NO}_{3}^{-}$consumption (about $-38 \%$ ). However, under the high- $\delta^{15} \mathrm{~N}-\mathrm{NH}_{4}^{+}$treatment, the $\delta^{15} \mathrm{~N}$ of $\mathrm{NH}_{4}^{+}$produced $\mathrm{NO}$ would increase to about $-14 \%$ and be higher than $\delta^{15} \mathrm{~N}$ values of $\mathrm{NO}_{3}^{-}$-produced $\mathrm{NO}$ (about $-26 \%$ ). Consequently, the production of $\mathrm{NO}$ from $\mathrm{NO}_{3}^{-}$consumption would dilute the $\delta^{15} \mathrm{~N}$ of total net NO production, pulling it to 
fall below the $1: 1$ line between the $\delta^{15} \mathrm{~N}^{-\mathrm{NH}_{4}^{+}}$and $\delta^{15} \mathrm{~N}-\mathrm{NO}$ values in Fig. 4. This dilution effect was more pronounced in the hypoxic incubation due to the lower $f_{\mathrm{NH}_{4}}$ (i.e., higher contribution of $\mathrm{NO}_{3}^{-}$-produced NO) (Fig. 4).

Therefore, under either oxic or hypoxic condition, the net $\mathrm{NO}$ production from $\mathrm{NH}_{4}^{+}$oxidation proceeded with a large ${ }^{15} \eta_{\mathrm{NH}_{4} / \mathrm{NO}}$. As $\mathrm{NH}_{3}$ oxidation to $\mathrm{NH}_{2} \mathrm{OH}$ was likely the ratelimiting step for the entire nitrification process, a fraction of the inferred large ${ }^{15} \eta_{\mathrm{NH}_{4} / \mathrm{NO}}$ can be accounted for by the isotope effect for $\mathrm{NH}_{3}$ oxidation to $\mathrm{NH}_{2} \mathrm{OH}$, which should be similar to the estimated ${ }^{15} \eta_{\mathrm{NH}_{4} / \mathrm{NO}_{3}}$ (e.g., $23 \%$ o to $28 \%$ ). The residual isotope effect, on the order of $40 \%$, must therefore stem from additional bond forming/breaking during net $\mathrm{NO}$ production in $\mathrm{NH}_{3}$ oxidation. This additional $\mathrm{N}$ isotope effect could be explained by $\mathrm{NO}_{2}^{-}$reduction catalyzed by AOB-encoded NIR if NO was dominantly produced through the nitrifier-denitrification pathway (Fig. 10). However, provided that the two oxidation steps of nitrification were tightly coupled under both oxic and hypoxic conditions, it is unlikely that $\mathrm{NO}_{2}^{-}$would accumulate to high enough intracellular concentrations to trigger nitrifier denitrification (WrageMönning et al., 2018). Similarly, we would not expect any substantial isotope fractionations to result from accumulation of intracellular $\mathrm{NH}_{2} \mathrm{OH}$ or enzyme-bound intermediate species (e.g., [HNO-Fe] and [NO-Fe]). Thus, we are left with either a large and normal isotope effect for NO dissociation from its enzyme-bound precursor if $\mathrm{NO}$ production was mainly routed through the $\mathrm{NH}_{2} \mathrm{OH}$ obligate intermediate pathway or an inverse isotope effect associated with $\mathrm{NO}$ oxidation if $\mathrm{NO}$ itself was an obligatory intermediate required for $\mathrm{NO}_{2}^{-}$production (Fig. 10). With respect to the first possibility, if NO dissociation from the Fe active site of HAO is mainly controlled by an equilibrium reaction between $\mathrm{NO}$ and enzyme-bound nitrosyl species, the forward and backward reactions may occur with distinctively different isotope effects, giving rise to an equilibrium isotope effect that favors partitioning of ${ }^{14} \mathrm{~N}$ to the dissociated NO. However, expression of this equilibrium isotope effect would be largely suppressed by limited isotope exchange between the two $\mathrm{N}$ pools due to the presumably transient presence of nitrosyl intermediate. Therefore, a partial expression of a large equilibrium isotope effect (e.g., $>40 \%$ ) would be required to explain the residual $\mathrm{N}$ isotopic fractionation during $\mathrm{NO}$ production in $\mathrm{NH}_{3}$ oxidation. Alternatively, in regards to the second possibility, if we assume that the enzyme-catalyzed oxidation of $\mathrm{NO}$ to $\mathrm{NO}_{2}^{-}$proceeds via an enzyme-bound transition state and that the transition state contains the newly formed $\mathrm{N}-\mathrm{O}$ bond, an inverse isotope effect may result from more strongly bonded $\mathrm{N}$ atom in the transition state, for which there is precedent in the literature (i.e., $\mathrm{NO}_{2}^{-}$oxidation to $\mathrm{NO}_{3}^{-}$; see above) (Casciotti, 2009). Moreover, the small NO yield observed in the oxic and hypoxic incubations would indicate a large consumption of NO (i.e., $95 \%$ to $99 \%$ ). With this high level of NO consumption, an inverse isotope effect on the order of $-13 \%$ o to $-9 \%$ would be sufficient to ac- count for the residual isotope effect for net NO production from $\mathrm{NH}_{4}^{+}$. This inferred isotope effect is of similar magnitude to that reported for NXR-catalyzed $\mathrm{NO}_{2}^{-}$oxidation (i.e., $-13 \%$ ) (Casciotti, 2009). However, to unambiguously determine the mechanisms giving rise to the large ${ }^{15} \eta_{\mathrm{NH}_{4} / \mathrm{NO}}$, further biochemical analyses will be needed to clarify the enzymatic pathways responsible for NO production by $\mathrm{AOB}$ and AOA under relevant soil conditions. Nonetheless, the results presented here provide evidence that production of NO with low $\delta^{15} \mathrm{~N}$ values may be a characteristic feature of nitrification in $\mathrm{NH}_{4}^{+}$-fertilized agricultural soils under both oxic and hypoxic conditions.

\section{Implications for NO emission from agricultural soils}

In this study, the net production rates and $\delta^{15} \mathrm{~N}$ values of NO were measured under a range of controlled laboratory conditions. The results provide insights into how stable $\mathrm{N}$ and $\mathrm{O}$ isotopes can be effectively used to understand the reaction mechanisms by which NO is produced and consumed in soils. While nitrification is the commonly cited source for NO emissions from agricultural soils, the measured net NO production rates in this study highlight the great potential of abiotic $\mathrm{NO}_{2}^{-}$reduction and denitrification in driving $\mathrm{NO}$ production and release from agricultural soils and thus should not be overlooked when attributing field soil $\mathrm{NO}$ emissions. Indeed, because NO is a direct product or free intermediate in these processes, abiotic $\mathrm{NO}_{2}^{-}$reduction and denitrification may inherently have a larger NO yield - that is, a bigger "hole" for NO leaking in the HIP model (Davidson and Verchot, 2000). We conclude that the isotope-based measurement and modeling framework established in this work is a powerful tool to bridge NO production with gross $\mathrm{N}$ transformation processes in agricultural soils, thereby providing a quantitative way to parameterize the HIP model for modeling soil NO emissions under dynamic environmental conditions (e.g., varying temperature and soil moisture content).

The differences in the net isotope effects for NO production from abiotic $\mathrm{NO}_{2}^{-}$reduction, denitrification, and nitrification revealed in this study (Fig. 12a) suggest that $\delta^{15} \mathrm{~N}-$ $\mathrm{NO}$ is a useful tracer for informing NO production pathways in agricultural soils. Specifically, the relatively small magni-

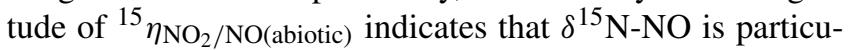
larly useful in probing the relative importance of NO production from abiotic vs. microbial reactions, lending support to our previous finding based on rewetting of a dry forest soil that high $\delta^{15} \mathrm{~N}$ values of rewetting-triggered NO pulses were mainly contributed by chemical $\mathrm{NO}_{2}^{-}$reduction (Yu and Elliott, 2017). Moreover, the large ${ }^{15} \eta_{\mathrm{NH}_{4} / \mathrm{NO}}$ revealed in the oxic and hypoxic incubations provides an empirical basis for discerning the relative role of $\mathrm{NH}_{4}^{+}$oxidation and $\mathrm{NO}_{3}^{-}$reduction in driving soil $\mathrm{NO}$ production and emissions. Interestingly, comparing the measured net isotope effects for $\mathrm{NO}$ production from abiotic $\mathrm{NO}_{2}^{-}$reduction, denitrification, and 

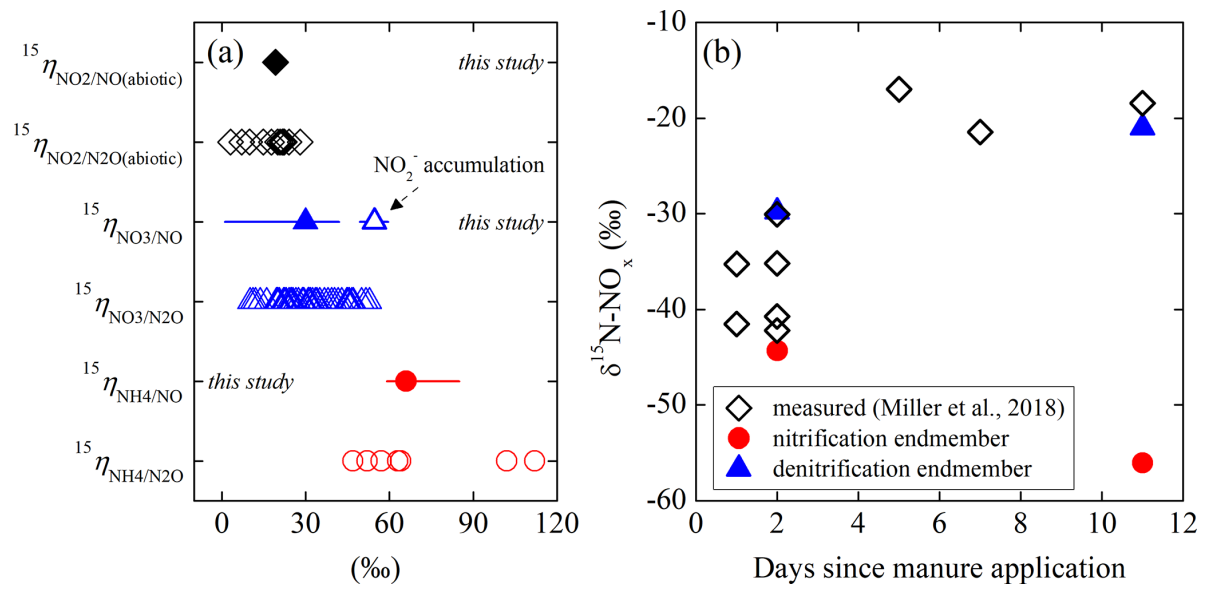

Figure 12. (a) Comparison of net isotope effects for $\mathrm{NO}$ production estimated in this study to net isotope effects for $\mathrm{N}_{2} \mathrm{O}$ production reported in the literature. (b) Comparison of in situ $\delta^{15} \mathrm{~N}$ of $\mathrm{NO}_{x}$ emission from a manure-fertilized soil (reported by Miller et al., 2018) to nitrification and denitrification $\delta^{15} \mathrm{~N}-\mathrm{NO}$ end-members derived using the estimated net isotope effects for NO production in the oxic and hypoxic incubations.

nitrification with those previously quantified for $\mathrm{N}_{2} \mathrm{O}$ production in soil incubations and pure cultures (Denk et al., 2017, and references therein; Jones et al., 2015; Wei et al., 2019), a similar pattern is evident across these three common production pathways for $\mathrm{NO}$ and $\mathrm{N}_{2} \mathrm{O}$ (Fig. 12a). This similarity reflects the intimate connection between $\mathrm{NO}$ and $\mathrm{N}_{2} \mathrm{O}$ turnover within each reaction pathway and provides strong evidence that simultaneous $\delta^{15} \mathrm{~N}-\mathrm{NO}$ and $\delta^{15} \mathrm{~N}-\mathrm{N}_{2} \mathrm{O}$ measurements can potentially yield unprecedented insights into the sources and processes controlling $\mathrm{NO}$ and $\mathrm{N}_{2} \mathrm{O}$ emissions from agricultural soils. However, on the other hand, the demonstrated reaction reversibility between $\mathrm{NO}_{2}^{-}$and $\mathrm{NO}_{3}^{-}$ under anoxic conditions is a new complication that needs to be considered when using $\delta^{15} \mathrm{~N}$ to examine soil $\mathrm{NO}$ and $\mathrm{N}_{2} \mathrm{O}$ emissions. $\mathrm{As}_{2}^{-}$is often accumulated in agricultural soils following fertilizer application (Venterea et al., 2020), expression of the equilibrium isotope effect between $\mathrm{NO}_{2}^{-}$and $\mathrm{NO}_{3}^{-}$in redox-dynamic surface soils may render $\delta^{15} \mathrm{~N}-\mathrm{NO}$ and $\delta^{15} \mathrm{~N}-\mathrm{N}_{2} \mathrm{O}$ less useful in tracing $\mathrm{NO}$ and $\mathrm{N}_{2} \mathrm{O}$ sources. Given that high soil $\mathrm{NO}_{2}^{-}$concentrations can trigger emission pulses of $\mathrm{NO}$ and $\mathrm{N}_{2} \mathrm{O}$ (Venterea et al., 2020), $\mathrm{NO}_{2}^{-}$ accumulation should be taken as a critical sign for careful evaluation of the reaction complexity underlying $\delta^{15} \mathrm{~N}$ distributions among the denitrification products.

To further assess the potential utility of $\delta^{15} \mathrm{~N}$ measurements in source partitioning NO emissions from agricultural soils, we applied the estimated $\mathrm{N}$ isotope effects to the in situ $\delta^{15} \mathrm{~N}^{-N} \mathrm{O}_{x}$ measurements reported by Miller et al. (2018). Importantly, the soil used in this study was collected from the same farm where Miller et al. (2018) conducted their field measurements (e.g., the USDA-managed corn-soybean field in central Pennsylvania, USA). Hence, the derived isotope effects may be particularly relevant to their reported $\delta^{15} \mathrm{~N}$ $\mathrm{NO}_{x}$ values due to similar soil microbial community struc- tures. Because $\mathrm{NO}_{2}^{-}$accumulation was not reported by Miller et al. (2018), we consider nitrification and denitrification to be the primary sources for the observed NO (and, to a much lesser extent, $\mathrm{NO}_{2}$ ) emissions. Therefore, the ${ }^{15} \eta_{\mathrm{NH}_{4} / \mathrm{NO}}$ and ${ }^{15} \eta_{\mathrm{NO}_{3} / \mathrm{NO}}$ values derived in the oxic and hypoxic incubations (i.e., $66 \%$ and $30 \%$, respectively) were used in combination with the $\delta^{15} \mathrm{~N}$ values of soil $\mathrm{NH}_{4}^{+}$and $\mathrm{NO}_{3}^{-}$reported in Miller et al. (2018) to calculate the $\delta^{15} \mathrm{~N}$ end-members for $\mathrm{NO}$ produced from $\mathrm{NH}_{4}^{+}$oxidation and $\mathrm{NO}_{3}^{-}$reduction. As shown in Fig. 12b, comparing the in situ $\delta^{15} \mathrm{~N}_{-} \mathrm{NO}_{x}$ measurements with the estimated isotopic end-members provides a compelling picture of soil NO dynamics following manure application. Notably, the initial low $\delta{ }^{15} \mathrm{~N}-\mathrm{NO}_{x}$ values reported by Miller et al. (2018) might indicate a mixed contribution of $\mathrm{NH}_{4}^{+}$oxidation and $\mathrm{NO}_{3}^{-}$reduction to soil $\mathrm{NO}_{x}$ emissions (Fig. 12b). Nevertheless, the increase in $\delta^{15} \mathrm{~N}^{1} \mathrm{NO}_{x}$ values measured 4 to $11 \mathrm{~d}$ after manure application may reflect a shift in the dominant NO production pathway to denitrification, in line with the increasing accumulation of $\mathrm{NO}_{3}^{-}$ supplied by nitrification in the soil (Miller et al., 2018). Although data-limited, this example provides promising initial evidence for the ability of multi-species $\delta^{15} \mathrm{~N}$ measurements to provide mechanistic information on soil $\mathrm{NO}$ dynamics and its environmental controls. Further experimental constraints on soil $\delta^{15} \mathrm{~N}-\mathrm{NO}$ variations can build on the measurement and modeling framework developed in this study to advance our understanding of soil NO source contributions over a wide range of environmental conditions and soil types.

Code and data availability. The datasets generated for this study and documentation about the equations and parameters of the isotopologue-specific models are available in the Supplement. The MATLAB codes for the isotopologuespecific models are available at https://github.com/zjyuuiuc/ 
Isotopologue-specific-models (last access: 1 February 2021) and at https://doi.org/10.5281/zenodo.4495715 (Yu, 2020).

Supplement. The supplement related to this article is available online at: https://doi.org/10.5194/bg-18-805-2021-supplement.

Author contributions. ZY and EME designed the study; ZY conducted the experiments and analyzed the data; ZY and EME wrote the paper.

Competing interests. The authors declare that they have no conflict of interest.

Acknowledgements. The authors thank Curtis Dell (USDA-ARS) for helping with the field soil sampling and Katherine Redling, Vivian Feng, Madeline Ellgass, and Madeline Gray (University of Pittsburgh) for assistance with the isotopic analyses.

Financial support. This work was supported by a National Science Foundation CAREER award (grant no. 1253000) to Emily M. Elliott.

Review statement. This paper was edited by Andreas Richter and reviewed by Wolfgang Wanek and one anonymous referee.

\section{References}

Almaraz, M., Bai, E., Wang, C., Trousdell, J., Conley, S., Faloona, I., and Houlton, B. Z.: Agriculture is a major source of $\mathrm{NO}_{x}$ pollution in California, Sci. Adv., 4, 3477, https://doi.org/10.1126/sciadv.aao3477, 2018.

Babbin, A. R., Peters, B. D., Mordy, C. W., Widner, B., Casciotti, K. L., and Ward, B. B.: Multiple metabolisms constrain the anaerobic nitrite budget in the Eastern Tropical South Pacific, Global Biogeochem. Cy., 31, 258-271, 2017.

Beeckman, F., Motte, H., and Beeckman, T.: Nitrification in agricultural soils: impact, actors and mitigation, Curr. Opin. Biotech., 50, 166-173, 2018.

Bock, E., Wilderer, P. A., and Freitag, A.: Growth of Nitrobacter in the absence of dissolved oxygen, Water Res., 22, 245-250, 1988.

Brunner, B., Contreras, S., Lehmann, M. F., Matantseva, O., Rollog, M., Kalvelage, T., Klockgether, G., Lavik, G., Jetten, M. S., Kartal, B., and Kuypers, M. M.: Nitrogen isotope effects induced by anammox bacteria, P. Natl. Acad. Sci. USA, 110, 1899418999, 2013.

Buchwald, C. and Casciotti, K. L.: Oxygen isotopic fractionation and exchange during bacterial nitrite oxidation, Limnol. Oceanogr., 55, 1064-1074, 2010.

Buchwald, C., Grabb, K., Hansel, C. M., and Wankel, S. D.: Constraining the role of iron in environmental nitrogen transformations: dual stable isotope systematics of abiotic $\mathrm{NO}_{2}^{-}$reduction by $\mathrm{Fe}$ (II) and its production of $\mathrm{N}_{2} \mathrm{O}$, Geochim. Cosmochim. Ac., 186, 1-12, 2016.

Buchwald, C., Homola, K., Spivack, A. J., Estes, E. R., Murray, R. W., and Wankel, S. D.: Isotopic constraints on nitrogen transformation rates in the deep sedimentary marine biosphere, Global Biogeochem. Cy., 32, 1688-1702, 2018.

Buessecker, S., Tylor, K., Nye, J., Holbert, K. E., Urquiza Muñoz, J. D., Glass, J. B., Hartnett, H. E., and CadilloQuiroz, H.: Effects of sterilization techniques on chemodenitrification and $\mathrm{N}_{2} \mathrm{O}$ production in tropical peat soil microcosms, Biogeosciences, 16, 4601-4612, https://doi.org/10.5194/bg-164601-2019, 2019.

Calvert, J. G., Lazrus, A., Kok, G. L., Heikes, B. G., Walega, J. G., Lind, J., and Cantrell, C. A.: Chemical mechanisms of acid generation in the troposphere, Nature, 317, 27-35, 1985.

Caranto, J. D. and Lancaster, K. M.: Nitric oxide is an obligate bacterial nitrification intermediate produced by hydroxylamine oxidoreductase, P. Natl. Acad. Sci. USA, 114, 8217-8222, 2017.

Casciotti, K. L.: Inverse kinetic isotope fractionation during bacterial nitrite oxidation, Geochim. Cosmochim. Ac., 73, 2061-2076, 2009.

Casciotti, K. L., Sigman, D. M., Hastings, M. G., Böhlke, J. K., and Hilkert, A.: Measurement of the oxygen isotopic composition of nitrate in seawater and freshwater using the denitrifier method, Anal. Chem., 74, 4905-4912, 2002.

Casciotti, K. L., Sigman, D. M., and Ward, B. B.: Linking diversity and stable isotope fractionation in ammonia-oxidizing bacteria, Geomicrobiol. J., 20, 335-353, 2003.

Casciotti, K. L., Böhlke, J. K., McIlvin, M. R., Mroczkowski, S. J., and Hannon, J. E.: Oxygen isotopes in nitrite: analysis, calibration, and equilibration, Anal. Chem., 79, 2427-2436, 2007.

Crutzen, P. J.: The role of $\mathrm{NO}$ and $\mathrm{NO}_{2}$ in the chemistry of the troposphere and stratosphere, Annu. Rev. Earth Pl. Sc., 7, 443472, 1979.

Davidson, E. A.: The contribution of manure and fertilizer nitrogen to atmospheric nitrous oxide since 1860, Nat. Geosci., 2, 659662, 2009.

Dähnke, K. and Thamdrup, B.: Isotope fractionation and isotope decoupling during anammox and denitrification in marine sediments, Limnol. Oceanogr., 61, 610-624, 2016.

Dale, A. W., Sommer, S., Ryabenko, E., Noffke, A., Bohlen, L., Wallmann, K., Stolpovsky, K., Greinert, J., and Pfannkuche, O.: Benthic nitrogen fluxes and fractionation of nitrate in the Mauritanian oxygen minimum zone (Eastern Tropical North Atlantic), Geochim. Cosmochim. Ac., 134, 234-256, 2014.

Davidson, E. A. and Verchot, L. V.: Testing the hole-in-the-pipe model of nitric and nitrous oxide emissions from soils using the TRAGNET database, Global Biogeochem. Cy., 14, 1035-1043, 2000.

Denk, T. R., Mohn, J., Decock, C., Lewicka-Szczebak, D., Harris, E., Butterbach-Bahl, K., Kiese, R., and Wolf, B.: The nitrogen cycle: A review of isotope effects and isotope modeling approaches, Soil Biol. Biochem., 105, 121-137, 2017.

Felix, D. J., Elliott, E. M., Gish, T. J., McConnell, L. L., and Shaw, S. L.: Characterizing the isotopic composition of atmospheric ammonia emission sources using passive samplers and a combined oxidation-bacterial denitrifier approach, Rapid Commun. Mass Sp., 27, 2239-2246, 2013. 
Firestone, M. K. and Davidson, E. A.: Microbiological basis of NO and $\mathrm{N}_{2} \mathrm{O}$ production and consumption in soil, in: Exchange of trace gases between terrestrial ecosystems and the atmosphere, edited by: Andreae, M. O., Schimel, D. S., and Robertson, G. P., John Wiley and Sons Ltd, Berlin, 7-21, 1989.

Freitag, A., Rudert, M., and Bock, E.: Growth of Nitrobacter by dissimilatoric nitrate reduction, FEMS Microbiol. Lett., 48, 105109, 1987.

Friedman, S. H., Massefski, W., and Hollocher, T. C.: Catalysis of intermolecular oxygen atom transfer by nitrite dehydrogenase of Nitrobacter agilis, J. Biol. Chem., 261, 10538-10543, 1986.

Fry, B.: Stable Isotope Ecology, Vol. 521, Springer, New York, 2006.

Galloway, J. N., Aber, J. D., Erisman, J. W., Seitzinger, S. P., Howarth, R. W., Cowling, E. B., and Cosby, B. J.: The nitrogen cascade, Bioscience, 53, 341-356, 2003.

Gaye, B., Nagel, B., Dähnke, K., Rixen, T., and Emeis, K. C.: Evidence of parallel denitrification and nitrite oxidation in the ODZ of the Arabian Sea from paired stable isotopes of nitrate and nitrite, Global Biogeochem. Cy., 27, 1059-1071, 2013.

Granger, J. and Sigman, D. M.: Removal of nitrite with sulfamic acid for nitrate $\mathrm{N}$ and $\mathrm{O}$ isotope analysis with the denitrifier method, Rapid Commun. Mass Sp., 23, 3753-3762, 2009.

Granger, J. and Wankel, S. D.: Isotopic overprinting of nitrification on denitrification as a ubiquitous and unifying feature of environmental nitrogen cycling, P. Natl. Acad. Sci. USA, 113, E6391E6400, 2016.

Granger, J., Sigman, D. M., Lehmann, M. F., and Tortell, P. D.: Nitrogen and oxygen isotope fractionation during dissimilatory nitrate reduction by denitrifying bacteria, Limnol. Oceanogr., 53, 2533-2545, 2008.

Heil, J., Vereecken, H., and Brüggemann, N.: A review of chemical reactions of nitrification intermediates and their role in nitrogen cycling and nitrogen trace gas formation in soil, Eur. J. Soil Sci., 67, 23-39, 2016.

Højberg, O., Binnerup, S. J., and Sørensen, J.: Potential rates of ammonium oxidation, nitrite oxidation, nitrate reduction and denitrification in the young barley rhizosphere, Soil Biol. Biochem., 28, 47-54, 1996.

Homyak, P. M., Vasquez, K. T., Sickman, J. O., Parker, D. R., and Schimel, J. P.: Improving nitrite analysis in soils: Drawbacks of the conventional $2 \mathrm{M} \mathrm{KCl}$ extraction, Soil Sci. Soc. Am. J., 79, 1237-1242, 2015.

Hooper, A. B., Arciero, D., Bergmann, D., and Hendrich, M. P.: The Oxidation of Ammonia as an Engergy Source in Bacteria, in: Respiration in archaea and bacteria, Springer, Dordrecht, 121147, 2004.

Hudman, R. C., Russell, A. R., Valin, L. C., and Cohen, R. C.: Interannual variability in soil nitric oxide emissions over the United States as viewed from space, Atmos. Chem. Phys., 10, 99439952, https://doi.org/10.5194/acp-10-9943-2010, 2010.

Hudman, R. C., Moore, N. E., Mebust, A. K., Martin, R. V., Russell, A. R., Valin, L. C., and Cohen, R. C.: Steps towards a mechanistic model of global soil nitric oxide emissions: implementation and space based-constraints, Atmos. Chem. Phys., 12, 77797795, https://doi.org/10.5194/acp-12-7779-2012, 2012.

Jones, L. C., Peters, B., Lezama Pacheco, J. S., Casciotti, K. L., and Fendorf, S.: Stable isotopes and iron oxide mineral products as markers of chemodenitrification, Environ. Sci. Technol., 49, 3444-3452, 2015.

Kaiser, J., Hastings, M. G., Houlton, B. Z., Röckmann, T., and Sigman, D. M.: Triple oxygen isotope analysis of nitrate using the denitrifier method and thermal decomposition of $\mathrm{N}_{2} \mathrm{O}$, Anal. Chem., 79, 599-607, 2007.

Kaneko, M. and Poulson, S. R.: The rate of oxygen isotope exchange between nitrate and water, Geochim. Cosmochim. Ac., 118, 148-156, 2013.

Kang, H., Stanley, E. H., and Park, S. S.: A sensitive method for the measurement of ammonium in soil extract and water, Commun. Soil Sci. Plan., 34, 2193-2201, 2003.

Ke, X., Angel, R., Lu, Y., and Conrad, R.: Niche differentiation of ammonia oxidizers and nitrite oxidizers in rice paddy soil, Environ. Microbiol., 15, 2275-2292, 2013.

Keiluweit, M., Gee, K., Denney, A., and Fendorf, S.: Anoxic microsites in upland soils dominantly controlled by clay content, Soil Biol. Biochem., 118, 42-50, 2018.

Kemeny, P. C., Weigand, M. A., Zhang, R., Carter, B. R., Karsh, K. L., Fawcett, S. E., and Sigman, D. M.: Enzyme-level interconversion of nitrate and nitrite in the fall mixed layer of the Antarctic Ocean, Global Biogeochem. Cy., 30, 1069-1085, 2016.

Kester, R. A., Meijer, M. E., Libochant, J. A., Boer, W. D., and Laanbroek, H. J.: Contribution of nitrification and denitrification to the $\mathrm{NO}$ and $\mathrm{N}_{2} \mathrm{O}$ emissions of an acid forest soil, a river sediment and a fertilized grassland soil, Soil Biol. Biochem., 29, 1655-1664, 1997.

Koch, H., Lücker, S., Albertsen, M., Kitzinger, K., Herbold, C., Spieck, E., Nielsen, P. H., Wagner, M., and Daims, H.: Expanded metabolic versatility of ubiquitous nitrite-oxidizing bacteria from the genus Nitrospira, P. Natl. Acad. Sci. USA, 112, 11371-11376, 2015.

Kool, D. M., Wrage, N., Oenema, O., Van Kessel, C., and Van Groenigen, J. W.: Oxygen exchange with water alters the oxygen isotopic signature of nitrate in soil ecosystems, Soil Biol. Biochem., 43, 1180-1185, 2011.

Kozlowski, J. A., Stieglmeier, M., Schleper, C., Klotz, M. G., and Stein, L. Y.: Pathways and key intermediates required for obligate aerobic ammonia-dependent chemolithotrophy in bacteria and Thaumarchaeota, ISME J., 10, 1836-1845, 2016.

Kremen, A., Bear, J., Shavit, U., and Shaviv, A.: Model demonstrating the potential for coupled nitrification denitrification in soil aggregates, Environ. Sci. Technol., 39, 4180-4188, 2005.

Kuypers, M. M., Marchant, H. K., and Kartal, B.: The microbial nitrogen-cycling network, Nat. Rev. Microbiol., 16, 263-276, https://doi.org/10.1038/nrmicro.2018.9, 2018.

Lancaster, K. M., Caranto, J. D., Majer, S. H., and Smith, M. A.: Alternative bioenergy: updates to and challenges in nitrification metalloenzymology, Joule, 2, 421-441, 2018.

Lehnert, N., Dong, H. T., Harland, J. B., Hunt, A. P., and White, C. J.: Reversing nitrogen fixation, Nat. Rev. Chem., 2, 278-289, 2018.

Le Roux, X., Bouskill, N. J., Niboyet, A., Barthes, L., Dijkstra, P., Field, C. B., Hungate, B. A., Lerondelle, C., Pommier, T., Tang, J., and Terada, A.: Predicting the responses of soil nitrite-oxidizers to multi-factorial global change: a trait-based approach, Front. Microbiol., 7, 628, https://doi.org/10.3389/fmicb.2016.00628, 2016. 
Lewicka-Szczebak, D., Well, R., Köster, J. R., Fuß R., Senbayram, M., Dittert, K., and Flessa, H.: Experimental determinations of isotopic fractionation factors associated with $\mathrm{N}_{2} \mathrm{O}$ production and reduction during denitrification in soils, Geochim. Cosmochim. Ac., 134, 55-73, 2014.

Lewicka-Szczebak, D., Dyckmans, J., Kaiser, J., Marca, A., Augustin, J., and Well, R.: Oxygen isotope fractionation during $\mathrm{N}_{2} \mathrm{O}$ production by soil denitrification, Biogeosciences, 13, 11291144, https://doi.org/10.5194/bg-13-1129-2016, 2016.

Li, D. and Wang, X.: Nitrogen isotopic signature of soil-released nitric oxide (NO) after fertilizer application, Atmos. Environ., 42, 4747-4754, 2008.

Lim, N. Y., Frostegård, Å., and Bakken, L. R.: Nitrite kinetics during anoxia: The role of abiotic reactions versus microbial reduction, Soil Biol. Biochem., 119, 203-209, 2018.

Liu, S., Lin, F., Wu, S., Ji, C., Sun, Y., Jin, Y., Li, S., Li, Z., and Zou, J.: A meta-analysis of fertilizer-induced soil NO and combined $\mathrm{NO}+\mathrm{N}_{2} \mathrm{O}$ emissions, Glob. Change Biol., 23, 2520-2532, 2017.

Loick, N., Dixon, E. R., Abalos, D., Vallejo, A., Matthews, G. P., McGeough, K. L., Well, R., Watson, C. J., Laughlin, R. J., and Cardenas, L. M.: Denitrification as a source of nitric oxide emissions from incubated soil cores from a UK grassland soil, Soil Biol. Biochem., 95, 1-7, 2016.

Maaz, T. M., Waldo, S., Bruulsema, T., and Mikkelsen, R.: Inconsistencies undermine the conclusion that agriculture is a dominant source of $\mathrm{NO}_{x}$ in California, Sci. Adv., 4, 4706, https://doi.org/10.1126/sciadv.aat4706, 2018.

Maggi, F. and Riley, W. J.: Mathematical treatment of isotopologue and isotopomer speciation and fractionation in biochemical kinetics, Geochim. Cosmochim. Ac., 74, 1823-1835, 2010.

Mariotti, A., Germon, J. C., Hubert, P., Kaiser, P., Letolle, R., Tardieux, A., and Tardieux, P.: Experimental determination of nitrogen kinetic isotope fractionation: some principles; illustration for the denitrification and nitrification processes, Plant Soil, 62, 413-430, 1981.

Mariotti, A., Leclerc, A., and Germon, J. C.: Nitrogen isotope fractionation associated with the $\mathrm{NO}_{2}^{-} \rightarrow \mathrm{N}_{2} \mathrm{O}$ step of denitrification in soils, Can. J. Soil Sci., 62, 227-241, 1982.

Martin, T. S. and Casciotti, K. L.: Nitrogen and oxygen isotopic fractionation during microbial nitrite reduction, Limnol. Oceanogr., 61, 1134-1143, 2016.

Martin, T. S. and Casciotti, K. L.: Paired N and O isotopic analysis of nitrate and nitrite in the Arabian Sea oxygen deficient zone, Deep-Sea Res. Pt. I, 121, 121-131, 2017.

McKenney, D. J., Shuttleworth, K. F., Vriesacker, J. R., and Findlay, W. I.: Production and loss of nitric oxide from denitrification in anaerobic Brookston clay, Appl. Environ. Microb., 43, 534$541,1982$.

McKenney, D. J., Lazar, C., and Findlay, W. J.: Kinetics of the nitrite to nitric oxide reaction in peat, Soil Sci. Soc. Am. J., 54, 106112, 1990.

Medinets, S., Skiba, U., Rennenberg, H., and Butterbach-Bahl, K.: A review of soil NO transformation: Associated processes and possible physiological significance on organisms, Soil Biol. Biochem., 80, 92-117, 2015.

Michalski, G., Meixner, T., Fenn, M., Hernandez, L., Sirulnik, A., Allen, E., and Thiemens, M.: Tracing atmospheric nitrate deposi- tion in a complex semiarid ecosystem using $\Delta^{17} \mathrm{O}$, Environ. Sci. Technol., 38, 2175-2181, 2004.

Miller, D. J., Chai, J., Guo, F., Dell, C. J., Karsten, H., and Hastings, M. G.: Isotopic Composition of In Situ Soil $\mathrm{NO}_{x}$ Emissions in Manure-Fertilized Cropland, Geophys. Res. Lett., 45, 12-058, 2018.

Peters, B. D., Babbin, A. R., Lettmann, K. A., Mordy, C. W., Ulloa, O., Ward, B. B., and Casciotti, K. L.: Vertical modeling of the nitrogen cycle in the eastern tropical South Pacific oxygen deficient zone using high-resolution concentration and isotope measurements, Global Biogeochem. Cy., 30, 1661-1681, 2016.

Russow, R., Stange, C. F., and Neue, H. U.: Role of nitrite and nitric oxide in the processes of nitrification and denitrification in soil: Results from ${ }^{15} \mathrm{~N}$ tracer experiments, Soil Biol. Biochem., 41, 785-795, 2009.

Santoro, A. E. and Casciotti, K. L.: Enrichment and characterization of ammonia-oxidizing archaea from the open ocean: phylogeny, physiology and stable isotope fractionation, ISME J., 5, 17961808, https://doi.org/10.1038/ismej.2011.58, 2011.

Shoun, H., Fushinobu, S., Jiang, L., Kim, S. W., and Wakagi, T.: Fungal denitrification and nitric oxide reductase cytochrome P450nor, Philos. T. R. Soc. B, 367, 1186-1194, 2012.

Sigman, D. M., Casciotti, K. L., Andreani, M., Barford, C., Galanter, M. B. J. K., and Böhlke, J. K.: A bacterial method for the nitrogen isotopic analysis of nitrate in seawater and freshwater, Anal. Chem., 73, 4145-4153, 2001.

Skiba, U., Fowler, D., and Smith, K. A.: Nitric oxide emissions from agricultural soils in temperate and tropical climates: sources, controls and mitigation options, Nutr. Cycl. Agroecosys., 48, 139-153, 1997.

Stange, C. F., Spott, O., Arriaga, H., Menéndez, S., Estavillo, J. M., and Merino, P.: Use of the inverse abundance approach to identify the sources of $\mathrm{NO}$ and $\mathrm{N}_{2} \mathrm{O}$ release from Spanish forest soils under oxic and hypoxic conditions, Soil Biol. Biochem., 57, 451458, 2013.

Stein, L. Y.: Insights into the physiology of ammonia-oxidizing microorganisms, Curr. Opin. Chem. Biol., 49, 9-15, 2019.

Sun, X., Ji, Q., Jayakumar, A., and Ward, B. B.: Dependence of nitrite oxidation on nitrite and oxygen in low-oxygen seawater, Geophys. Res. Lett., 44, 7883-7891, 2017.

Sutka, R. L., Ostrom, N. E., Ostrom, P. H., Breznak, J. A., Gandhi, H., Pitt, A. J., and Li, F.: Distinguishing nitrous oxide production from nitrification and denitrification on the basis of isotopomer abundances, Appl. Environ. Microb., 72, 638-644, 2006.

Taylor, A. E., Myrold, D. D., and Bottomley, P. J.: Temperature affects the kinetics of nitrite oxidation and nitrification coupling in four agricultural soils, Soil Biol. Biochem., 136, 107523, https://doi.org/10.1016/j.soilbio.2019.107523, 2019.

Toyoda, S., Yoshida, N., and Koba, K.: Isotopocule analysis of biologically produced nitrous oxide in various environments, Mass Spectrom. Rev., 36, 135-160, 2017.

Treibergs, L. A. and Granger, J.: Enzyme level N and O isotope effects of assimilatory and dissimilatory nitrate reduction, Limnol. Oceanogr., 62, 272-288, 2017.

Van Cleemput, O. and Samater, A. H.: Nitrite in soils: accumulation and role in the formation of gaseous N compounds, Fert. Res., 45, 81-89, 1995. 
Veldkamp, E. and Keller, M.: Fertilizer-induced nitric oxide emissions from agricultural soils, Nutr. Cycl. Agroecosys., 48, 69-77, 1997.

Venterea, R. T., Rolston, D. E. E., and Cardon, Z. G.: Effects of soil moisture, physical, and chemical characteristics on abiotic nitric oxide production, Nutr. Cycl. Agroecosys., 72, 27-40, 2005.

Venterea, R. T., Coulter, J. A., and Clough, T. J.: Nitrite accumulation and nitrogen gas production increase with decreasing temperature in urea-amended soils: Experiments and modeling, Soil Biol. Biochem., 142, 107727, https://doi.org/10.1016/j.soilbio.2020.107727, 2020.

Vinken, G. C. M., Boersma, K. F., Maasakkers, J. D., Adon, M., and Martin, R. V.: Worldwide biogenic soil $\mathrm{NO}_{x}$ emissions inferred from $\mathrm{OMI} \mathrm{NO} 2$ observations, Atmos. Chem. Phys., 14, 10363 10381, https://doi.org/10.5194/acp-14-10363-2014, 2014.

Wei, J., Ibraim, E., Brüggemann, N., Vereecken, H., and Mohn, J.: First real-time isotopic characterisation of $\mathrm{N}_{2} \mathrm{O}$ from chemodenitrification, Geochim. Cosmochim. Ac., 267, 17-32, 2019.

Wrage-Mönnig, N., Horn, M. A., Well, R., Müller, C., Velthof, G., and Oenema, O.: The role of nitrifier denitrification in the production of nitrous oxide revisited, Soil Biol. Biochem., 123, A3A16, 2018.

Wunderlich, A., Meckenstock, R. U., and Einsiedl, F.: A mixture of nitrite-oxidizing and denitrifying microorganisms affects the $\delta^{18} \mathrm{O}$ of dissolved nitrate during anaerobic microbial denitrification depending on the $\delta^{18} \mathrm{O}$ of ambient water, Geochim. Cosmochim. Ac., 119, 31-45, 2013.

Yamazaki, T., Hozuki, T., Arai, K., Toyoda, S., Koba, K., Fujiwara, T., and Yoshida, N.: Isotopomeric characterization of nitrous oxide produced by reaction of enzymes extracted from nitrifying and denitrifying bacteria, Biogeosciences, 11, 26792689, https://doi.org/10.5194/bg-11-2679-2014, 2014.
Yang, H., Gandhi, H., Ostrom, N. E., and Hegg, E. L.: Isotopic fractionation by a fungal $\mathrm{P} 450$ nitric oxide reductase during the production of $\mathrm{N}_{2} \mathrm{O}$, Environ. Sci. Technol., 48, 10707-10715, 2014.

Ye, R. W., Averill, B. A., and Tiedje, J. M.: Denitrification: production and consumption of nitric oxide, Appl. Environ. Microb., 60, 1053-1058, 1994.

Yu, Z.: Isotopologue-specific models, Zenodo, https://doi.org/10.5281/zenodo.4495715, 2021.

$\mathrm{Yu}, \mathrm{Z}$. and Elliott, E. M.: Novel method for nitrogen isotopic analysis of soil-emitted nitric oxide, Environ. Sci. Technol., 51, 62686278, 2017.

Yu, Z. and Elliott, E. M.: Probing soil nitrification and nitrate consumption using $\Delta^{17} \mathrm{O}$ of soil nitrate, Soil Biol. Biochem., 127, 187-199, 2018.

Zhang, L., Altabet, M. A., Wu, T., and Hadas, O.: Sensitive measurement of $\mathrm{NH}_{4}^{+15} \mathrm{~N} /{ }^{14} \mathrm{~N}\left(\delta^{15} \mathrm{NH}_{4}^{+}\right)$at natural abundance levels in fresh and saltwaters, Anal. Chem., 79, 5297-5303, 2007.

Zhang, S., Fang, Y., and Xi, D.: Adaptation of micro-diffusion method for the analysis of ${ }^{15} \mathrm{~N}$ natural abundance of ammonium in samples with small volume, Rapid Commun. Mass Sp., 29, 1297-1306, 2015.

Zhu-Barker, X., Cavazos, A. R., Ostrom, N. E., Horwath, W. R., and Glass, J. B.: The importance of abiotic reactions for nitrous oxide production, Biogeochemistry, 126, 251-267, 2015.

Zumft, W. G.: Cell biology and molecular basis of denitrification, Microbiol. Mol. Biol. R., 61, 533-616, 1997. 